\title{
STRUCTURE AND APPLICATION OF AN INTERFACE PROGRAM BETWEEN A GEOGRAPHIC-INFORMATION SYSTEM AND A GROUND-WATER FLOW MODEL
}

U.S. GEOLOGICAL SURVEY

Open-File Report 90-165

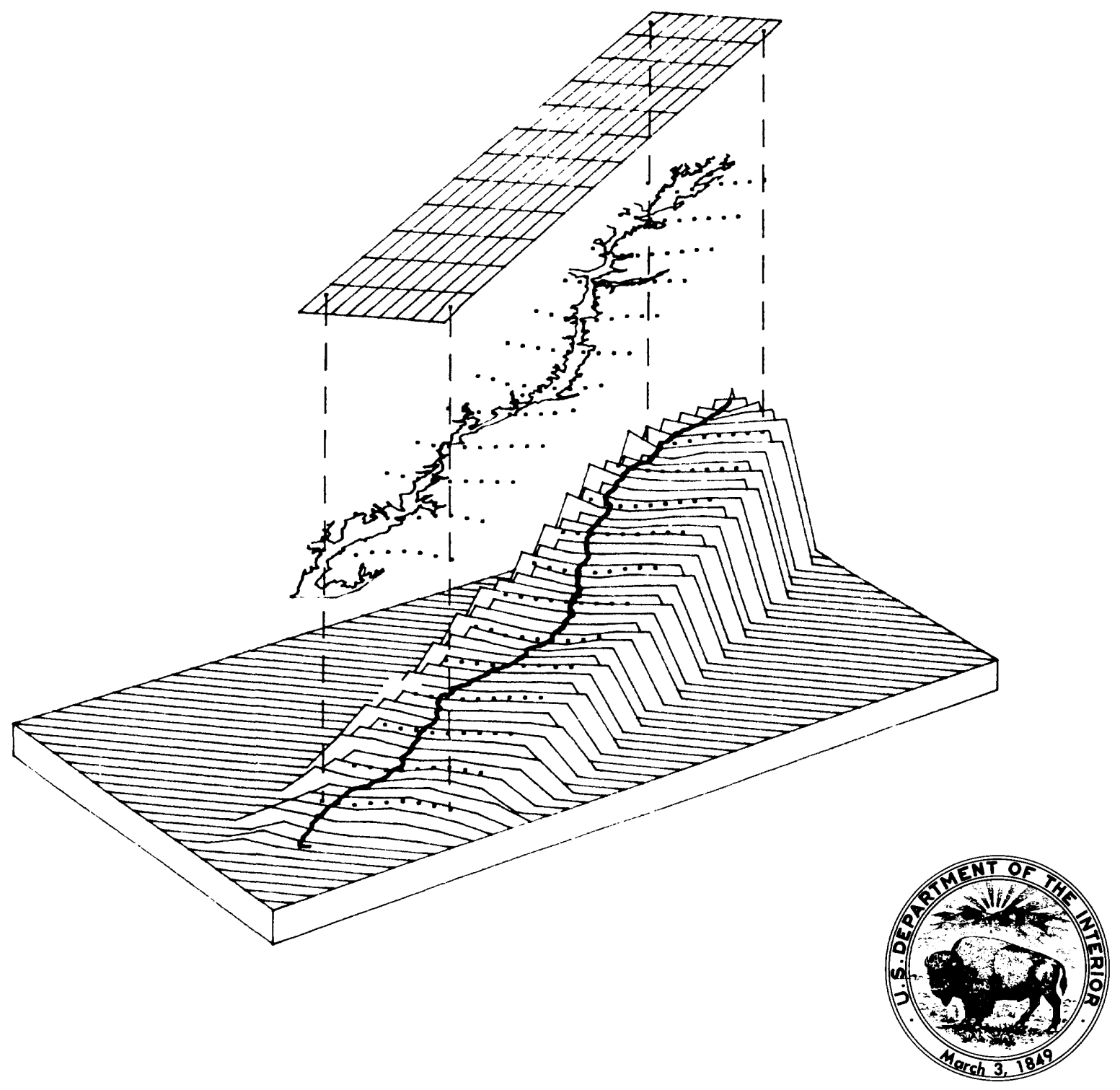




\section{STRUCTURE AND APPLICATION OF AN INTERFACE PROGRAM BETWEEN A GEOGRAPHIC-INFORNATION SYSTEM AND A GROUND-HATER FLOW MODEL}

By Peter C. Van Metre

U.S. GEOLOGICAL SURVEY

Open-File Report 90-165 
Cover: Overlay of a ground-water model grid with digital coverages to develop model data sets using geographic-information system techniques. Upper layer is a polygon coverage of the model grid. Middle layer is a line coverage of the extent of an aquifer and a point coverage of center points of the model grid. Lower layer is a surface coverage of land-surface elevation, a line coverage of a stream, and a point coverage of center points of the model grid. 


\title{
UNITED STATES DEPARTMENT OF THE INTERIOR
}

MANUEL LUJAN, JR., Secretary

GEOLOGICAL SURVEY

Dallas L. Peck, Director

Copies of the computer program and test data sets on tape or diskette are available at cost of processing from:

\author{
U.S. Geological Survey \\ National Water Information System \\ 437 National Center \\ Reston, VA 22092 \\ Telephone: (703) 648-5695
}

For additional information write to:

District Chief

U.S. Geological Survey

Federal Building, FB-44

300 West Congress Street

Tucson, Arizona 85701-1393
Copies of this report can be purchased from:

U.S. Geological Survey

Books and Open-File Reports Section

Federal Center, Building 810

Box 25425

Denver, Colorado 80225 


\section{CONTENTS}

Page

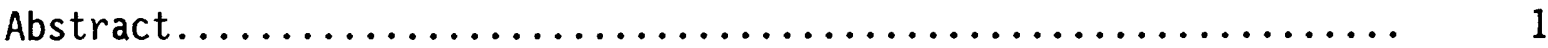

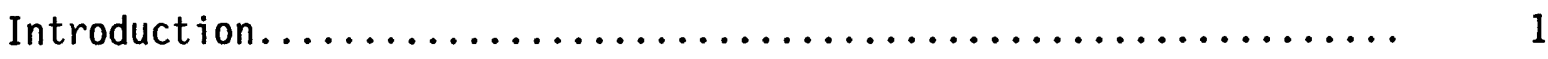

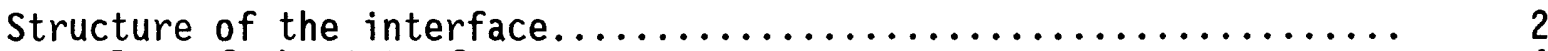

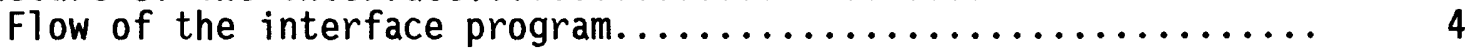

Description of package output programs and INFO data files.... 5

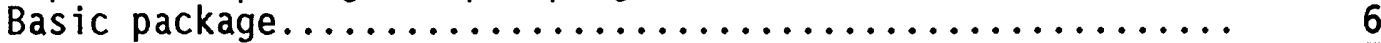

INF0 file structure and example data files............ 7

Narrative of basic output program............... 9

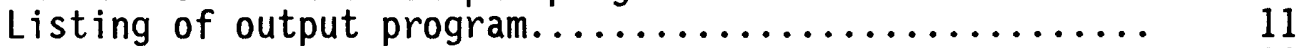

Listing of program FMTIN.PG.................. 12

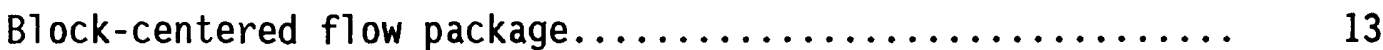

INF0 file structure and example data files........... 13

Narrative of block-centered flow output program....... 16

Listing of output program..................... 17

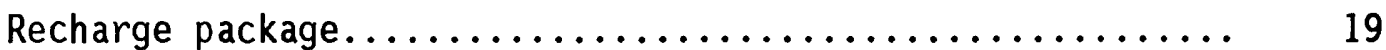

INF0 file structure and example data files............ 19

Narrative of recharge output program............. 20

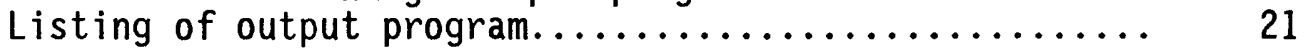

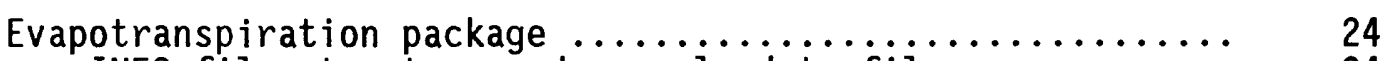

INF0 file structure and example data files............ 24

Narrative of evapotranspiration output program........ 25

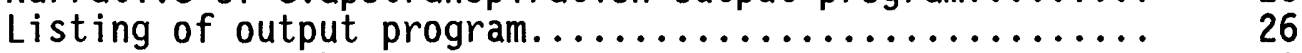

Listing of a subroutine output program........... 28

Listing of update program...................... 29

River package............................ 30

INFO file structure and example data files.......... 31

Narrative of river output program................ 31

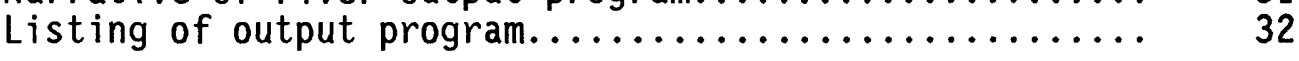

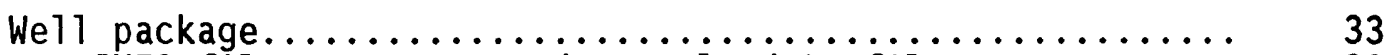

INF0 file structure and example data files........... 33

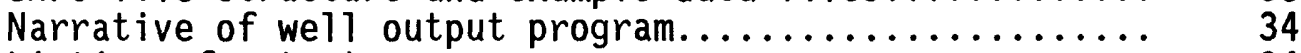

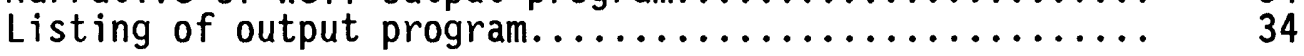

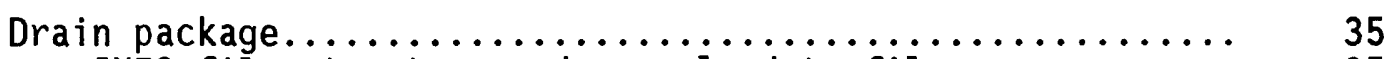

INF0 file structure and example data files........... 35

Narrative of drain output program................ 36

Listing of output program................... 36 
IV

Structure of the interface-Continued

Description of package output programs and INFO data files-Continued

General -head boundary package.................... 37

INF0 file structure........................... 37

Narrative of general-head boundary output program..... 38

Listing of output program....................... 38

Strongly implicit procedure, slice-successive

overrelaxation, and output control packages..............

INFO file structure and example data files.............

Listing of strongly implicit procedure

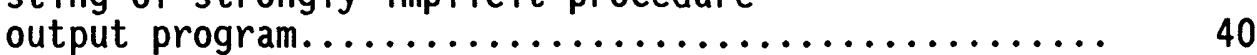

Listing of slice-successive overrelaxation

output program............................ 40

Listing of output control program.................. 41

Control of the package output programs................. 41

Listing of MAIN.CPL program....................... 42

Description of programs OUTALL and OUTSEL............... 45

Narrative of INFO program OUTALL......................... 45

Listing of INFO program OUTALL...................... 45

Narrative of INFO program OUTSEL................... 47

Listing of INFO program OUTSEL..................... 48

Listing of INFO Input Form OUTSEL.DF................... 50

INFO file structure and example data files for

OUTSEL.DF................................... 51

Returning model output to ARC/INF0................... 51

Listing of CPL program WLSIN.CPL..................... 52

Listing of CPL program CBCIN.CPL..................... 53

INFO file structure of files CBC.DAT and WLS.DAT......... 54

Listing of INFO program LOADWLS.PG................... 56

Description of Fortran program WLSIN.F77............... 56

Listing of Fortran program WLSIN.F $77 \ldots \ldots \ldots \ldots \ldots \ldots \ldots \ldots \ldots \ldots \ldots \ldots, 57$

Application of the interface program............................. 62

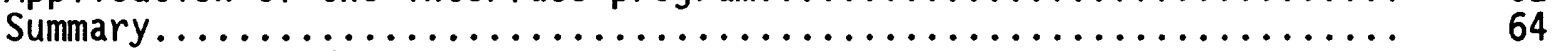

References cited....................................... 65

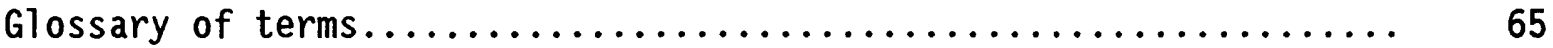

\section{ILLUSTRATIONS}

Figure 1. Diagram showing ARC/INF0 coverages, subroutines GRID and NODES............................... 3

2. Diagram showing organization of PRIMOS directories for $A R C / I N F O$ and the interface program. 


\title{
STRUCTURE AND APPLICATION OF AN INTERFACE PROGRAM BETWEEN A GEOGRAPHIC-INFORMATION SYSTEM AND A GROUND-WATER FLOW MODEL
}

By

Peter C. Van Metre

\begin{abstract}
A computer-program interface between a geographic-information system and a ground-water flow model links two unrelated software systems for use in developing the flow models. The interface program allows the modeler to compile and manage geographic components of a ground-water model within the geographic-information system. A significant savings of time and effort is realized in developing, calibrating, and displaying the ground-water flow model. Four major guidelines were followed in developing the interface program: (1) no changes to the ground-water flow model code were to be made, (2) a data structure was to be designed within the geographic-information system that follows the same basic data structure as the ground-water flow model, (3) the interface program was to be flexible enough to support all options available within the model, and (4) the interface program was to be as efficient as possible in terms of computer time used and online-storage space needed. Because some programs in the interface are written in control-program language, the interface will run only on a computer with the PRIMOS operating system.
\end{abstract}

\section{INTRODUCTION}

A computer-program interface between a geographic-information system (GIS) and a ground-water flow model links two unrelated software systems for use in developing the flow models. The geographic-information system, ARC/INF0 ${ }^{1}$, is a digital-mapping and data-management system that is used to develop and manage geographic data bases. ARC/INF0 was interfaced in this study with the modular three-dimensional finite-difference ground-water flow model of McDonald and Harbaugh (1984 and 1988). The interface program is designed to enter, store, update, and output all controlling and geographic information from ARC/INF0 that is necessary to run the ground-water flow model. The interface program is written for a PRIME computer. Use of the interface on a different system such as a VAX would entail modifying programs written in control-program language (CPL) to ARC macro language (AML) or some other supported macro language.

1 Use of the brand or trade names in this report is for identification purposes only and does not constitute endorsement by the U.S. Geological Survey. 
In ground-water modeling, the initial data collection, compilation, interpretation, and integration are time-consuming tasks. For example, in order to develop a data file that defines the top of an aquifer, plotted well locations and their associated geologic information are hand contoured and overlaid on a plot of the model grid. Values are interpolated and assigned to the grid, and the grid values are then input to a computer data file called an array. The geographic and data-base management capabilities of ARC/INFO can be used to automate most of these tasks.

ARC/INF0 also can be used to edit arrays during calibration, input various stresses for predictive model runs, and create report products. Geographic data in ARC/INFO are edited interactively on a computer-graphics terminal. The user selects model nodes or areas of nodes by pointing to them or defining a box around them with the cursor on the screen. Parameter values of selected nodes then can be changed with a calculate command. Changes can also be made using INF0 commands that are independent of ARC. INFO data files associated with an ARC/INFO coverage can be reselected for subsets of those files, and variables can be recalculated. A program in the ARC/INF0 system called ARCPLOT offers a convenient way of plotting both input data and model results.

The interface program performs no data transformations or manipulations and is used only to conveniently store and move data between ARC/INF0 and the ground-water flow model. A working knowledge of the ground-water flow model and ARC/INFO is necessary to understand the relation between those programs and the interface program. Documentation of the interface program includes a listing and description of the INF0 data files and a listing and description of all INFO, control-program language (CPL), and Fortran programs. A glossary of terms is included at the end of this report for the reader who may be unfamiliar with the terms used in the ground-water model and ARC/INFO.

The purpose of this report is to document an interface program that can be used to move data between a GIS and a ground-water flow model. Four major guidelines were followed in developing the interface program: (1) no changes to the ground-water flow model code were to be made, (2) a structure was to be designed within the GIS that follows the same basic structure as the ground-water flow model, (3) the interface program was to be flexible enough to support all options available within the model, and (4) the interface program was to be as efficient as possible in terms of computer time used and online-storage space needed. Application of the interface program was tested using a two-column by nine-row by four-layer ground-water flow model (fig. 1). The author wishes to thank Dean Anderson of Environmental Systems Research Institute for his valuable advice in devising file structure and INFO programs in this study.

\section{STRUCTURE OF THE INTERFACE}

The interface program was developed on the PRIME computer (Seybold, 1985) and uses a tree-structure system for directories within the program (fig. 2). Directories of the interface program include the following: 


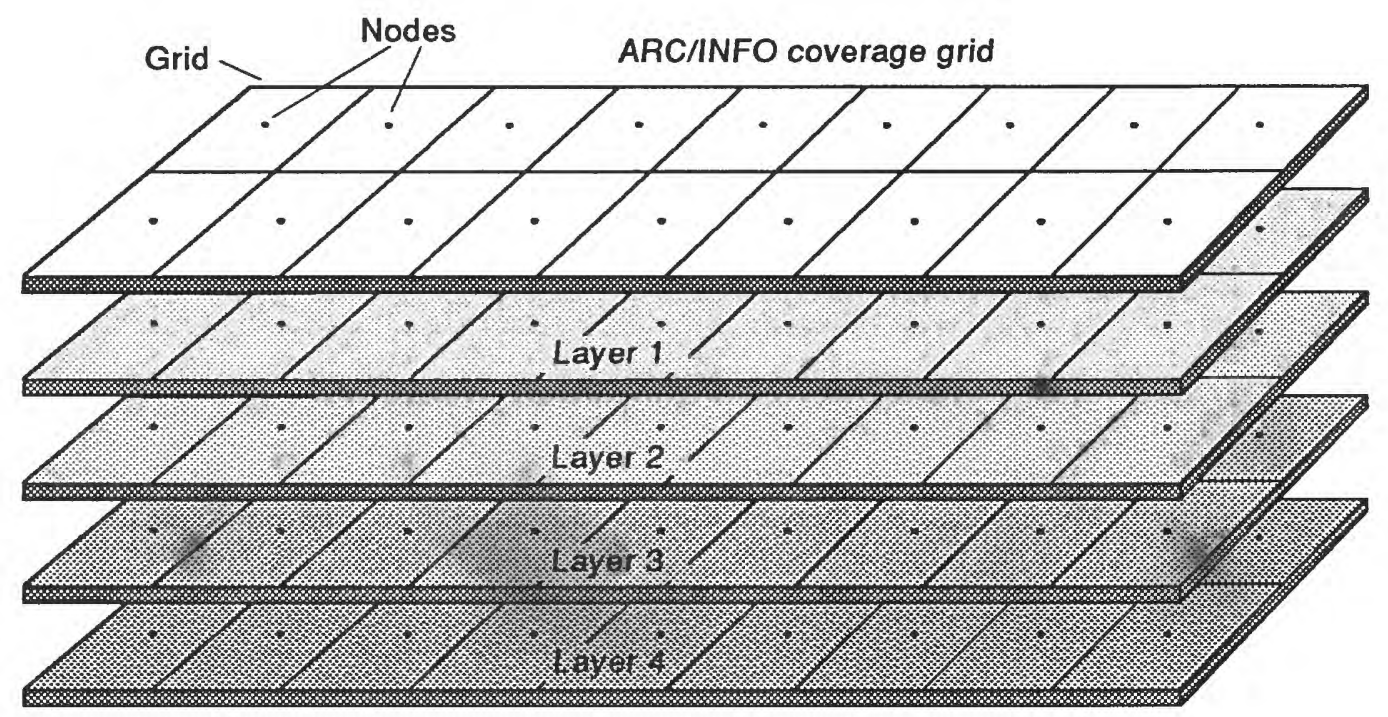

Figure 1.-ARC/INFO coverages, subroutines GRID and NODES.

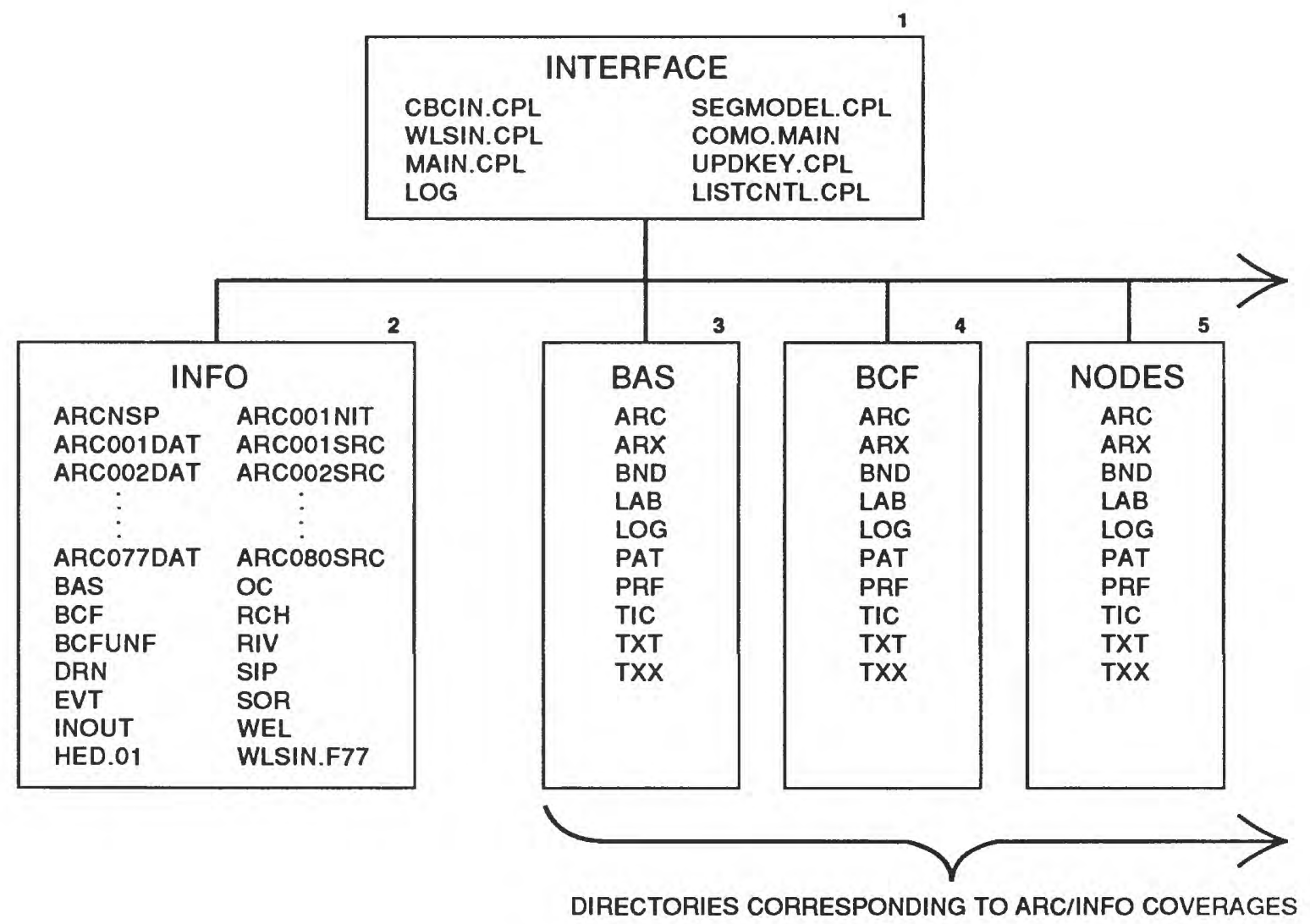

Figure 2.-Organization of PRIMOS directories for ARC/INFO and the interface program. 
- Directory 1 , which is named Interface, holds the command programming languages (CPLS) that drive and execute the interface program. The output of model data from ARC/INFO, the running of the model, and the return of model-output values to ARC/INFO can be executed from this directory.

- Directory 2 is created by ARC/INFO to hold INFO files associated with all coverages (Environmental Systems Research Institute, 1987). Data files associated with coverages and INFO programs that are part of the interface are accessed within INFO at this level. Those files can be viewed by attaching to INFO, entering the command "INFO", and specifying INFO user name "ARC." INFO files in this directory can also be viewed by attaching to directory 1, entering the command "ARC", and then entering the command "INFO".

Directory 2 can have two distinct sets of files, those within INFO and those at the PRIMOS level. By default, the PRIMOS data files associated with each model package are in directory 2 , and the model output is written in directory 2. The user can view ASCII model-output files before generating ARC/INFO coverages of model output in this directory.

- Directories 3-5 are PRIMOS directories that are created by ARC/INFO to hold data files associated with coverages. Each of these directories holds files for one coverage and has the same name as that coverage.

\section{Flow of the Interface Program}

The interface program is controlled by MAIN.CPL, WLSIN.CPL, and CBCIN.CPL. The three CPLs reside and are executed from directory 1 (fig. 1) and are described in detail in the sections "Control of Package Output Programs" and "Returning the Model Output to ARC/INFO." A brief narrative of the flow of a model run using the interface program is as follows.

To initiate a model run, the user invokes MAIN.CPL, which performs the following steps:

1. Enters INFO and determines which packages are in use and which of those packages will require new PRIMOS data files.

2. Runs the INFO package output program for each of those packages creating a new PRIMOS data file for each package at the PRIMOS level in directory 2 (fig. 1).

3. Runs SEGMODEL.CPL to open all necessary data files and runs the model.

4. Runs Fortran program WLSIN.F77, which opens the output control (OC) PRIMOS file and selected other PRIMOS data files, determines what was saved (unformatted) on disk, then reads and reformats those records for input to INFO. 
Program execution then is stopped to allow the user to view model output, such as the statistics generated for a model run, before generating coverages of model-output heads, drawdowns, or flow terms. To generate coverage files of those outputs, the user runs either WLSIN.CPL for heads and drawdowns or CBCIN.CPL for flow terms. The argument required for each CPL is the name of the reformatted model-output file generated by WLSIN. F77.

Steps performed by WLSIN.CPL and CBCIN.CPL:

1. Determine if a coverage already exists by the argument name.

2. If so, bring the specified data into INFO and use it to overwrite that attribute in the coverage. PAT file. If a coverage does not exist, use ARC commands to create a new coverage by that name by copying coverage NODES, then bring the specified data into INFO and add it to the new coverage .PAT file.

\section{Description of Package Output Programs and INFO Data Files}

McDonald and Harbaugh (1988) includes 13 packages. Two of the packages are undefined; therefore, they are not included in the interface program. The 11 packages, their abbreviations, and their IUNIT locations are given in the table on p. 6 .

Discussion of the packages in this report is based on similar structure of the packages and not on a numerical order. Each package has a PRIMOS data-file structure as defined by McDonald and Harbaugh (1984 and 1988). Each PRIMOS data file can contain control information, one-dimensional arrays, two-dimensional arrays, and lists of data by layer, row, and column. Control information can include number of layers, rows, and columns or maximum number of wells for a particular stress period. One-dimensional arrays may be arrays such as the TRPY array in the block-centered flow package that are constant through a simulation. Two-dimensional arrays can be arrays such as the IBOUND array in the basic package; some two-dimensional arrays can be constant through a simulation or can vary for different stress periods.

The basic (BAS), block-centered flow (BCF), recharge ( $\mathrm{RCH}$ ), and evapotranspiration (EVT) packages can contain two-dimensional arrays that are number of rows times number of columns in length. An item or variable output from INF0 will, by default, appear as a list with one value per line. Because the arrays output for each of those four packages are held as items in INF0 data files, the most efficient way to output them to PRIMOS data files is as lists. Lists, however, are not convenient to work with in the PRIMOS file structure, particularly if the model is large. An option was added to the interface program to write arrays across the page.

The BCF package can contain one-dimensional arrays-either number of layers in length, number of rows in length, or number of columns in length. By default, those arrays are written from INFO across the page 


\begin{tabular}{|c|c|c|c|}
\hline Package & Abbreviation & $\begin{array}{l}\text { IUNIT } \\
\text { location }\end{array}$ & $\begin{array}{c}\text { Default } \\
\text { IUNIT } \\
\text { value }\end{array}$ \\
\hline 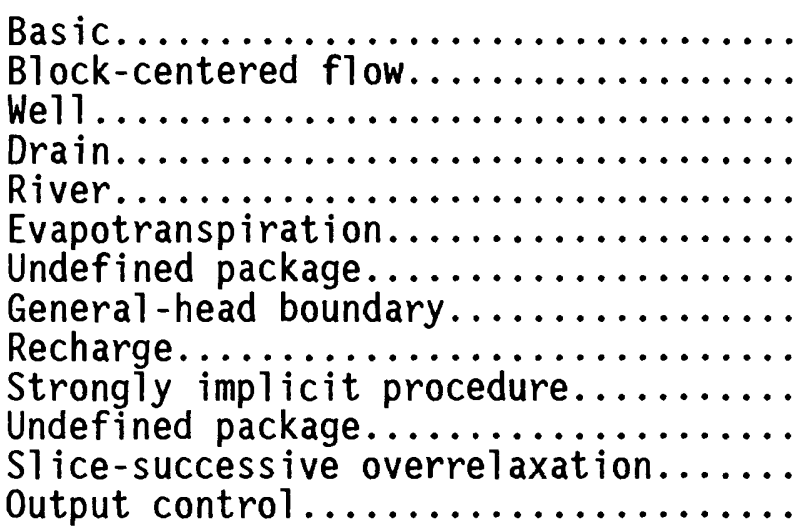 & $\begin{array}{l}\text { BAS } \\
\text { BCF } \\
\text { WEL } \\
\text { DRN } \\
\text { RIV } \\
\text { EVT } \\
- \text { GHB } \\
\text { RCH } \\
\text { SIP } \\
-\overline{\text { SOR }} \\
\text { OC }\end{array}$ & $\begin{array}{r}- \\
1 \\
2 \\
3 \\
4 \\
5 \\
6 \\
7 \\
8 \\
9 \\
10 \\
11 \\
12\end{array}$ & $\begin{array}{r}5 \\
29 \\
30 \\
31 \\
32 \\
33 \\
-- \\
35 \\
36 \\
37 \\
-- \\
--\end{array}$ \\
\hline
\end{tabular}

with a page width of 132 columns. The well (WEL), drain (DRN), river (RIV), and general-head boundary (GHB) packages can contain 1ists of data by layer, row, and column and are stored and output from INFO as 1 ists. The strongly implicit procedure (SIP), slice-successive overrelaxation (SOR), and output-control (OC) packages contain only controlling information. Data that are not arrays are defined in the INFO data structure as single 80-character-wide items with redefined items for each model variable. Output from INFO is executed as whole files with either the "save compress" command or the "display print" command.

\section{Basic Package}

Three INF0 data files-control (BAS.CNTL), formats (BAS.FMTS), and attribute (BAS.PAT)-are used to hold the data required for the BAS package. The control information contained in the first five cards in the BAS package (McDonald and Harbaugh, 1988) is contained in the BAS.CNTL data file. The array-control card for each two-dimensional (row by column) array is held in the BAS.FMTS file. Data arrays that are not represented by a constant value in the corresponding array-control card are in the BAS.PAT file. The BAS.PAT file is the point-attribute file for a point coverage in ARC/INFO that contains the center point of every block in the model grid, and, therefore, is number of rows times number of columns in length. One additional file, BAS.KEY, is used to generate output for the BAS package. BAS.KEY includes KEY, BAS\#, IKEY, and ROW and contains one record for each model node. KEY is a unique integer that corresponds to the record number for the BAS.PAT file when it is sorted on row and column. BAS\# is the unique integer associated with each node in the BAS.PAT file; however, it generally will not match KEY. 
INFO File Structure and Example Data Files

DATAFILE NAME: BAS.CNTL

1 ITEMS: STARTING IN

COL ITEM NAME

1 TEXT $\star \star$ REDEFINED ITEMS

WDTH OPUT TYP N.DEC ALTERNATE NAME $80 \quad 80$

1 CD1.HEADNG

1 CD2. HEADNG

1 NLAY

11 NROW

$21 \mathrm{NCOL}$

31 NPER

41 ITMUNI

1 IUNITI

4 IUNIT2

7 IUNIT3

10 IUNIT4

13 IUNIT5

16 IUNIT6

19 IUNIT7

22 IUNIT8

25 IUNIT9

28 IUNITIO

31 IUNIT11

34 IUNITI2

$\begin{array}{rrrr}80 & 80 & \mathrm{C} & - \\ 48 & 48 & \mathrm{C} & - \\ 10 & 10 & \mathrm{I} & - \\ 10 & 10 & \mathrm{I} & - \\ 10 & 10 & \mathrm{I} & - \\ 10 & 10 & \mathrm{I} & - \\ 10 & 10 & \mathrm{I} & - \\ 3 & 3 & \mathrm{I} & - \\ 3 & 3 & \mathrm{I} & - \\ 3 & 3 & \mathrm{I} & - \\ 3 & 3 & \mathrm{I} & - \\ 3 & 3 & \mathrm{I} & - \\ 3 & 3 & \mathrm{I} & - \\ 3 & 3 & \mathrm{I} & - \\ 3 & 3 & \mathrm{I} & - \\ 3 & 3 & \mathrm{I} & - \\ 3 & 3 & \mathrm{I} & - \\ 3 & 3 & \mathrm{I} & - \\ 3 & 3 & \mathrm{I} & -\end{array}$

$\begin{array}{ll}1 & \text { IAPART } \\ 11 & \text { ISTRT }\end{array}$

$\begin{array}{lll}10 & 10 & \mathrm{I} \\ 10 & 10 & \mathrm{I}\end{array}$

$12 / 5 / 1988$

ENTER COMMAND >LI

\$RECNO TEXT

1 TEST RUN OF ARC/INFO-GWMDL WITH CONTROL CARDS IN INFO $2 \quad * * 4 / 1 / 87 * *$

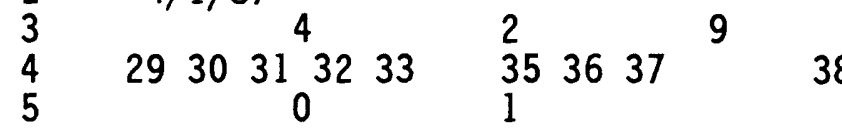

DATAFILE NAME: BAS.FMTS

$12 / 5 / 1988$

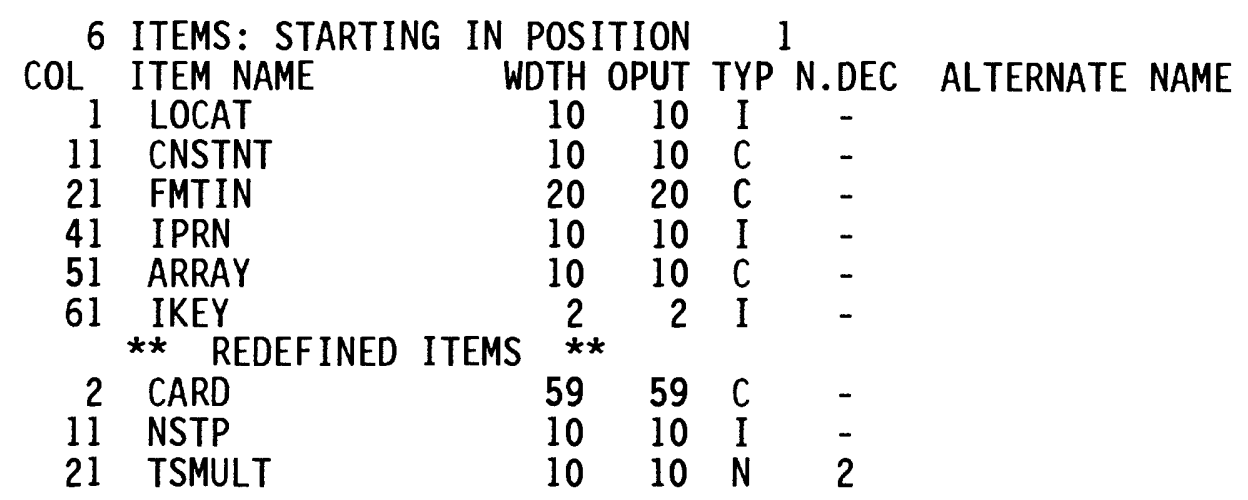


ENTER COMMAND >LI

\begin{tabular}{|c|c|c|}
\hline $\begin{array}{r}\text { \$RECNO } \\
1 \\
2 \\
3 \\
4 \\
5 \\
6 \\
7 \\
8 \\
9 \\
10\end{array}$ & $\begin{array}{r}\text { LOCAT CNSTNT } \\
5 \\
5 \\
5 \\
5 \\
999 \\
5 \\
5 \\
5 \\
5 \\
86400\end{array}$ & $\begin{array}{l}\text { FMTIN } \\
(20 \mathrm{I} 4) \\
(20 \mathrm{I} 4) \\
(20 \mathrm{I} 4) \\
(20 \mathrm{I} 4) \\
(20 \mathrm{~F} 6.0) \\
(20 \mathrm{~F} 6.0) \\
(20 \mathrm{~F} 6.0) \\
(20 \mathrm{~F} 6.0) \\
1.00\end{array}$ \\
\hline
\end{tabular}

DATAFILE NAME: BAS.PAT
IPRN ARRAY IKEY

-1 IBOUND1 9

-1 IBOUND2 9

-1 IBOUND3 9

-1 IBOUND4 9

0 HNOFLO 9

-1 SHEAD1 9

-1 SHEAD2 9

-1 SHEAD3 9

-1 SHEAD4 9

$12 / 5 / 1988$

14 ITEMS: STARTING IN POSITION 1

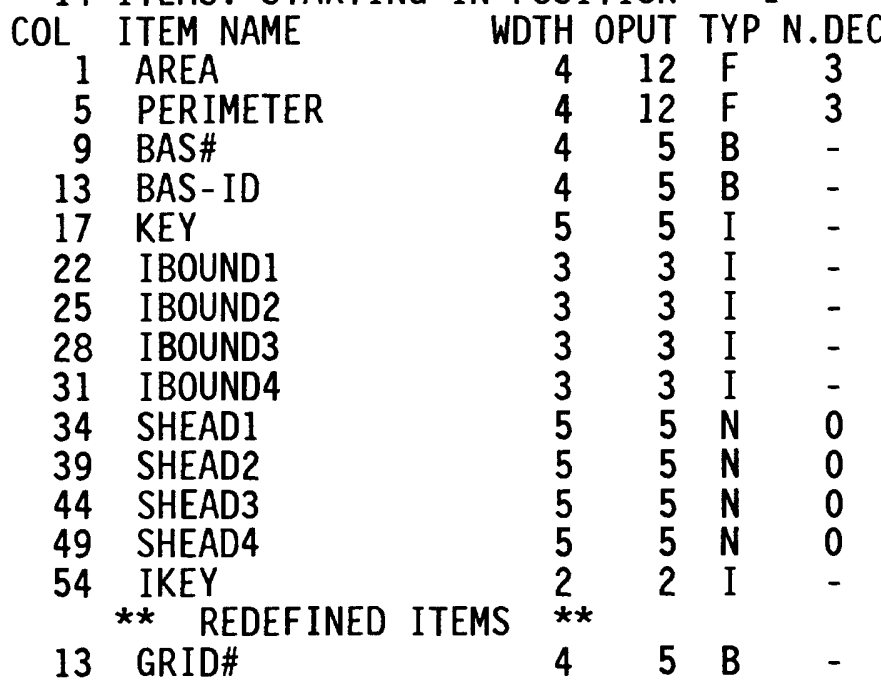

ENTER COMMAND >LI

SRECNO AREA PERIMETER BAS\# BAS-ID KEY IBOUND1 IBOUND2 IBOUND3 IBOUND4 SHEAD1 SHEAD2 SHEAD3 SHEAD4 IKEY

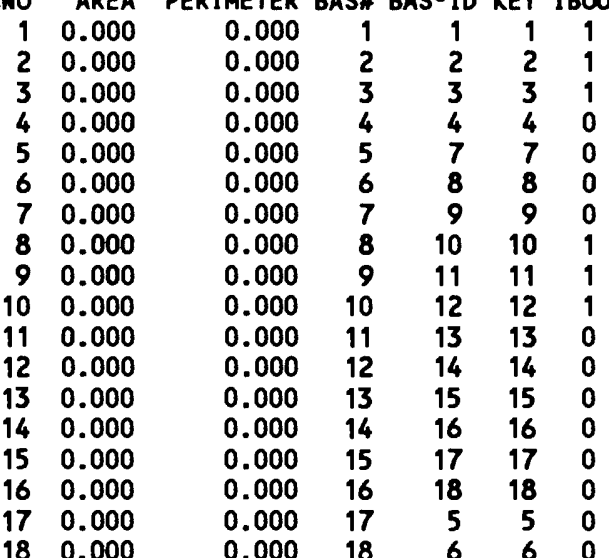




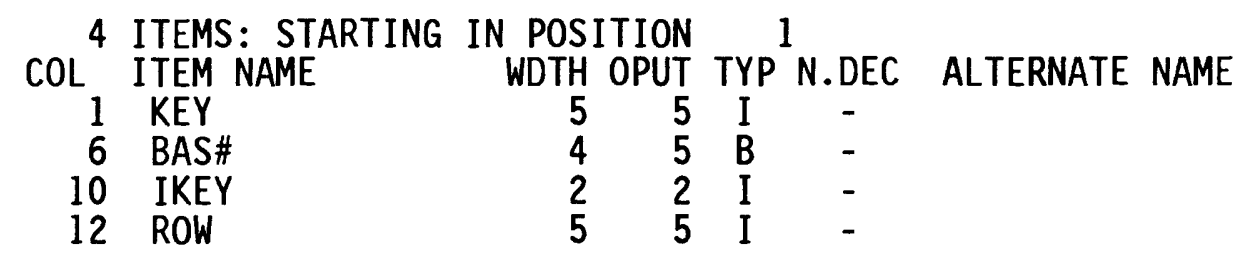

\begin{tabular}{rrrrr}
\multicolumn{6}{l}{ ENTER COMMAND $>$ LI } & & \\
\$RECNO & KEY & BAS\# & IKEY & ROW \\
1 & 1 & 1 & 9 & 1 \\
2 & 2 & 2 & 9 & 1 \\
3 & 3 & 3 & 9 & 1 \\
4 & 4 & 4 & 9 & 1 \\
5 & 5 & 17 & 9 & 1 \\
6 & 6 & 18 & 9 & 1 \\
7 & 7 & 5 & 9 & 1 \\
8 & 8 & 6 & 9 & 1 \\
9 & 9 & 7 & 9 & 1 \\
10 & 10 & 8 & 9 & 2 \\
11 & 11 & 9 & 9 & 2 \\
12 & 12 & 10 & 9 & 2 \\
13 & 13 & 11 & 9 & 2 \\
14 & 14 & 12 & 9 & 2 \\
15 & 15 & 13 & 9 & 2 \\
16 & 16 & 14 & 9 & 2 \\
17 & 17 & 15 & 9 & 2 \\
18 & 18 & 16 & 9 & 2
\end{tabular}

Narrative of Basic Output Program

The basic package output program (BASOUT.PG) generates a PRIMOS file named BAS for a model run. The generated BAS file can be used for model input and requires no modification to the ground-water flow model. The program is executed in the following manner:

1. Select the BAS.CNTL file and use "SAVE BAS COMPRESS INIT" to open a PRIMOS file named BAS, initialize that file, and write all selected records in BAS.CNTL to that file.

2. Select BAS.FMTS and relate to files BAS.KEY and BAS.PAT if any arrays are nonconstant.

3. Loop through each record in the BAS.FMTS file to test for FMTIN that contain parentheses. Each record in BAS.FMTS is either an array-control card, HNOFLO card, or a PERLEN, NSTP, and TSMULT data card (McDonald and Harbaugh, 1988). In other package-output programs where the. FMTS file contains array-control cards only, the test at this step is 
for LOCAT greater than zero. If FMTIN does not contain parentheses, the array is represented by a constant value and only the array-control card is output. If FMTIN contains parentheses, a format is being given to read an array. Then the value of LOCAT is tested. If LOCAT equals 5 , the default FORTRAN unit number for PRIMOS data file BAS, the array is output to PRIMOS file BAS. If LOCAT does not equal 5, a PRIMOS file named with the value in INFO item ARRAY is opened and the array is output to that file. In this way, the array control cards can be loaded to PRIMOS file BAS and the arrays can be loaded to separate PRIMOS files. Either LIST or WIDE output format is specified when executing the interface program. The effect of each is as follows:

a. If LIST output format is specified, the array-control card is output and the corresponding array in BAS. PAT is output as a list.

b. If WIDE output format is specified and each row of data will fit within 132 characters, the array-control card is output and the corresponding array in BAS.PAT is output across the page.

c. If WIDE output format is specified and each row of data will not fit within 132 characters, the array-control card is output, BAS.KEY is selected and related to BAS.PAT, and rows are reselected one at a time and output across the page wrapping to the subsequent lines as necessary. BAS.FMTS is then selected and the relate sequence in step 2 is re-established. The test mode 1 in this situation took two to three times more central-processing unit (CPU) and input and output (I/0) time to generate files as a list format or the wide format described in b. above.

ARRAY and IKEY are two items in the. FMTS files that are not found in the model documentation. ARRAY is the character name of the array that the array-control card corresponds to and must match the item name of that array in the corresponding. PAT file. The value stored in ARRAY is used to output its corresponding data values from the .PAT file. IKEY is an integer item that equals 9 in all files and is used as part of the file-relating sequence in INFO that is used for all packages that produce two-dimensional arrays.

In the test model, SORT was added to the BCF.FMTS data file and is an integer equal to the record number of the. FMTS file when it is properly sorted. If new array-control cards are added or if the order needs to be changed for any reason, values of SORT can be updated and the file resorted. 
Listing of Output Program

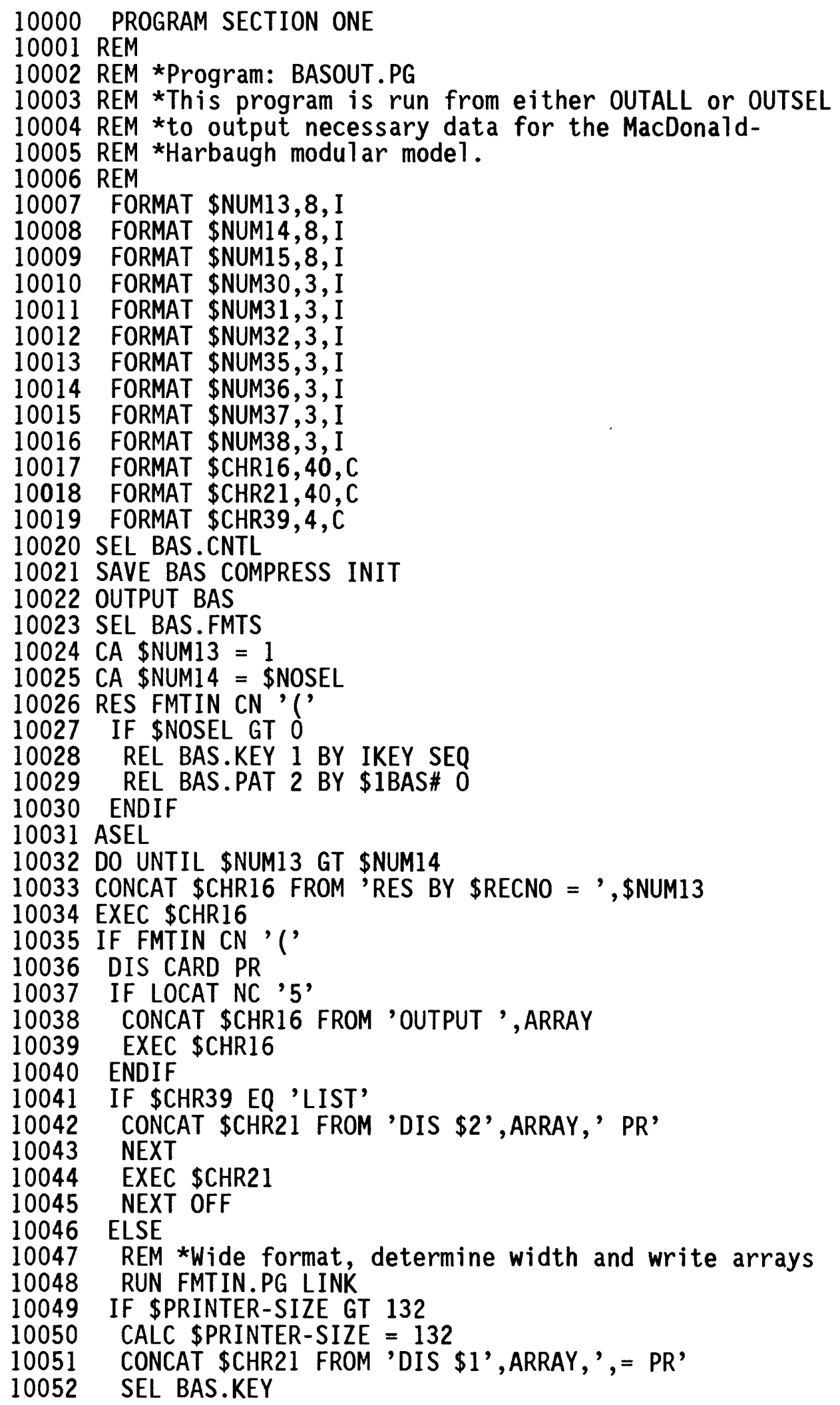




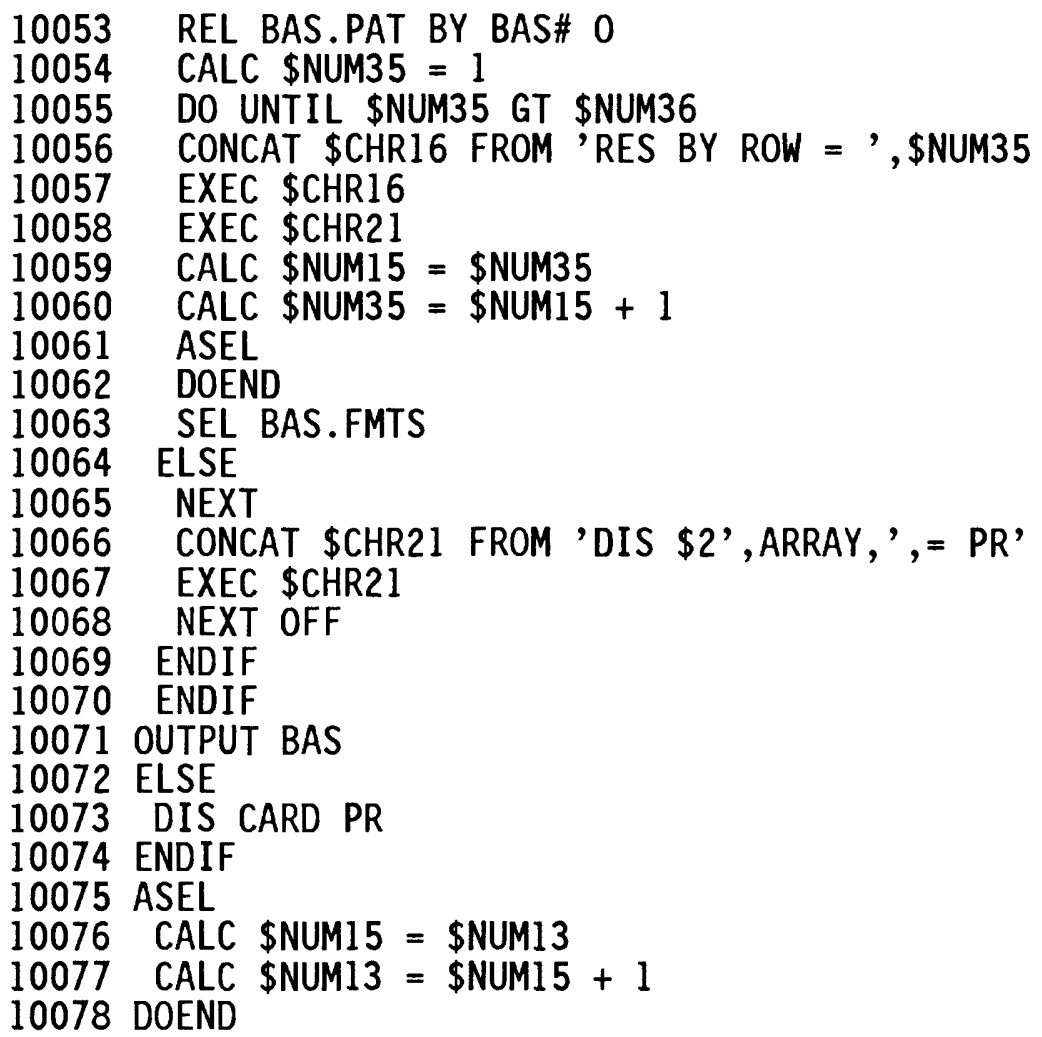

\section{Listing of Program FMTIN.PG}

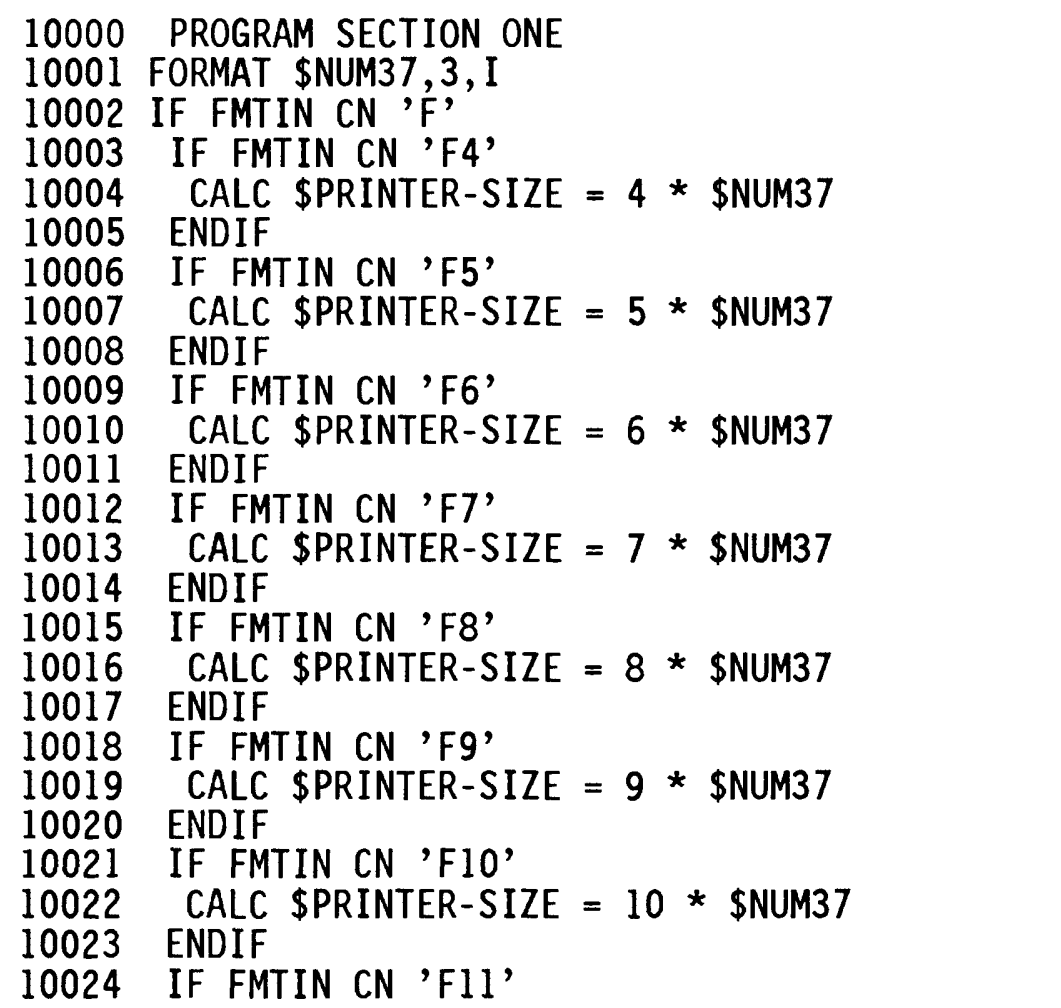




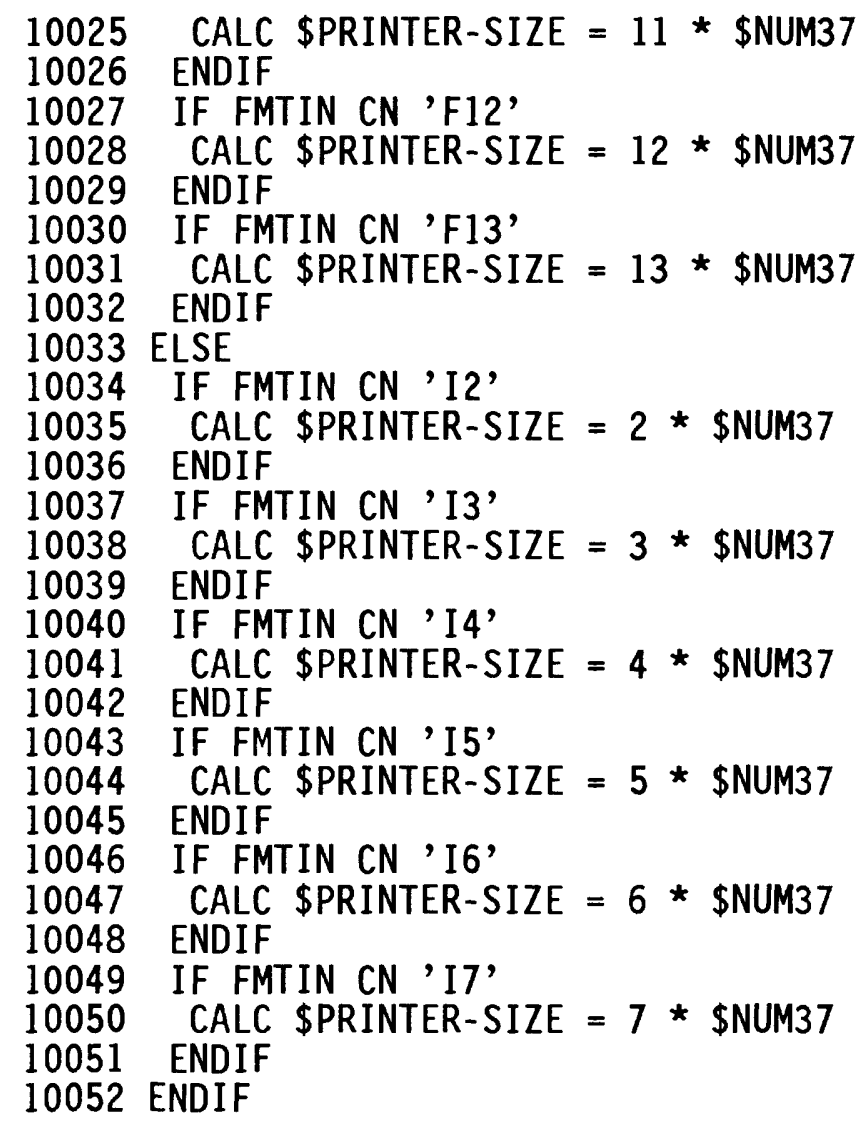

\section{Block-Centered Flow Package}

A storage and output structure similar to BAS is used for the BCF package. Three additional INFO files for one-dimensional arrays are included in BCF. Only one-dimensional arrays that are not constant need to have the corresponding data file defined in INFO.

INF0 File Structure and Example Data Files

DATAFILE NAME: BCF.CNTL

1 ITEMS: STARTING IN POSITION 1

COL ITEM NAME WDTH OPUT TYP N.DEC ALTERNATE NAME

$12 / 5 / 1988$

\begin{tabular}{rlrrrr}
1 & TEXT & 80 & 80 & $\mathrm{C}$ & - \\
\multirow{2}{*}{$\begin{array}{l}\text { T* REDEFINED ITEMS } \\
\text { *** }\end{array}$} & & & \\
1 & ISS & 10 & 10 & $\mathrm{I}$ & - \\
11 & IBCFCB & 10 & 10 & $\mathrm{I}$ & - \\
1 & LAYCON1 & 2 & 2 & $\mathrm{I}$ & - \\
3 & LAYCON2 & 2 & 2 & $\mathrm{I}$ & - \\
5 & LAYCON3 & 2 & 2 & $\mathrm{I}$ & - \\
7 & LAYCON4 & 2 & 2 & $\mathrm{I}$ & -
\end{tabular}

ENTER COMMAND >LI

\$RECNO TEXT

$\begin{array}{llllll}1 & 1 & 3 & 3 & 3^{1}\end{array}$ 
7 ITEMS: STARTING IN POSITION 1

COL ITEM NAME

$\begin{array}{ll}1 & \text { LOCAT } \\ 11 & \text { CNSTNT } \\ 21 & \text { FMTIN } \\ 41 & \text { IPRN } \\ 51 & \text { ARRAY } \\ 61 & \text { IKEY } \\ 63 & \text { SORT\# } \\ * * & \text { REDEFINED ITEMS }\end{array}$

2 CARD
WDTH OPUT TYP N.DEC

$\begin{array}{crrr}10 & 10 & \text { I } & - \\ 10 & 10 & \mathrm{C} & - \\ 20 & 20 & \mathrm{C} & - \\ 10 & 10 & \mathrm{I} & - \\ 10 & 10 & \mathrm{C} & - \\ 2 & 2 & \mathrm{I} & - \\ 2 & 2 & \mathrm{I} & - \\ \star * & & \\ 59 & 59 & \mathrm{C} & -\end{array}$

ENTER COMMAND >LI

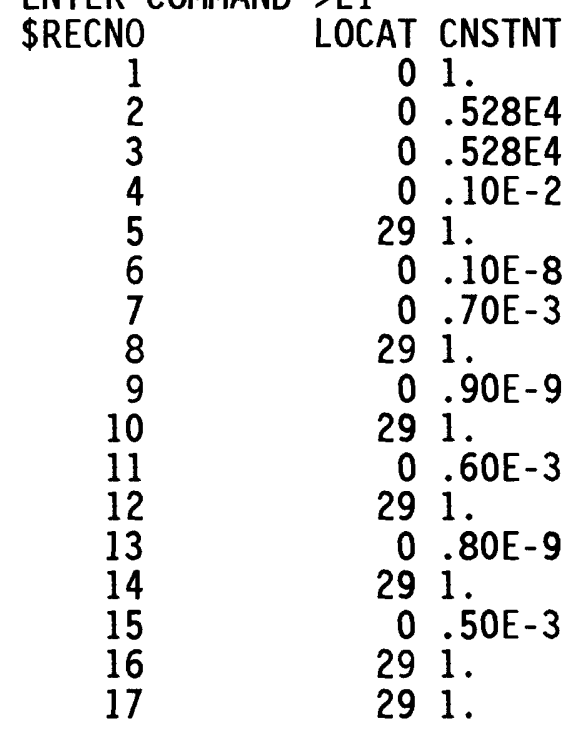

\section{FMTIN}

(20F6.0)

(20F6.0)

(20F6.0)

(20F6.0)

(20F6.0)

(20F6.0)

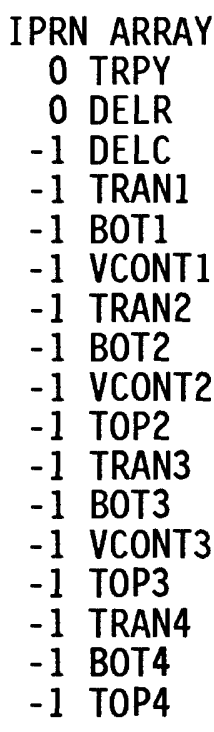

IKEY SORT\#

$$
\begin{array}{rr}
9 & 1 \\
9 & 2 \\
9 & 3 \\
9 & 4 \\
9 & 5 \\
9 & 6 \\
9 & 7 \\
9 & 8 \\
9 & 9 \\
9 & 10 \\
9 & 11 \\
9 & 12 \\
9 & 13 \\
9 & 14 \\
9 & 15 \\
9 & 16 \\
9 & 17
\end{array}
$$

DATAFILE NAME: BCF.PAT

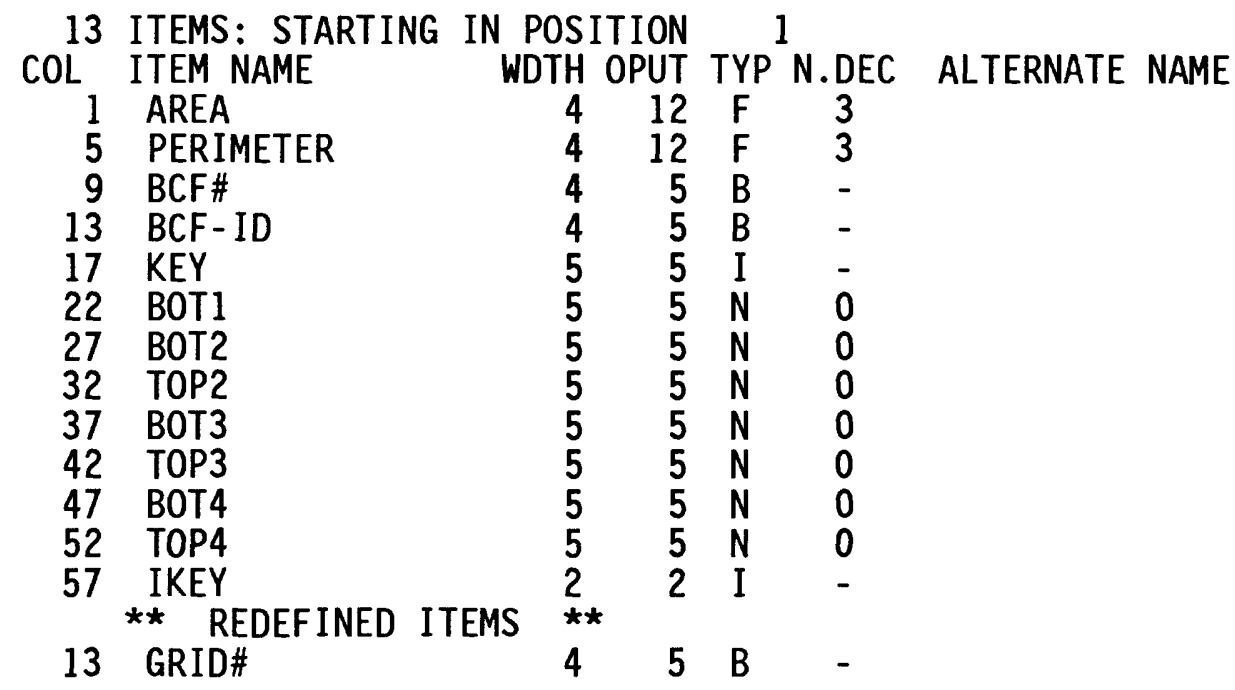


ENTER COMAND >LI

SRECNO AREA

$199,934.800$

$199,934.800$

$199,934.800$

$199,934.800$

$199,934.800$

$199,934.800$

$199,934.800$

$199,934.800$

$199,934.800$

$199,934.800$

$199,934.800$

$199,934.800$

$199,934.800$

$199,934.800$

$199,934.800$

$199,934.800$

$199,934.800$

$199,934.800$

PERIMETER
0.000
0.000
0.000
0.000
0.000
0.000
0.000
0.000
0.000
0.000
0.000
0.000
0.000
0.000
0.000
0.000
0.000
0.000

$\begin{array}{ccc}\text { ECF* } & \text { BCF-1D } \\ 1 & 1 & \text { KEY } \\ 2 & 2 & 2 \\ 3 & 3 & 3 \\ 4 & 4 & 5 \\ 5 & 5 & 5 \\ 6 & 6 & 6 \\ 7 & 7 & 7 \\ 8 & 8 & 8 \\ 9 & 9 & 9 \\ 10 & 10 & 10 \\ 11 & 11 & 11 \\ 12 & 12 & 12 \\ 13 & 13 & 13 \\ 14 & 14 & 14 \\ 15 & 15 & 15 \\ 16 & 16 & 16 \\ 17 & 17 & 17 \\ 18 & 18 & 18 \\ & \end{array}$
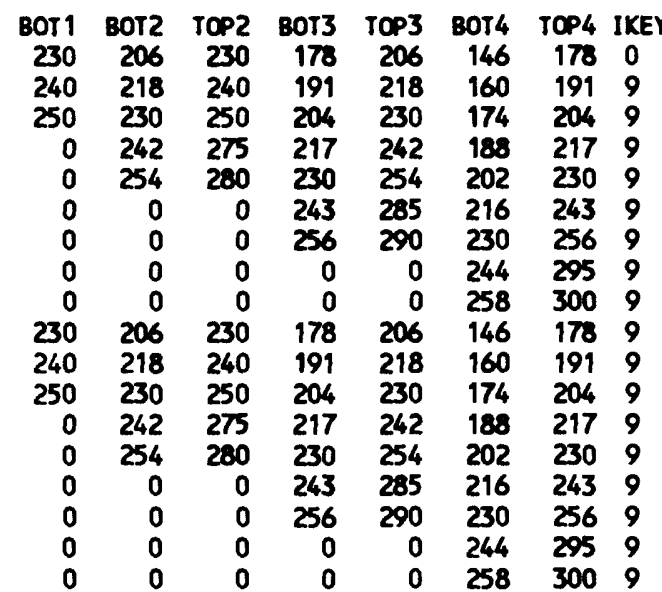

DATAFILE NAME: BCF.KEY

4 ITEMS: STARTING IN POSITION 1

COL ITEM NAME

$\begin{aligned} 1 & \text { KEY } \\ 6 & \text { BCF\# } \\ 10 & \text { IKEY } \\ 12 & \text { ROW }\end{aligned}$
WDTH OPUT TYP N.DEC ALTERNATE NAME

$\begin{array}{llll}5 & 5 & \text { I } & - \\ 4 & 5 & \text { B } & - \\ 2 & 2 & \text { I } & - \\ 3 & 3 & \text { I } & -\end{array}$

ENTER COMMAND $>$ LI

$\begin{array}{rrrrr}\text { \$RECNO } & \text { KEY } & \text { BCF\# } & \text { IKEY } & \text { ROW } \\ 1 & 1 & 1 & 9 & 1 \\ 2 & 2 & 2 & 9 & 1 \\ 3 & 3 & 3 & 9 & 1 \\ 4 & 4 & 4 & 9 & 1 \\ 5 & 5 & 5 & 9 & 1 \\ 6 & 6 & 6 & 9 & 1 \\ 7 & 7 & 7 & 9 & 1 \\ 8 & 8 & 8 & 9 & 1 \\ 9 & 9 & 9 & 9 & 1 \\ 10 & 10 & 10 & 9 & 2 \\ 11 & 11 & 11 & 9 & 2 \\ 12 & 12 & 12 & 9 & 2 \\ 13 & 13 & 13 & 9 & 2 \\ 14 & 14 & 14 & 9 & 2 \\ 15 & 15 & 15 & 9 & 2 \\ 16 & 16 & 16 & 9 & 2 \\ 17 & 17 & 17 & 9 & 2 \\ 18 & 18 & 18 & 9 & 2\end{array}$


Narrative of Block-Centered Flow Output Program

1. Select the BCF.CNTL file and use "SAVE BCF COMPRESS INIT" to open PRIMOS file named BCF, initialize that file, and write all selected records in BCF.CNTL to that file.

2. Select BCF.FMTS and loop through the first three records that are the array-control cards for the one-dimensional arrays TRPY, DELR, and DELC. If FMTIN contains parentheses, the array is not constant and values are expected. Relate data file TRPY, DELR, or DELC, depending on the value of item ARRAY, and output the array-control card and its associated data array. If FMTIN does not contain parentheses, output array-control card only.

3. Establish a file relate between the selected file BCF.FMTS and the files BCF.KEY and BCF.PAT if any arrays are nonconstant.

4. Loop through each remaining record in BCF.FMTS testing for FMTIN that contain parentheses. If FMTIN contains parentheses, the array is not constant and values are expected. The value of LOCAT is then tested. If LOCAT equals 29 , the default FORTRAN unit number for BCF, the array is output to PRIMOS file BCF. If LOCAT does not equal 29, a PRIMOS file named with the value in INFO item ARRAY is opened, for example BOTl for the array describing the bottom of layer one, and the array is output to that file. Either LIST or WIDE output format is specified when executing the interface program. The effect of each is as follows:

a. If LIST output format is specified, the array-control card is output and the corresponding array in BCF.PAT is output as a list.

b. If WIDE output format is specified and each row of data will fit within 132 characters, the array-control card is output and the corresponding array in BCF.PAT is output across the page.

c. If WIDE output format is specified and each row of data will not fit within 132 characters, the array-control card is output, BCF.KEY is selected and related to BCF.PAT, and rows are reselected one at a time and output across the page, wrapping to subsequent lines as necessary. BAS.FMTS is then selected and the relate sequence in step 2 is re-established.

If FMTIN does not contain parentheses, the array is represented by a constant value and only the array-control card is output. 
Listing of Output Program

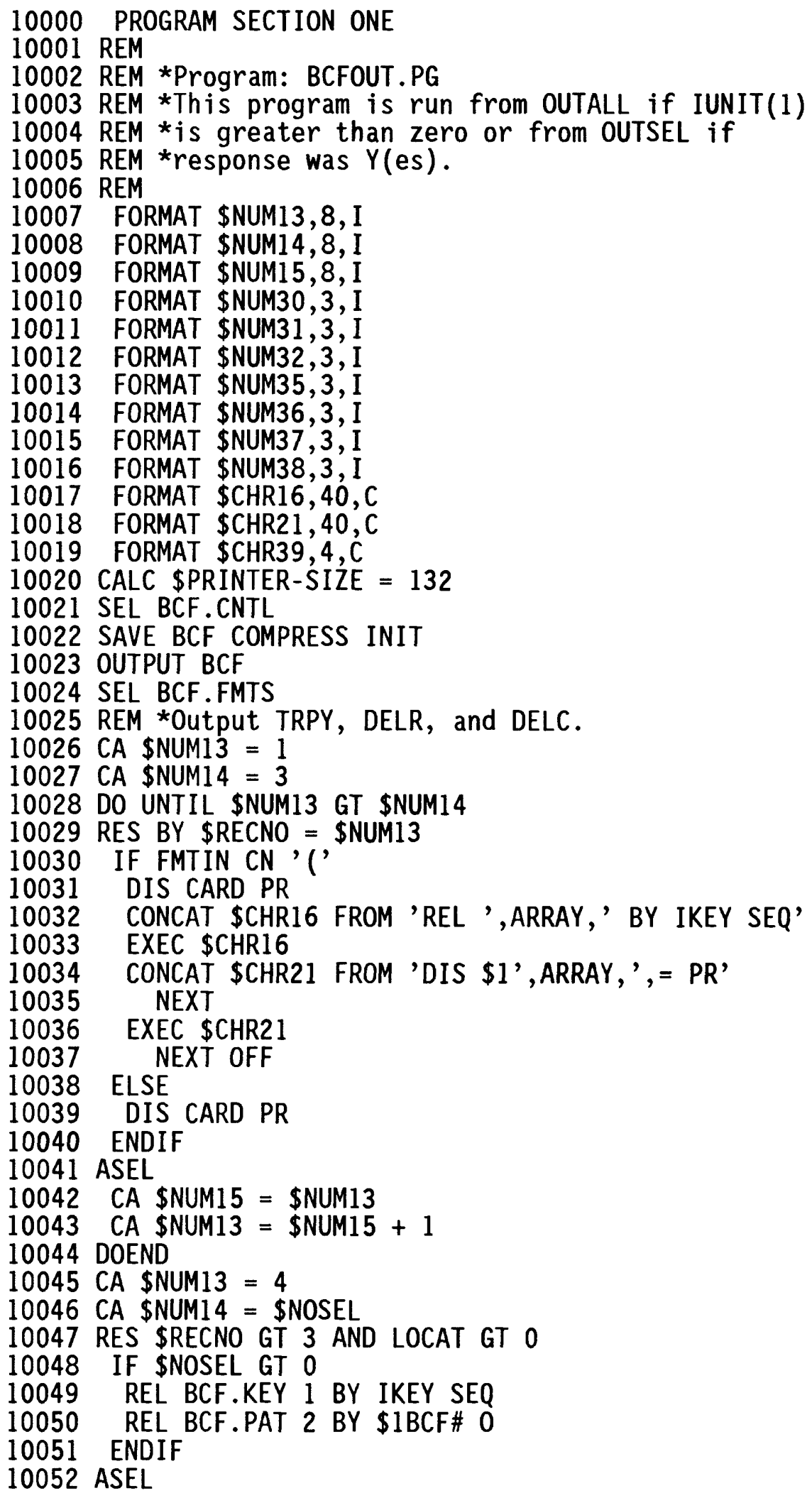




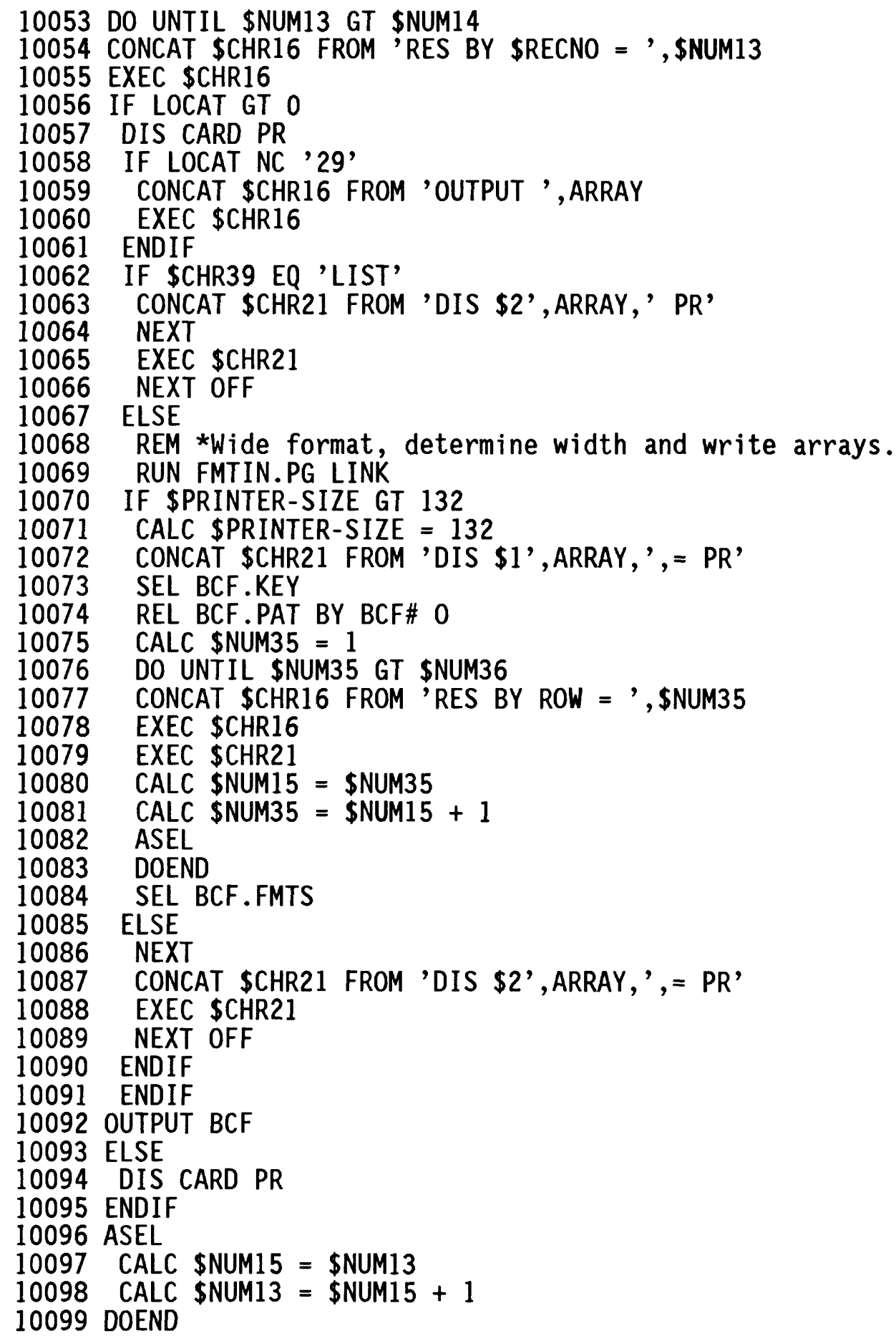




\section{Recharge Package}

The recharge (RCH) package and the evapotranspiration (EVT) packages are similar in that they both can contain a different set of data arrays for each stress period simulated. This capability differs from the $B A S$ and BCF packages, which require only one set of arrays for each simulation. In addition, both RCH and EVT can have a variable number of arrays for any given stress period-0, 1 , or 2 for $\mathrm{RCH}$ and $0,1,2,3$, or 4 for EVT.

Each unique set of nonconstant arrays to be used for one or more stress periods is held as a separate INFO data file instead of an ARC/INFO point coverage. This reduces the amount of on-line disk space required to hold the data. Each data file is number of rows times number of columns in length and is sorted on row and column. The file that contains values for a particular modeled stress period is specified in item KPER in the RCH.CNTL file. If KPER contains the value RCH.PER3, data file RCH.PER3 will be related to RCH.CNTL and array values will be output.

Each unique data array for RCH or EVT can be output for as many different stress periods as desired. Each file has the structure of a key file built into it for faster relating and to control the order of data output.

INFO File Structure and Example Data Files

DATAFILE NAME: RCH.CNTL

$12 / 9 / 1988$

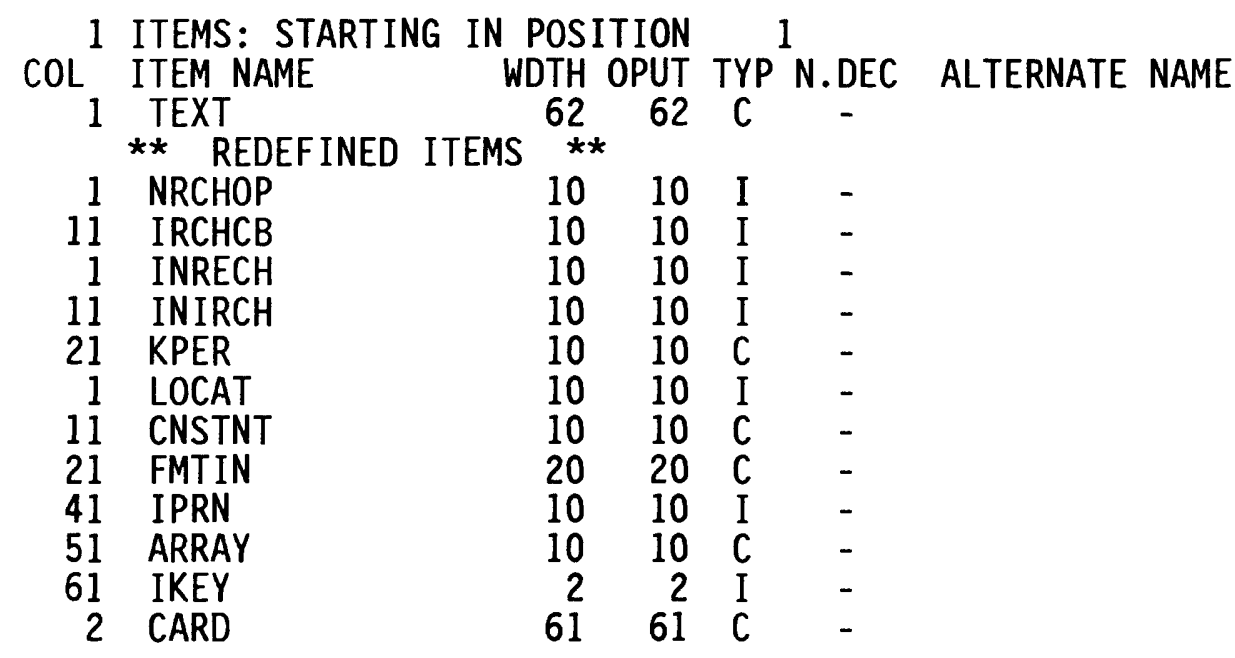

ENTER COMMAND >LI

\$RECNO TEXT

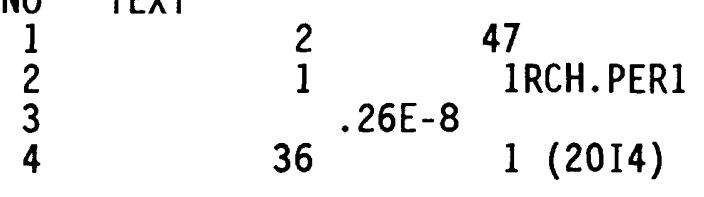

-1RECH

-IIRCH 
DATAFILE NAME: RCH.PERI

$12 / 9 / 1988$

6 ITEMS: STARTING IN POSITION 1

COL ITEM NAME

1 KEY

6 RECH

12 IRCH

15 IKEY

17 RCH\#

21 ROW
WDTH OPUT TYP N.DEC ALTERNATE NAME

$\begin{array}{llll}5 & 5 & \text { I } & - \\ 6 & 6 & \text { N } & 2 \\ 3 & 3 & \text { I } & - \\ 2 & 2 & \text { I } & - \\ 4 & 5 & \text { B } & - \\ 3 & 3 & \text { I } & -\end{array}$

ENTER COMMAND >LI

\$RECNO KEY RECH IRCH IKEY RCH\# ROW

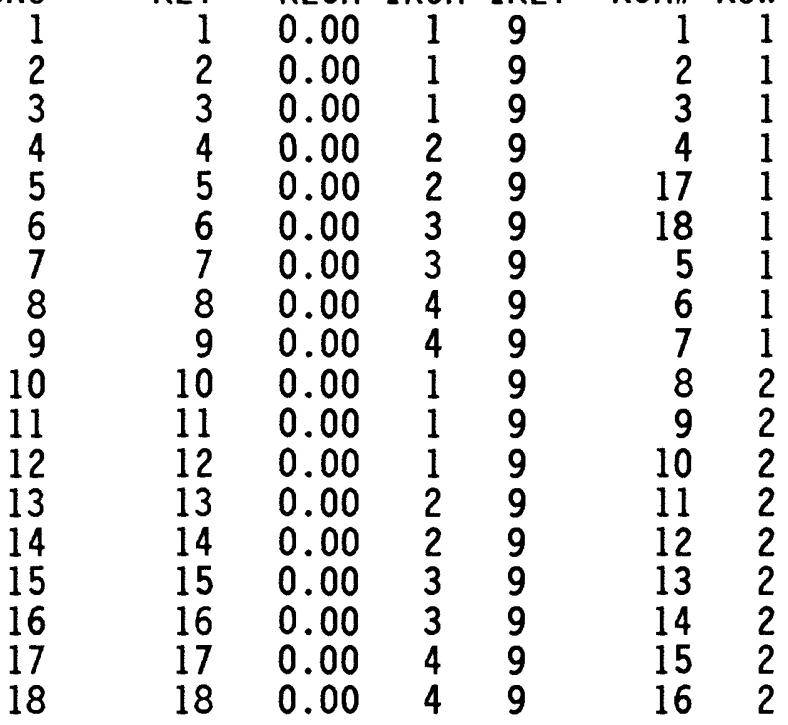

Note: Item KEY in INF0 file RCH.PER1 is not needed by the output program but can be used to relate this file to a coverage of the model grid (NODES or GRID). KEY is equal to record number when the model grid data file (NODES.PAT or GRID.PAT) is sorted on row, column.

Narrative of Recharge Output Program

1. Select the RCH.CNTL file, open PRIMOS file RCH with INIT, reselect for first record and output to PRIMOS file RCH.

2. Reselect for the second record in $\mathrm{RCH} . \mathrm{CNTL}$, output that record to RCH, and determine if arrays will be output (INRECH and (or) INIRCH greater than or equal to 0 ). There will be one card with INRECH and INIRCH for each stress period modeled. If INRECH or INIRCH are greater than or equal to zero, loop through control card for each array (the next one or two records in $\mathrm{RCH}$. CNTL). 
3. If LOCAT is greater than zero, the array is not constant and values are expected. Relate data file specified in item KPER of RCH.CNTL. Either LIST or WIDE output format is specified when executing the interface program. The effect of each is as follows:

a. If LIST output format is specified, the array-control card is output and the corresponding array in the related data file is output as a list.

b. If WIDE output format is specified and each row of data will fit within 132 characters, the array-control card is output and the corresponding array in the related data file is output across the page.

c. If WIDE output format is specified and each row of data will not fit within 132 characters, the array-control card is output, the data file specified in KPER is selected, and rows are reselected one at a time and output across the page, wrapping to subsequent lines as necessary.

If LOCAT is less than or equal to zero, only the arraycontrol card is output.

4. Select RCH.CNTL, if necessary, and reselect for control card for next stress period. Repeat steps two and three.

5. Repeat steps 2,3 , and 4 as necessary.

Listing of Output Program

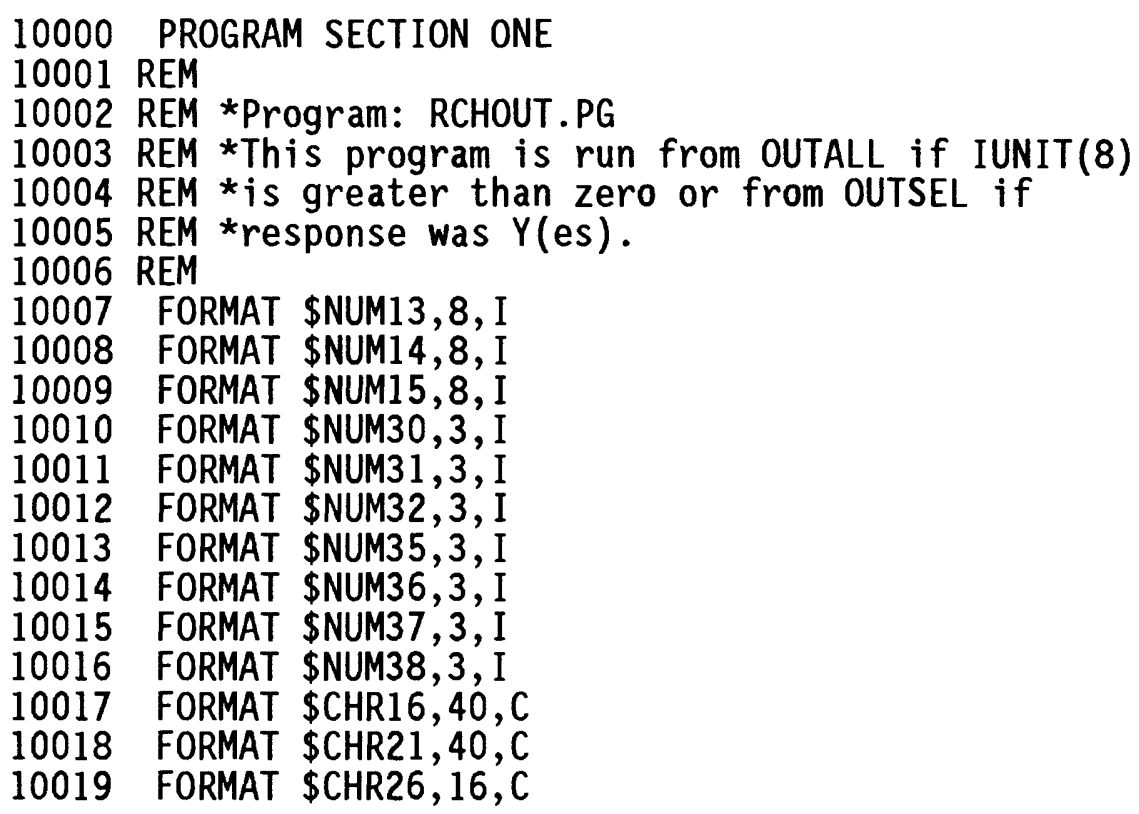




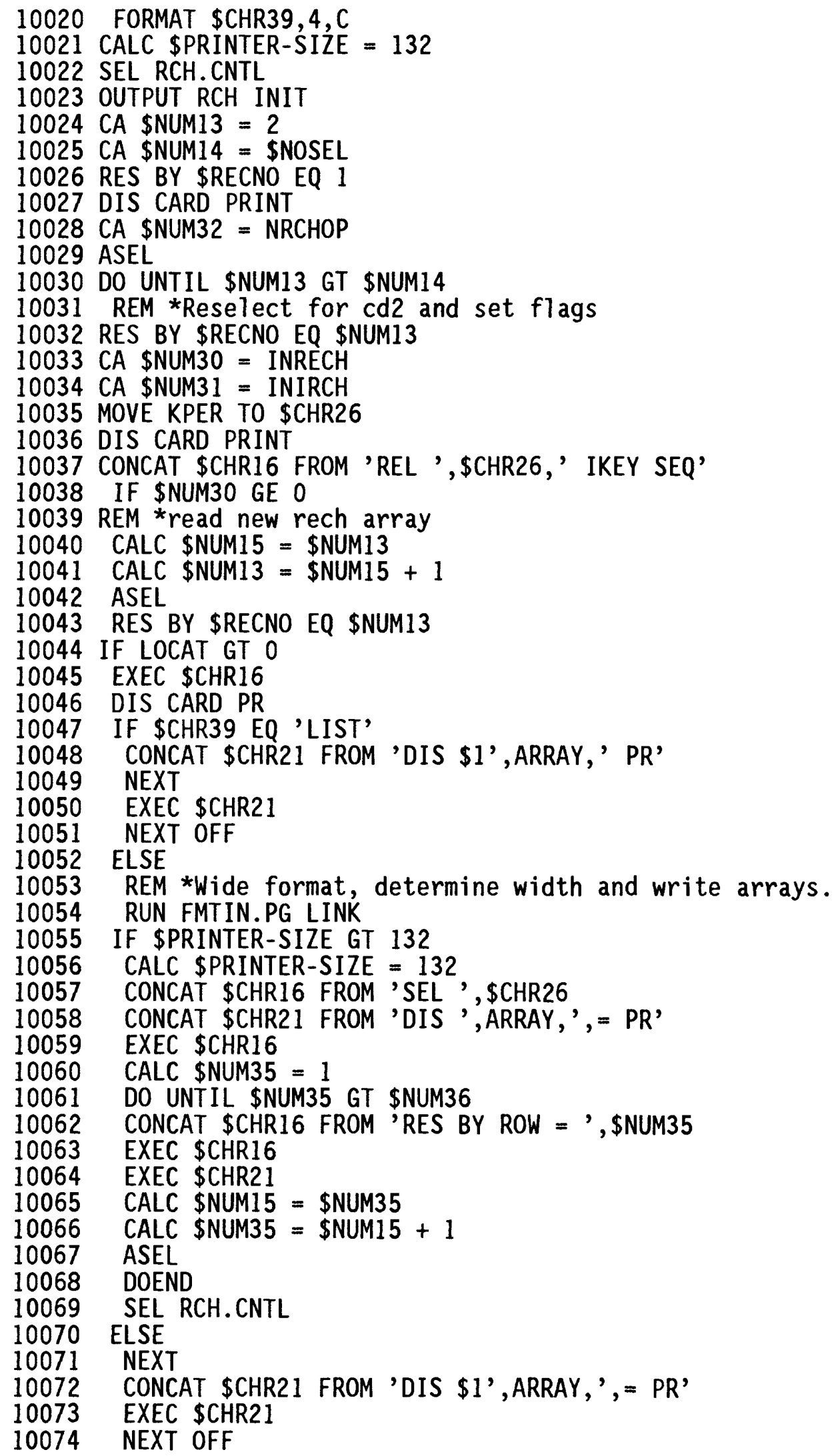




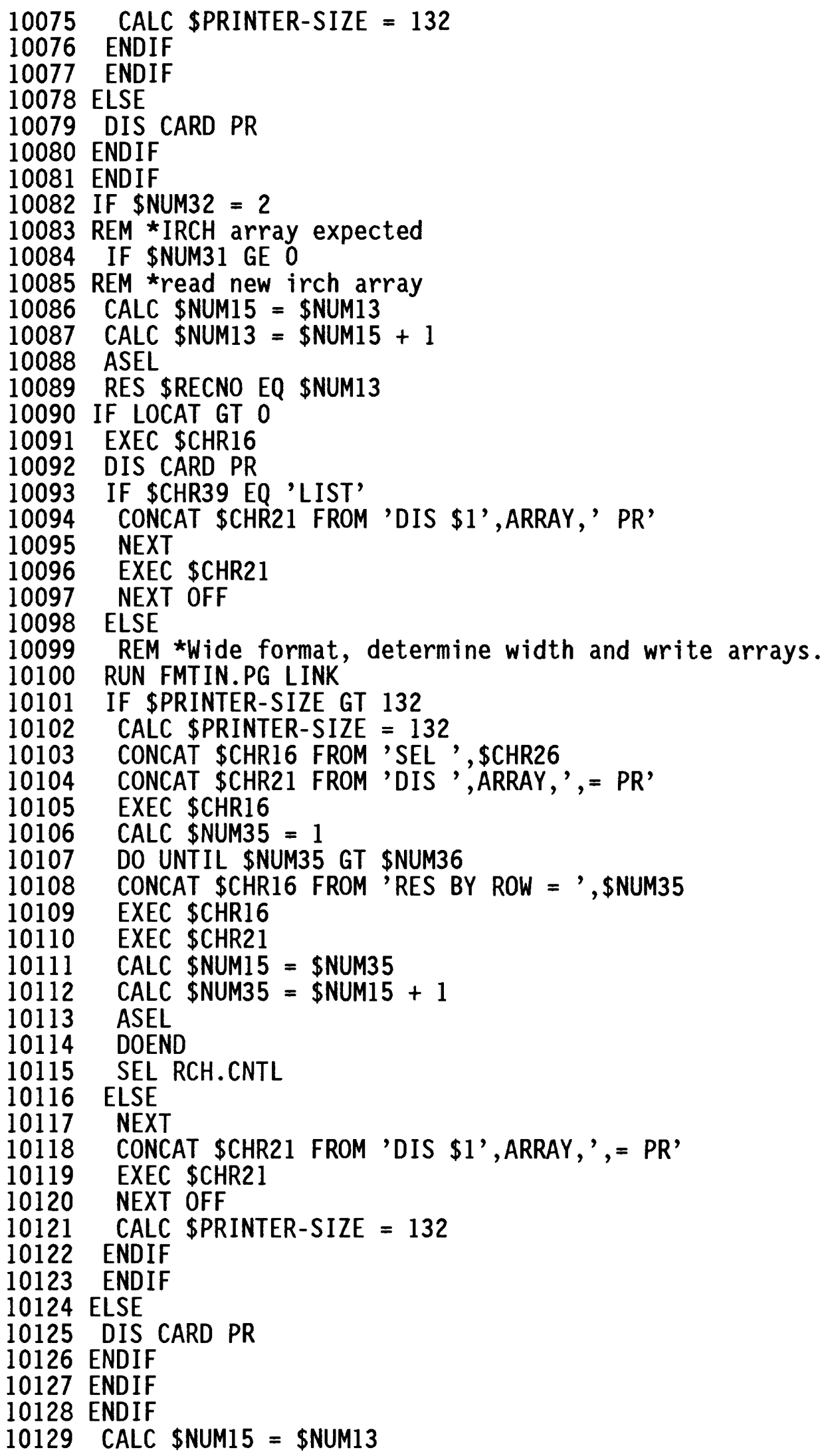


10130 CALC \$NUM13 $=\$ N U M 15+1$

10131 ASEL

10132 DOEND

Evapotranspiration Package

A file (EVT.CNTL) that contains package control information and array-control cards is used in conjunction with a variable number of data files. Each unique set of nonconstant arrays, to be used for one or more stress periods modeled, is held as an INF0 data file. The file containing values that are desired for a particular modeled stress period is specified in item KPER in the EVT.CNTL file. If KPER contains the value, EVT.PER3, data file EVT.PER3 will be related to EVT.CNTL, and array values will be output.

INFO File Structure and Example Data Files

DATAFILE NAME: EVT.CNTL

$12 / 5 / 1988$

1 ITEMS: STARTING IN POSITION 1

COL ITEM NAME WDTH OPUT TYP N.DEC ALTERNATE NAME

1 TEXT $6262 \mathrm{C}$ ** REDEFINED ITEMS

$\begin{array}{rr}1 & \text { NEVTOP } \\ 11 & \text { IEVTCB }\end{array}$

1 INSURF

11 INEVTR

21 INEXDP

31 INIEVT

41 KPER

1 LOCAT

11 CNSTNT

21 FMTIN

41 IPRN

51 ARRAY

61 IKEY

2 CARD

$10 \quad 10$

$10 \quad 10$

10

10

10

10

10

10

10

20

10

10

2

$6161 \mathrm{C}$

ENTER COMMAND >LI

SRECNO
1
2
3
4
5
6

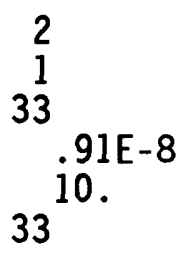

45

$1(20 \mathrm{~F} 7.0)^{1}$

1EVT.PER1

-1SURF
-1EVTR
-1EXDP
-1IEVT

1 (20I4) 
8 ITEMS: STARTING IN POSITION 1

$\begin{aligned} \text { COL } & \text { ITEM NAME } \\ 1 & \text { KEY } \\ 6 & \text { SURF } \\ 12 & \text { EVTR } \\ 18 & \text { EXDP } \\ 24 & \text { IEVT } \\ 27 & \text { IKEY } \\ 29 & \text { EVTH } \\ 33 & \text { ROW }\end{aligned}$

WDTH OPUT TYP N.DEC ALTERNATE NAME

ENTER COMMAND >LI

$\begin{array}{rrrrrrrrr}\text { \$RECNO } & \text { KEY } & \text { SURF } & \text { EVTR } & \text { EXDP } & \text { IEVT } & \text { IKEY } & \text { EVT\# } & \text { ROW } \\ 1 & 1 & 260.0 & 0.00 & 0.0 & 1 & 9 & 1 & 1 \\ 2 & 2 & 265.0 & 0.00 & 0.0 & 1 & 9 & 2 & 1 \\ 3 & 3 & 270.0 & 0.00 & 0.0 & 1 & 9 & 3 & 1 \\ 4 & 4 & 275.0 & 0.00 & 0.0 & 2 & 9 & 4 & 1 \\ 5 & 5 & 280.0 & 0.00 & 0.0 & 2 & 9 & 17 & 1 \\ 6 & 6 & 285.0 & 0.00 & 0.0 & 3 & 9 & 18 & 1 \\ 7 & 7 & 290.0 & 0.00 & 0.0 & 3 & 9 & 5 & 1 \\ 8 & 8 & 295.0 & 0.00 & 0.0 & 4 & 9 & 6 & 1 \\ 9 & 9 & 300.0 & 0.00 & 0.0 & 4 & 9 & 7 & 1 \\ 10 & 10 & 260.0 & 0.00 & 0.0 & 1 & 9 & 8 & 2 \\ 11 & 11 & 265.0 & 0.00 & 0.0 & 1 & 9 & 9 & 2 \\ 12 & 12 & 270.0 & 0.00 & 0.0 & 1 & 9 & 10 & 2 \\ 13 & 13 & 275.0 & 0.00 & 0.0 & 2 & 9 & 11 & 2 \\ 14 & 14 & 280.0 & 0.00 & 0.0 & 2 & 9 & 12 & 2 \\ 15 & 15 & 285.0 & 0.00 & 0.0 & 3 & 9 & 13 & 2 \\ 16 & 16 & 290.0 & 0.00 & 0.0 & 3 & 9 & 14 & 2 \\ 17 & 17 & 295.0 & 0.00 & 0.0 & 4 & 9 & 15 & 2 \\ 18 & 18 & 300.0 & 0.00 & 0.0 & 4 & 9 & 16 & 2\end{array}$

Note: Item KEY in INF0 file EVT.PER1 is not used by the output program but can be used to relate this file to a coverage of the model grid (NODES or GRID). KEY is equal to record number when the model grid data file (NODES.PAT or GRID.PAT) is sorted on row, column.

Narrative of Evapotranspiration Output Program

1. Select the EVT.CNTL file, open PRIMOS file EVT with INIT, reselect for the first record and output it to PRIMOS file EVT.

2. Reselect for the second record in EVT.CNTL, output that record to EVT, and determine if arrays will be output (INSURF, INEVTR, INEXDP, or INIEVT read flags greater than or equal to 0 ). There will be one card with either the first three or all four read flags for each stress period 
modeled depending on the variable NEVTOP. If the read flags indicate a control card and possibly an array will be read by the model, then loop through each of the subsequent control cards (the next one, two, three of four records in EVT.CNTL).

3. If LOCAT is greater than zero, the array is not constant and values are expected. Relate EVT.CNTL to the data file specified in item KPER. Either LIST or WIDE output format is specified when executing the interface program. The effect of each is as follows:

a. If LIST output format is specified, the array-control card is output and the corresponding array in the related data file is output as a list.

b. If WIDE output format is specified and each row of data will fit within 132 characters, the array-control card is output and the corresponding array in the related data file is output across the page.

c. If WIDE output format is specified and each row of data will not fit within 132 characters, the array-control card is output, the data file specified in KPER is selected, and rows are reselected one at a time and output across the page wrapping to subsequent lines as necessary.

If LOCAT is less than or equal to zero, only the arraycontrol card is output.

4. Select EVT.CNTL, if necessary, and reselect for control card for next stress period. Repeat steps two and three.

5. Repeat steps two, three, and four as necessary.

\section{Listing of Output Program}

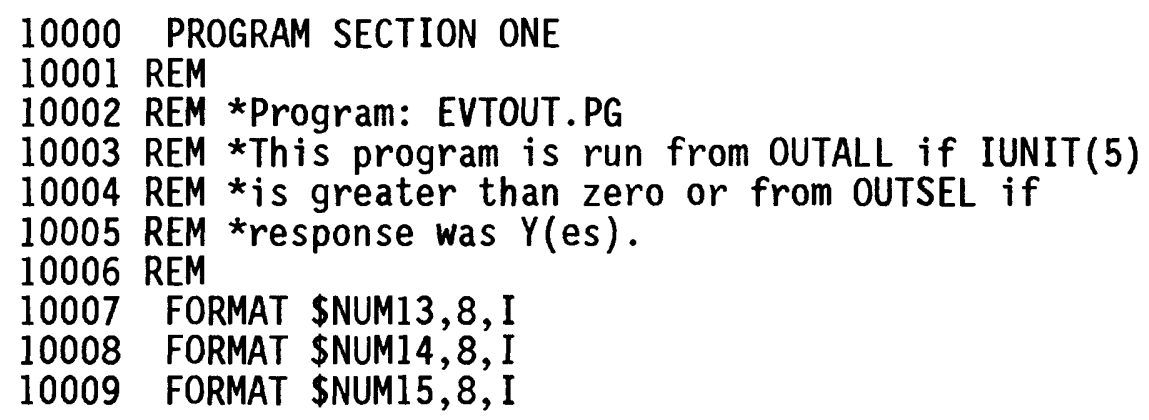




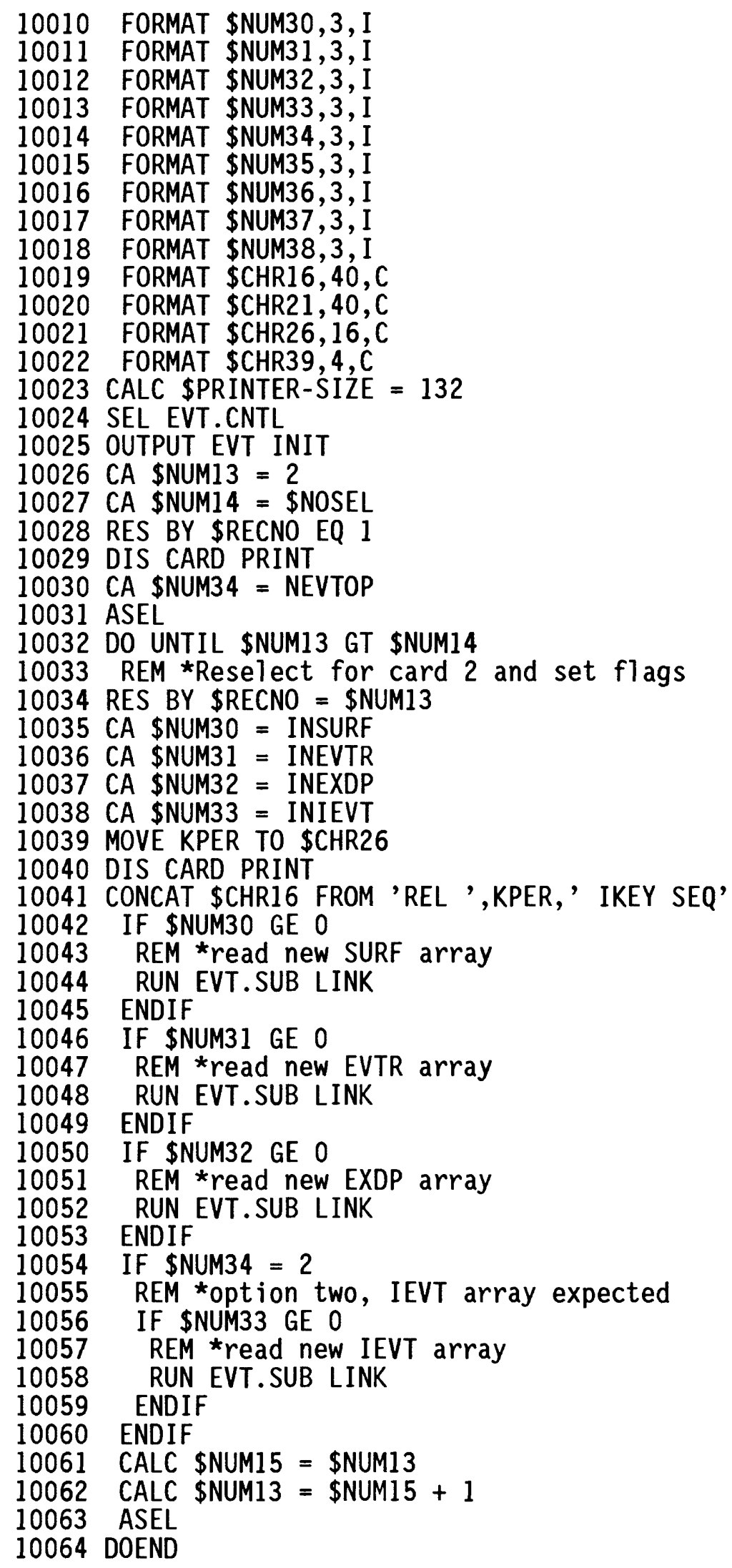


Listing of a Subroutine Output Program

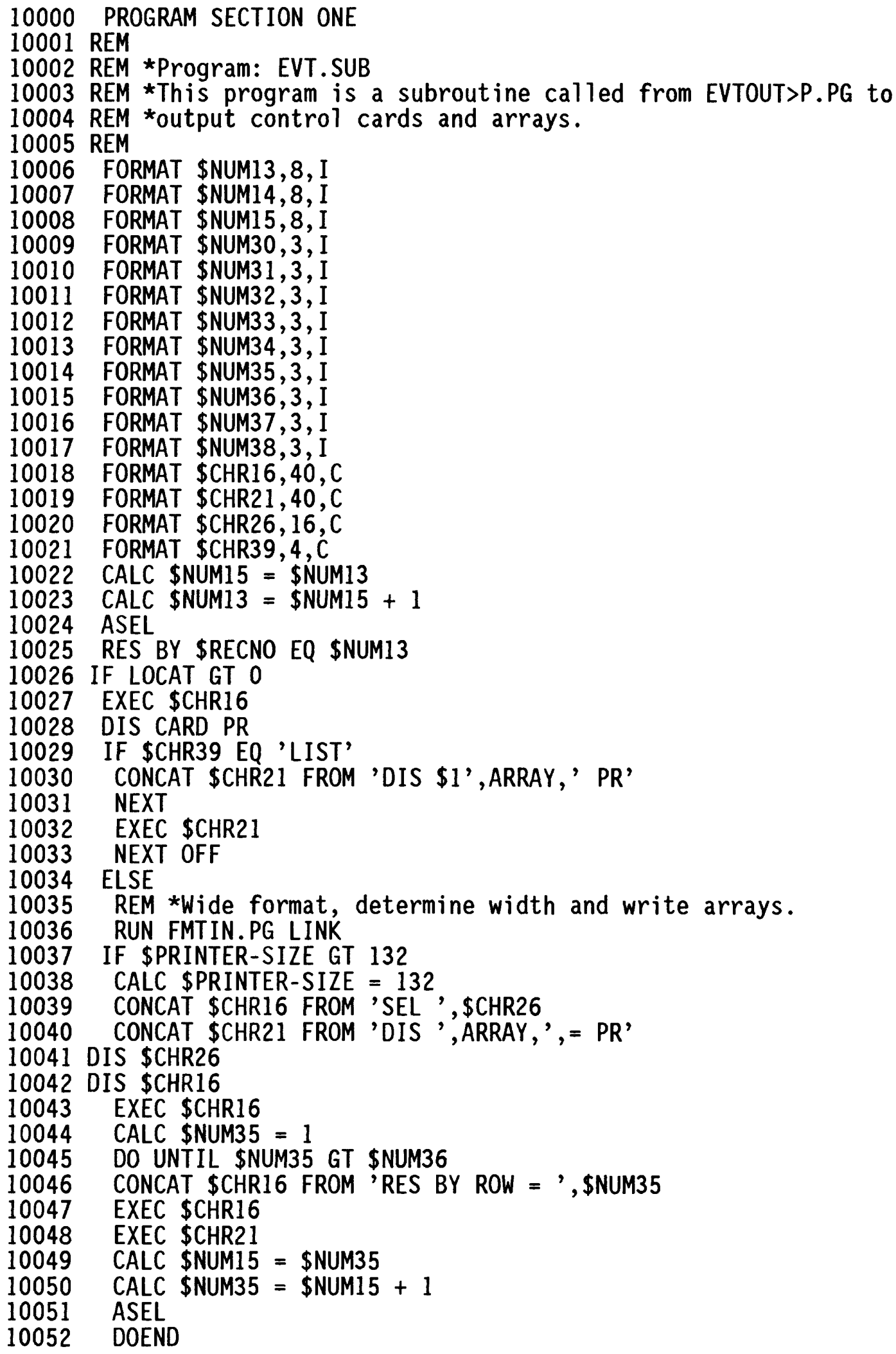


10053 SEL EVT.CNTL

10054 ELSE

10055 CONCAT \$CHR21 FROM 'DIS \$1', ARRAY,', = PR'

10056 NEXT

10057 EXEC \$CHR21

10058 NEXT OFF

10059 CALC \$PRINTER-SIZE $=132$

10060 ENDIF

10061 ENDIF

10062 ELSE

10063 DIS CARD PR

10064 ENDIF

In addition to the output program, an interactive update program was written for the EVT package. It uses INFO program language and INFO input forms to allow the user to easily add or update records for the file EVT.CNTL. To invoke the update sequence, issue the command 'RUN EVT.UPD' from within the INFO workspace.

\section{Listing of Update Program}

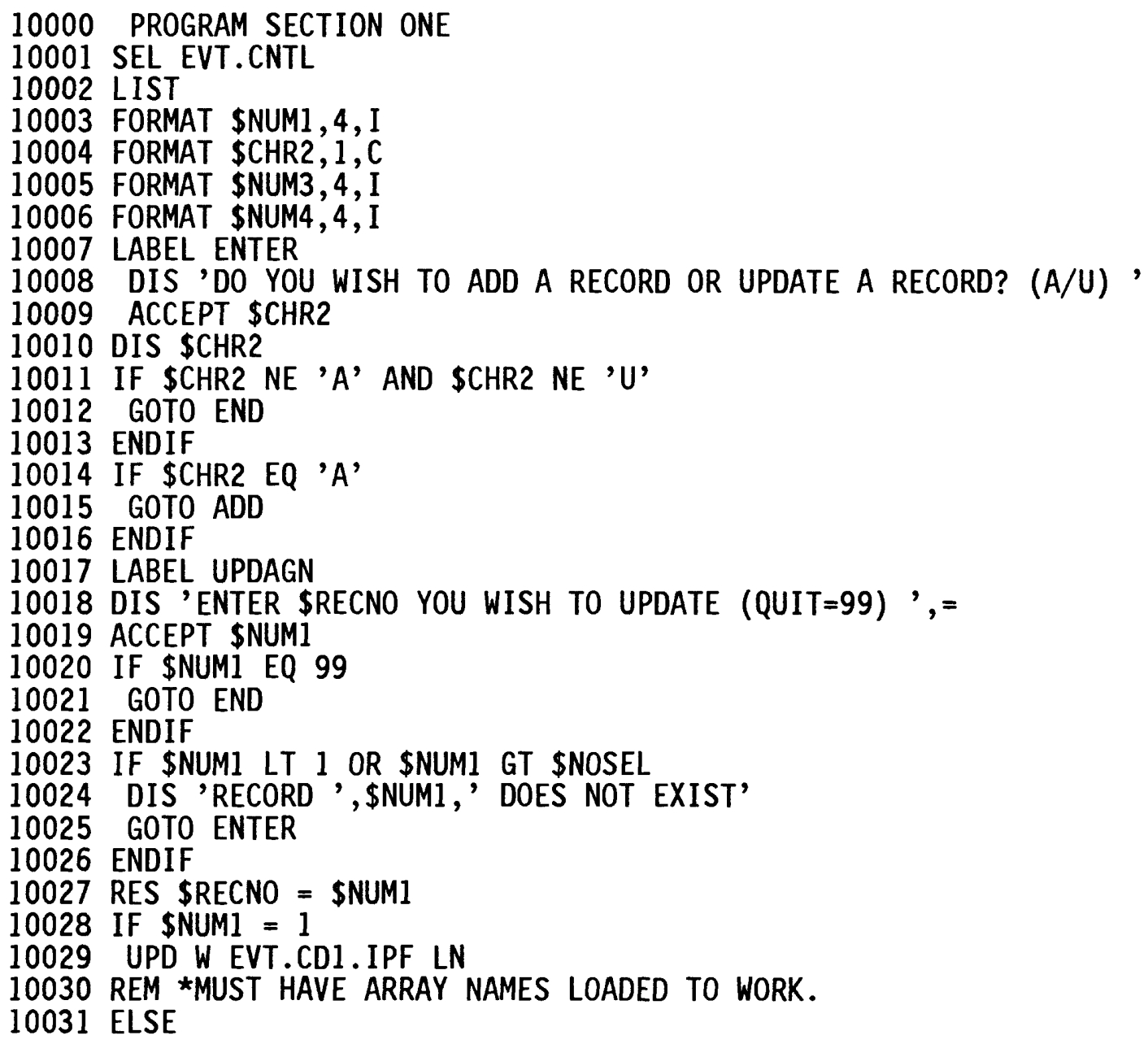




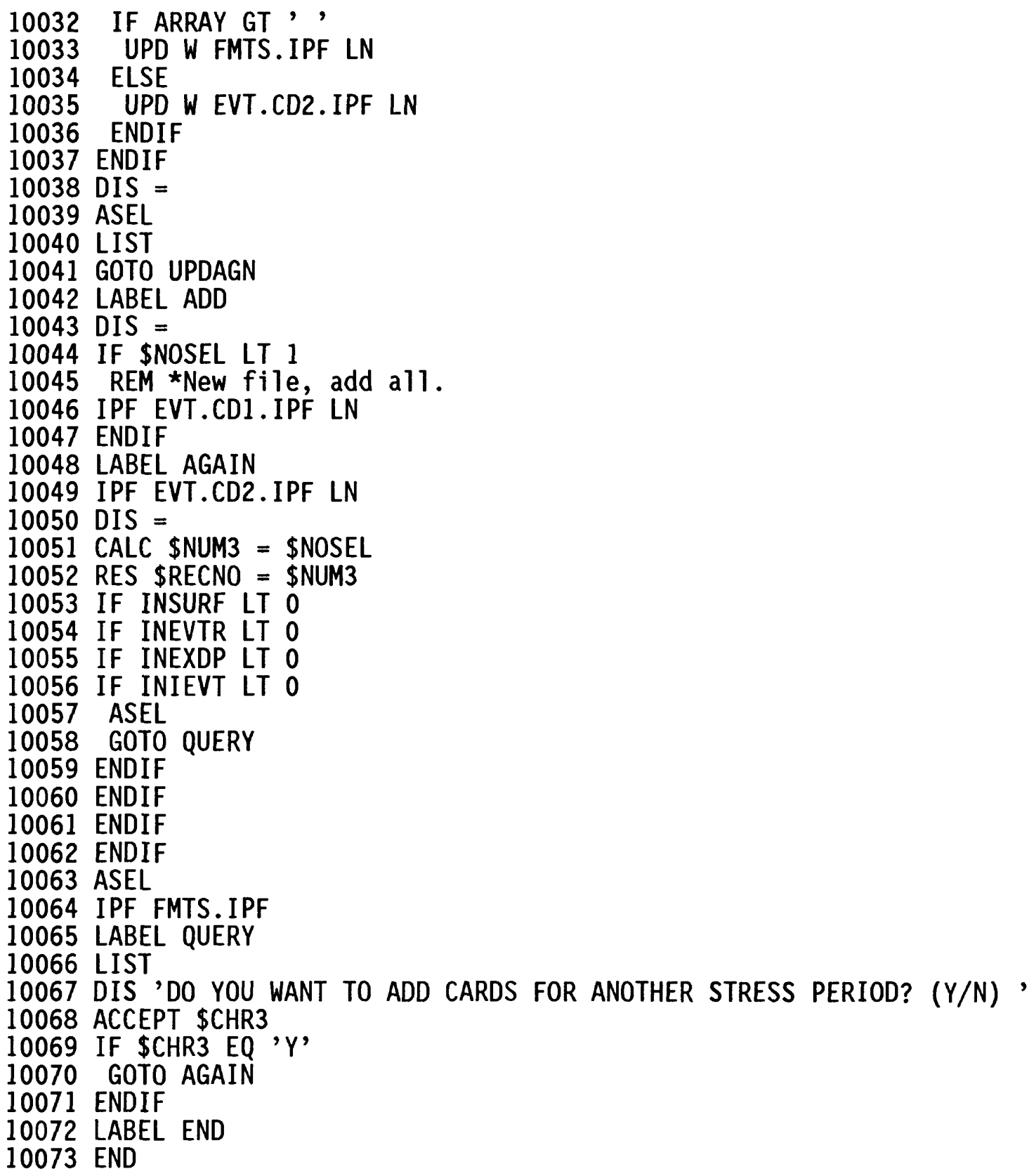

River Package

The river (RIV) package consists of a control file (RIV.CNTL) and a file or files containing layer, row, column, stage, conductance, altitude of the river bottom, and IKEY. Each simulated stress period can optionally have a new data file for input. The INFO data file that is desired for a particular modeled stress period is specified in item KPER in the RIV.CNTL file. If KPER contains the value RIV.PER2, data file RIV.PER2 will be output. This allows one feature that is not available within the model structure. The model allows use of the data list from 
the previous stress period or will read a new 1ist. Output from INF0 can use data from any stress period stored for any stress period given. This structure is used for all packages containing list format data by layer, row, and column.

INF0 File Structure and Example Data Files

DATAFILE NAME: RIV.CNTL

$12 / 5 / 1988$

1 ITEMS: STARTING IN POSITION 1

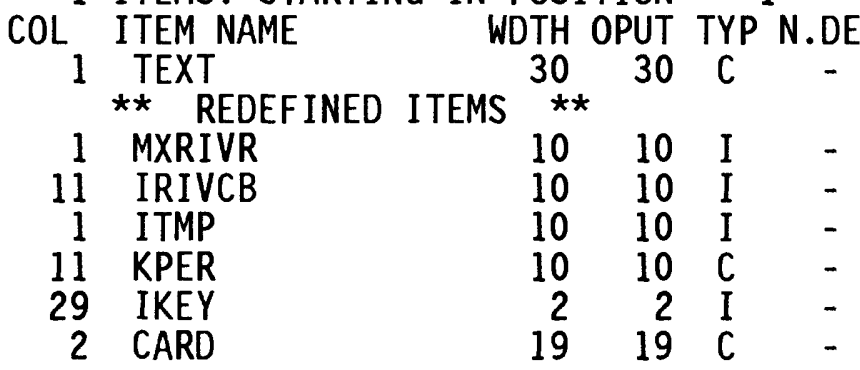

ENTER COMMAND >LI

\$RECNO TEXT

$\begin{array}{lll}1 & 1 & \\ 2 & \text { 1RIV.PERI } & \end{array}$

DATAFILE NAME: RIV.PER1

$12 / 5 / 1988$

7 ITEMS: STARTING IN POSITION 1

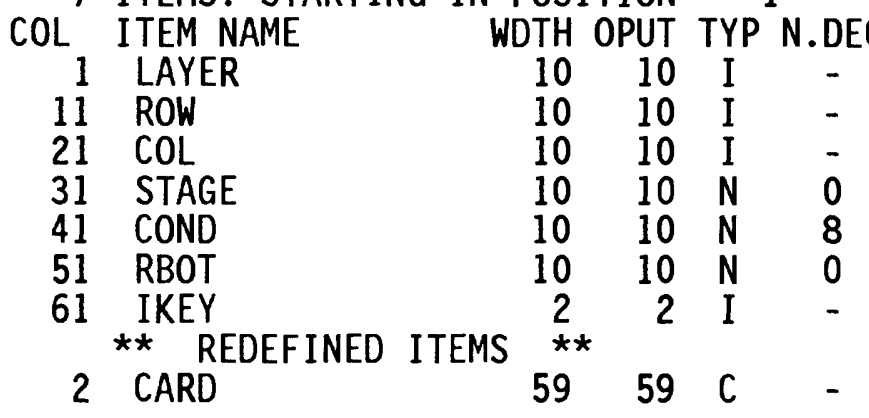

ENTER COMMAND >LI

$\begin{array}{ccccccrr}\$ R E C N O & \text { LAYER } & \text { ROW } & \text { COL } & \text { STAGE } & \text { COND } & \text { RBOT } & \text { IKEY } \\ 1 & 1 & 1 & 3 & 270 & 0.00000600 & 260 & 9\end{array}$

Narrative of River Output Package

1. Select the RIV.CNTL file, open PRIMOS file RIV with INIT, reselect for the first record and output it to PRIMOS file RIV. 
2. Loop through each remaining record in RIV.CNTL testing for value. ITMP, corresponding to ITMP in the model, less than zero. If less than or equal to zero, output selects control card only. If greater than zero, use value of item KPER as the file name containing data to output for this stress period, relate to that file, and output data.

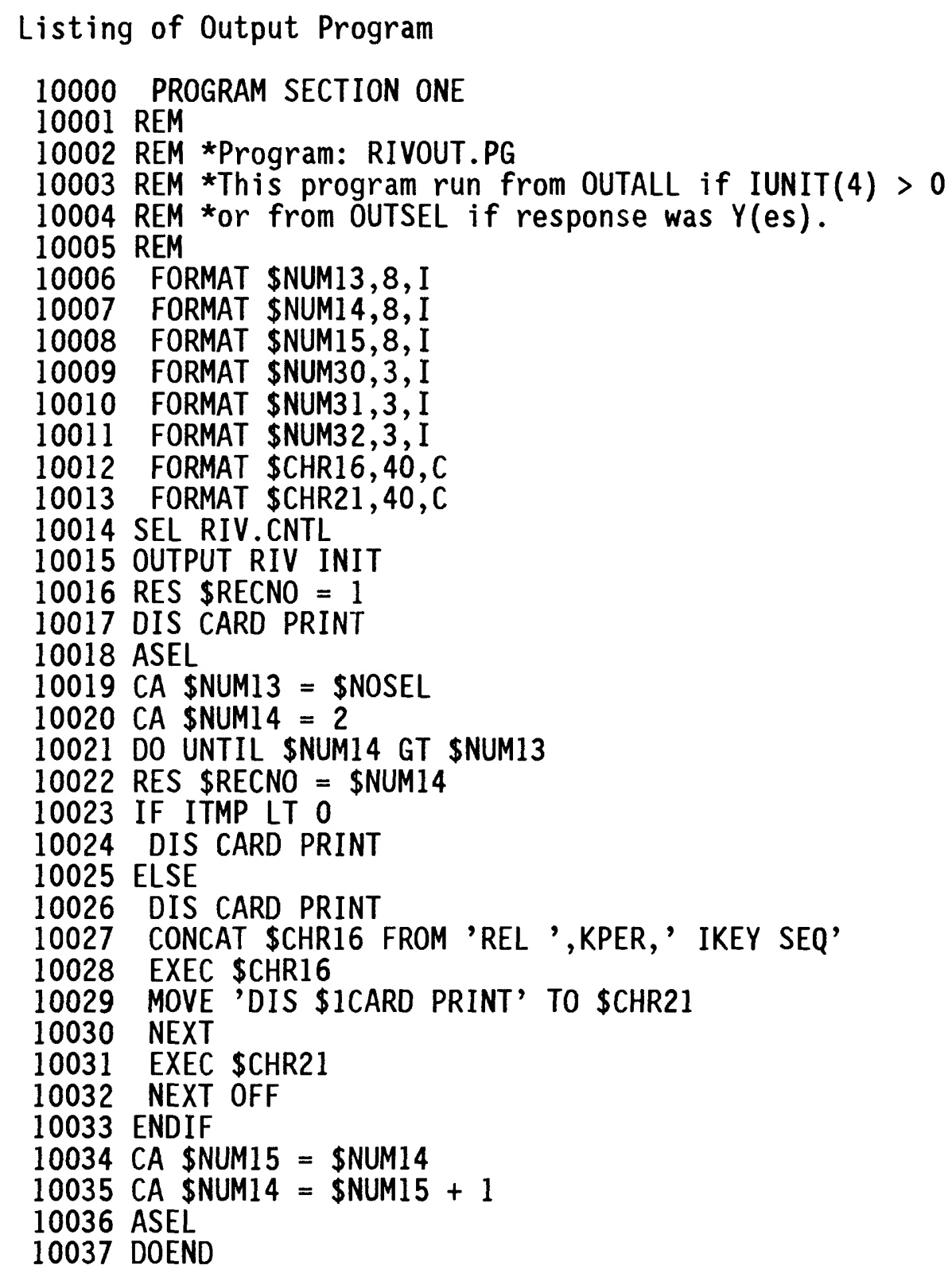




\section{Well Package}

The well (WEL) package consists of a control file (WEL.CNTL) and a file or files containing layer, row, column, and discharge. Each file name is entered in item KPER of WEL.CNTL for the appropriate stress period. Files can be output any number of times in any order. The order is controlled by the order of records in the WEL.CNTL file. By this method, if annual pumpage remains constant through time even though two distinct seasons occur, two pumpage data files can be used in an alternating manner. Only those two unique files need to be held in INF0. In this case, the interface output program would al ternate between writing each INFO file to the PRIMOS data file WEL.

INFO File Structure and Example Data Files

DATAFILE NAME: WEL.CNTL

$12 / 5 / 1988$

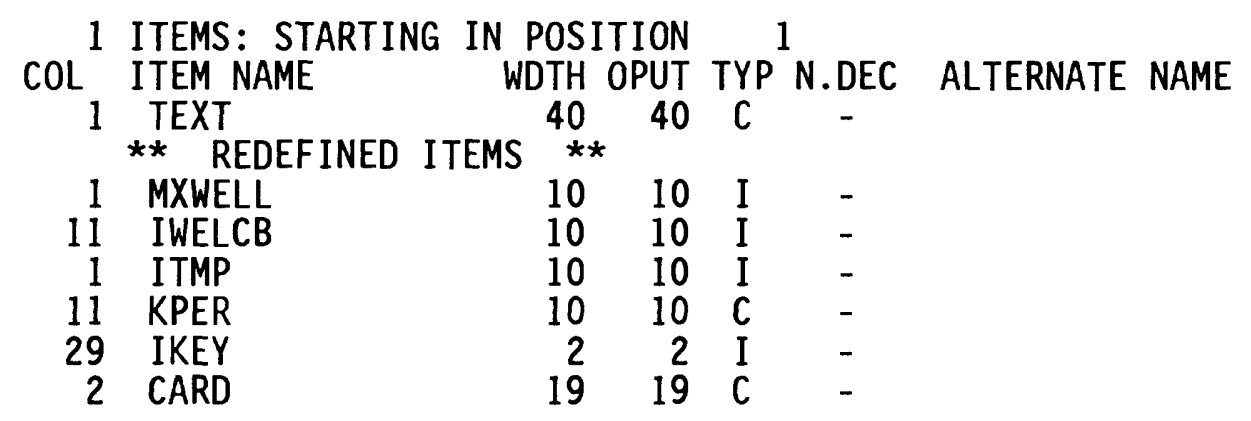

ENTER COMMAND >LI

\$RECNO TEXT

$\begin{array}{ll}1 & 4 \\ 2 & 4 W E L . P E R 1\end{array}$

DATAFILE NAME: WEL.PERI

$12 / 5 / 1988$

5 ITEMS: STARTING IN POSITION 1

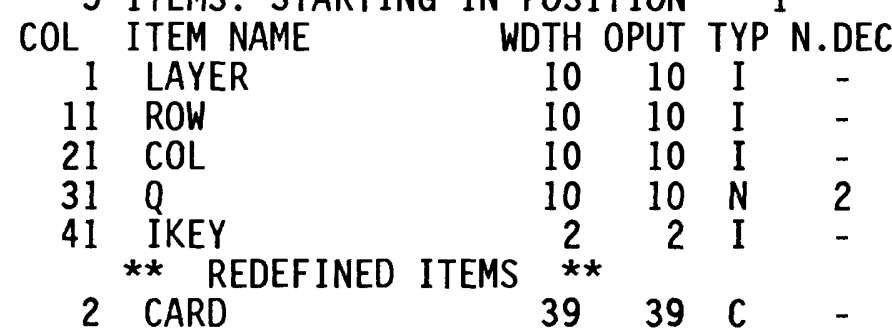

ENTER COMMAND >LI

$\begin{array}{rrrrrr}\text { \$RECNO } & \text { LAYER } & \text { ROW } & \text { COL } & \text { Q IKEY } \\ 1 & 1 & 1 & 2 & 0.50 & 9 \\ 2 & 2 & 2 & 4 & 0.75 & 9 \\ 3 & 3 & 1 & 5 & 0.50 & 9 \\ 4 & 4 & 2 & 4 & 0.75 & 9\end{array}$


Narrative of Well Output Program

1. Select the WEL.CNTL file, open PRIMOS file WEL with INIT, reselect for the first record and output to PRIMOS file WEL.

2. Loop through each remaining record in WEL.CNTL testing for value ITMP less than, equal to or greater than zero. If less than or equal to zero, output selected control card only. If greater than zero, use value of item KPER as the file name containing data to output for this stress period, relate to that file and output data.

Listing of Output Program

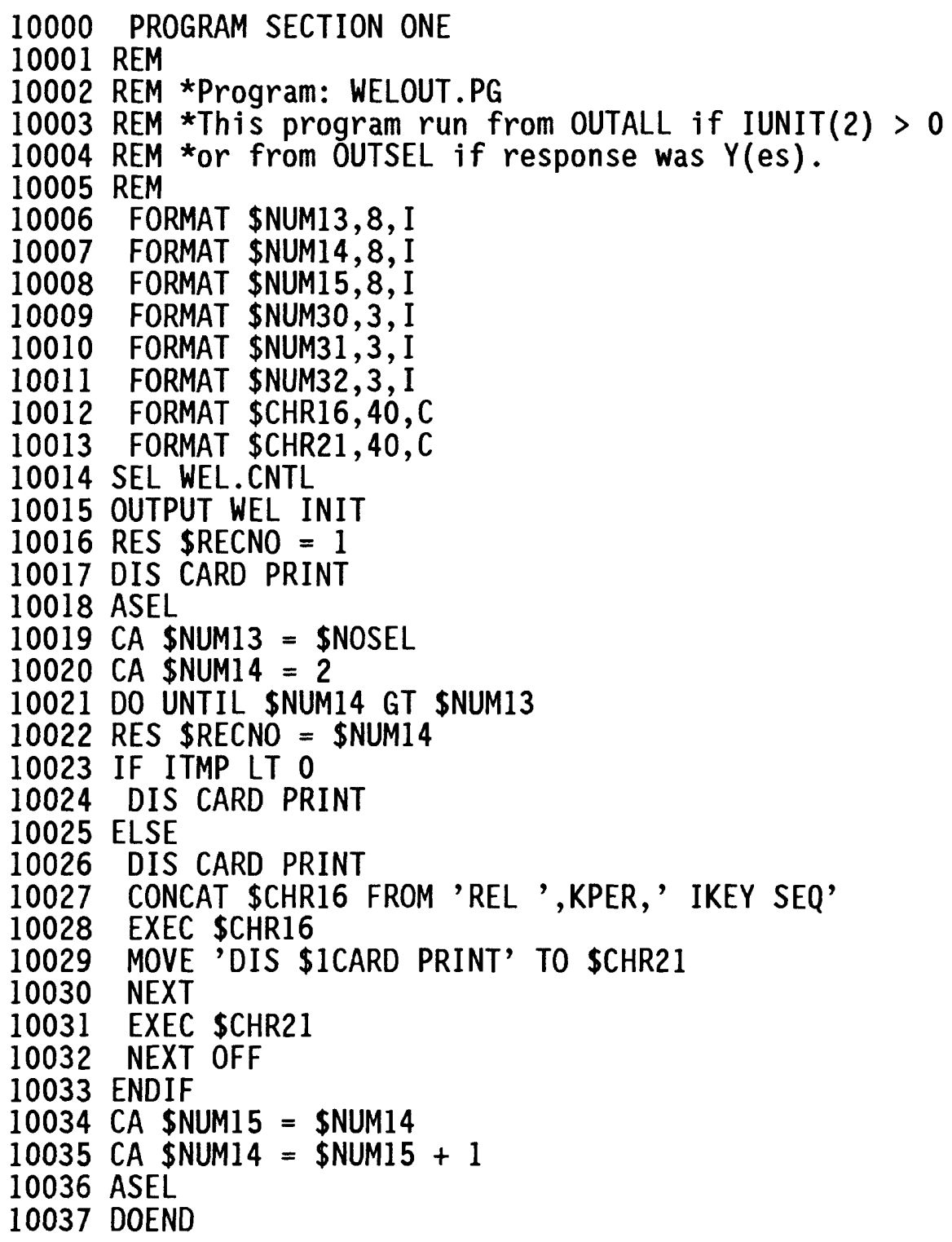




\section{Drain Package}

The drain (DRN) package consists of a control file (DRV.CNTL) and a file or files containing layer, row, column, elevation, conductance, and IKEY. Each simulated stress period can optionally have a new data file for input. The INFO data file that is desired for a particular modeled stress period is specified in item KPER in the DRN.CNTL file. If KPER contains the value DRN.PER2, data file DRN.PER2 will be output.

INFO File Structure and Example Data Files

DATAFILE NAME: DRN.CNTL

$12 / 5 / 1988$

1 ITEMS: STARTING IN POSITION 1

COL ITEM NAME WDTH OPUT TYP N.DEC ALTERNATE NAME

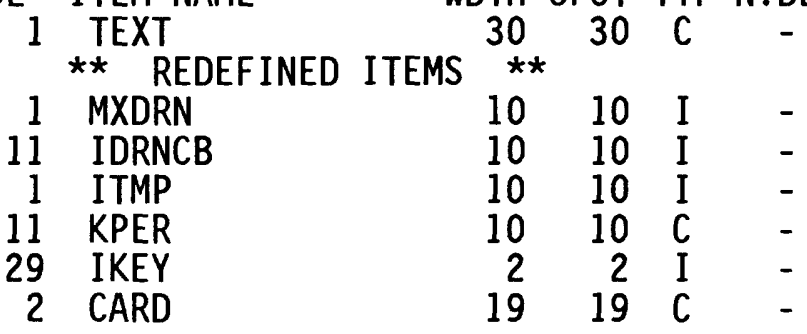

ENTER COMMAND >LI

\$RECNO TEXT

$\begin{array}{ll}1 & 2 \\ 2 & 2 D R N . P E R 1^{43}\end{array}$

DATAFILE NAME：DRN.PERI

$12 / 5 / 1988$

6 ITEMS: STARTING IN POSITION 1

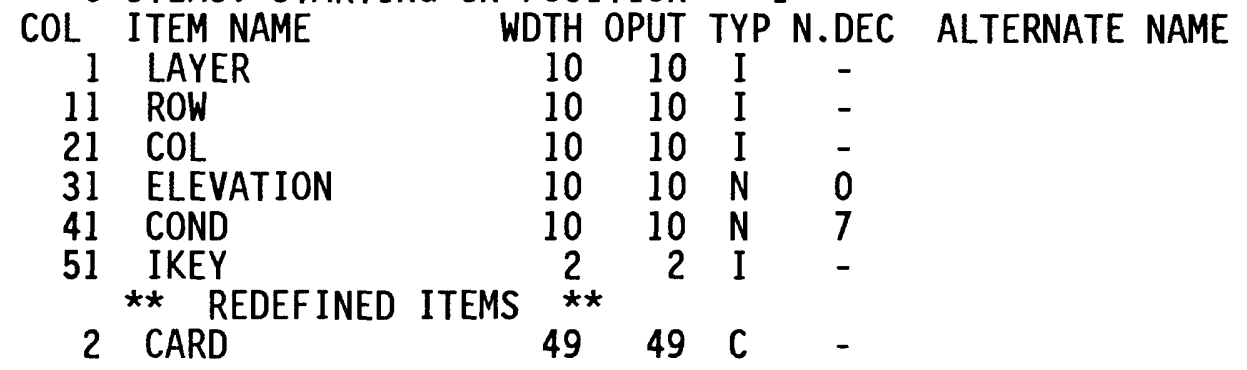

ENTER COMMAND >LI

$\begin{array}{rr}\text { \$RECNO } & \text { LAYER } \\ 1 & 1 \\ 2 & 1\end{array}$

ROW
1
2

COL ELEVATION

$\begin{array}{rrr}1 & 1 & 250 \\ 2 & 1 & 250\end{array}$

$\begin{array}{lll}1 & 1 & 250 \\ 2 & 1 & 250\end{array}$

COND IKEY

0.20000009

0.20000009 
Narrative of Drain Output Program

1. Select the DRN.CNTL file, open PRIMOS file DRN with INIT, reselect for the first record and output it to PRIMOS file DRN.

2. Loop through each remaining record in DRN.CNTL testing for value ITMP less than, equal to or greater than zero. If less than or equal to zero, output selected control card only. If greater than zero, use value of item KPER as the file name containing data to output for this stress period, relate to that file and output data.

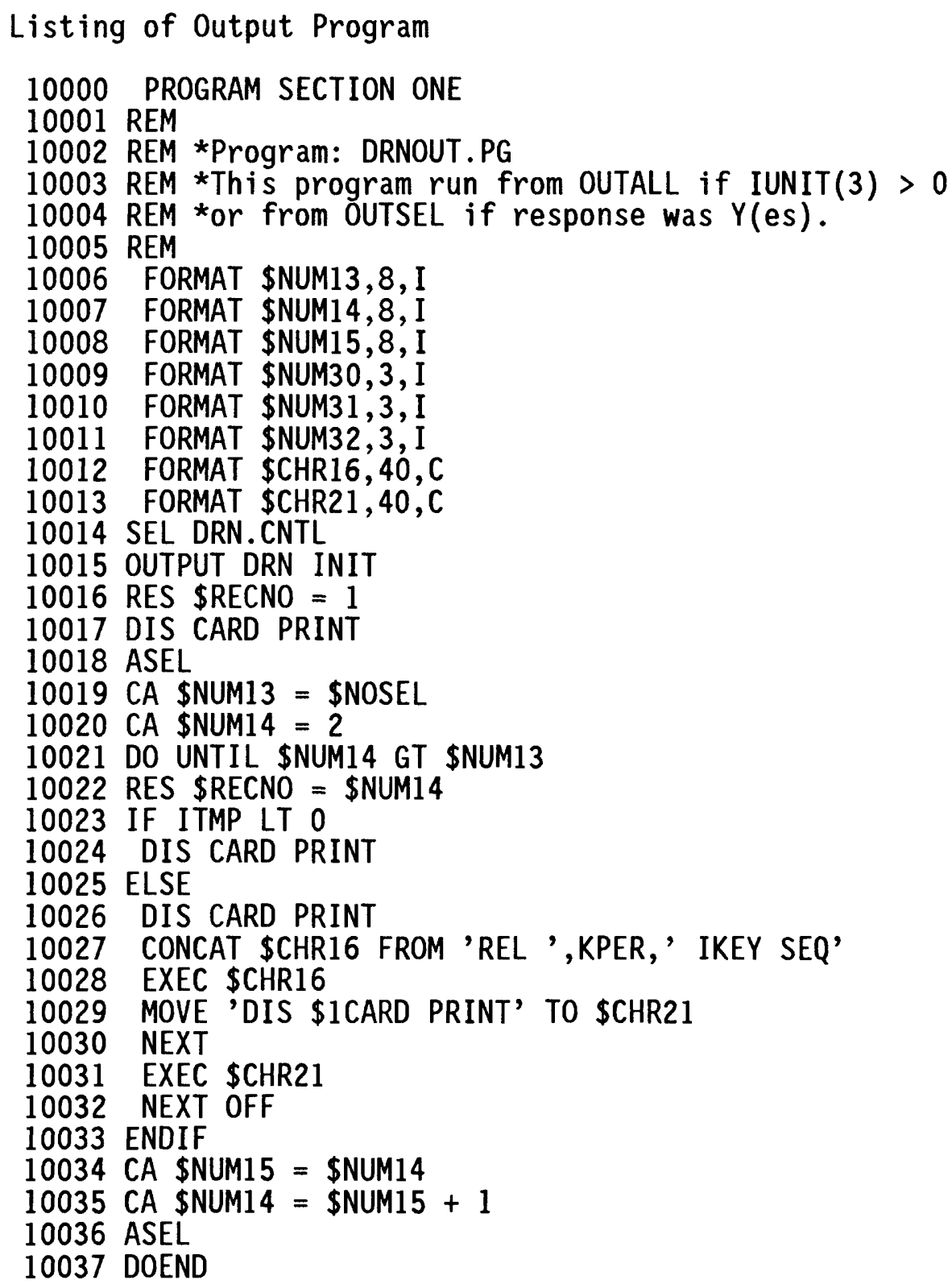


General-Head Boundary Package

The general-head boundary (GHB) package consists of a control file (GHB.CNTL) and a file or files containing layer, row, column, boundary head, conductance, and IKEY. Each simulated stress period can optionally have a new data file for input. The INF0 data file that is desired for a particular modeled stress period is specified in item KPER in the GHB.CNTL file. If KPER contains the value GHB.PER2, data file GHB.PER2 will be output.

INFO File Structure

DATAFILE NAME: GHB.CNTL

$12 / 5 / 1988$

1 ITEMS: STARTING IN POSITION 1

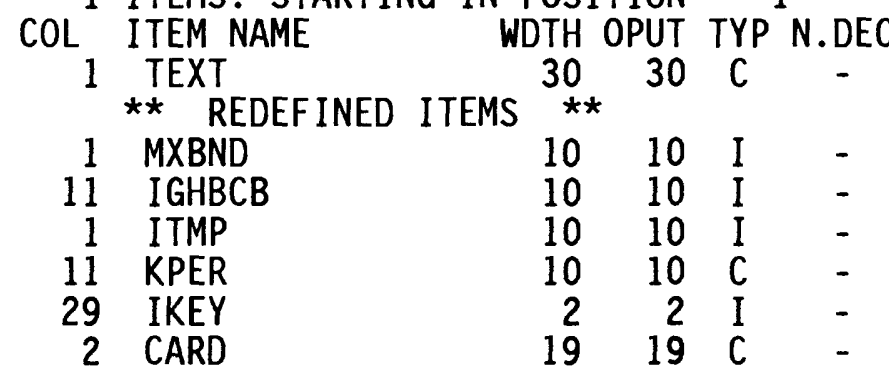

ENTER COMMAND >LI

\$RECNO TEXT

$\begin{array}{ll}1 & 2 \\ 2 & \text { 2GHB.PER1 }\end{array}$

DATAFILE NAME: GHB.PER1

$12 / 5 / 1988$

6 ITEMS: STARTING IN POSITION 1

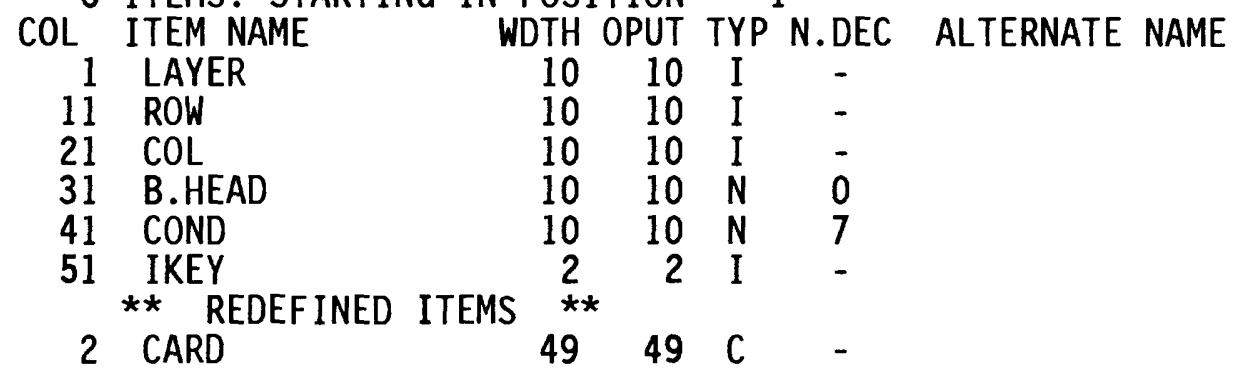

$\begin{array}{rrrrrrr}\text { \$RECNO } & \text { LAYER } & \text { ROW } & \text { COL } & \text { B. HEAD } & \text { COND IKEY } \\ 1 & 1 & 1 & 1 & 270.000 & 0.00010 & 9 \\ 2 & 1 & 1 & 2 & 270.000 & 0.00010 & 9\end{array}$ 
Narrative of General-Head Boundary Output Program

1. Select the GHB.CNTL file, open PRIMOS file GHB with INIT, reselect for the first record and output it to PRIMOS file GHB.

2. Loop through each remaining record in GHB.CNTL testing for value ITMP less than, equal to, or greater than zero. If less than or equal to zero, output selected control card only. If greater than zero, use value of item KPER as the file name containing data to output for this stress period, relate to that file and output data.

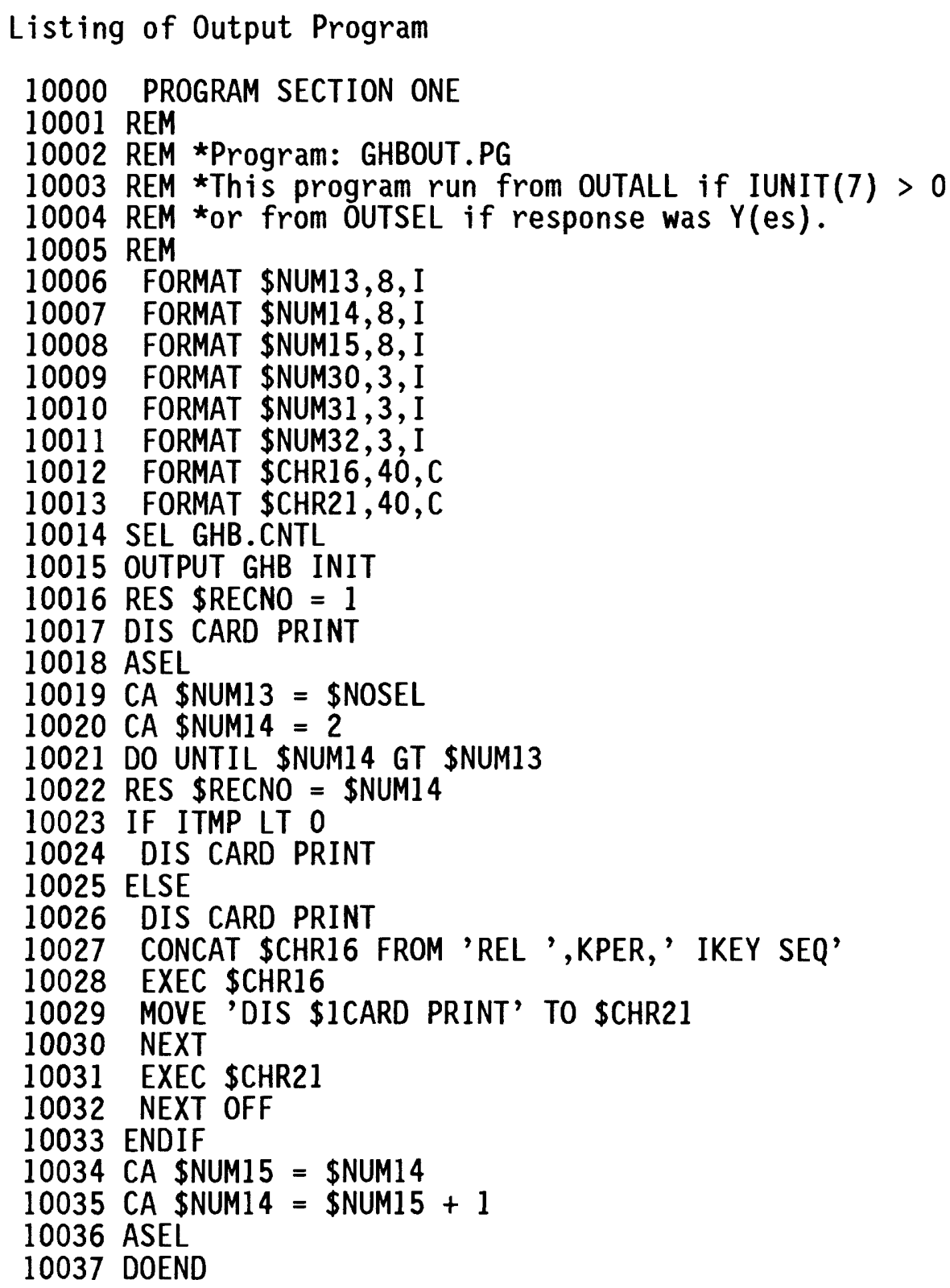


Strongly Implicit Procedure, Slice-Successive Overrelaxation, and Output Control Packages

Strongly implicit procedure (SIP), slice-successive overrelaxation (SOR), and output control (OC) packages can only contain controlling information. The INFO file structures and output programs are all similar, and in each case, only one INFO data file is definedSIP.CNTL, SOR.CNTL, or OC.CNTL. Output is produced by selecting that file and issuing the "SAVE COMPRESS" command that moves the file directly to PRIMOS. Those files match the PRIMOS files exactly and, therefore, can be moved from PRIMOS into INFO by issuing the "GET filename COPY" command from within INF0.

INFO File Structure and Example Data Files

DATAFILE NAME: SIP.CNTL

$12 / 5 / 1988$

1 ITEMS: STARTING IN POSITION 1 COL ITEM NAME WDTH OPUT TYP N.DEC ALTERNATE NAME

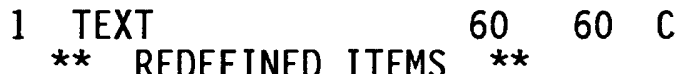

$\begin{array}{rlllll}1 & \text { MXITER } & 10 & 10 & \mathrm{I} & - \\ 11 & \text { NPARM } & 10 & 10 & \mathrm{I} & - \\ 1 & \text { ACCL } & 10 & 10 & \mathrm{~N} & 3 \\ 11 & \text { HCLOSE } & 10 & 10 & \mathrm{~N} & 6 \\ 21 & \text { IPCALC } & 10 & 10 & \mathrm{I} & - \\ 31 & \text { WSEED } & 10 & 10 & \mathrm{~N} & 6 \\ 41 & \text { IPRSIP } & 10 & 10 & \mathrm{I} & -\end{array}$

ENTER COMMAND $>$ L I

\$RECNO TEXT

$\begin{array}{rrrrrr}1 & 78 & 5 & & \\ 2 & 1.200 & .00002 & 1 & .00002 & 91\end{array}$

DATAFILE NAME：SOR.CNTL

$12 / 5 / 1988$

1 ITEMS: STARTING IN POSITION 1

COL ITEM NAME WDTH OPUT TYP N.DEC ALTERNATE NAME

1 TEXT

1 MXITER

1 ACCL

11 HCLOSE

21 IPRSOR

$10 \quad 10$ I -

$\begin{array}{llll}10 & 10 & \mathrm{~N} & 3\end{array}$

$\begin{array}{llll}10 & 10 & \mathrm{~N} & 6\end{array}$

1010 I - 
1 ITEMS: STARTING IN POSITION 1

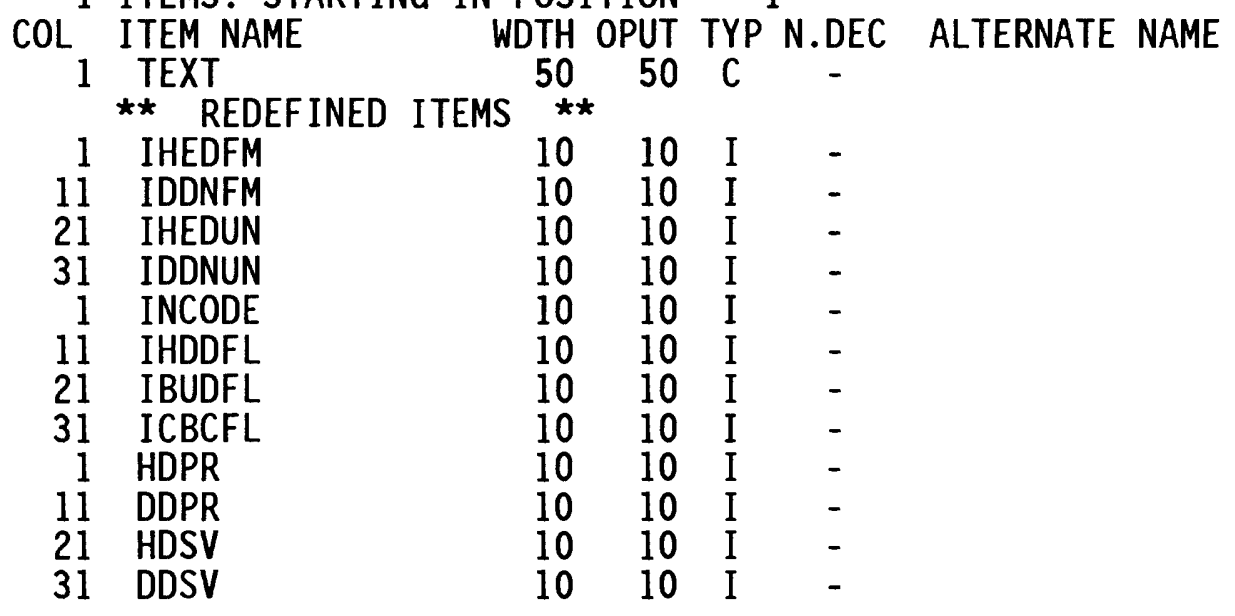

ENTER COMMAND >LI

\$RECNO TEXT

$\begin{array}{rrrrr}1 & 3 & 3 & 48 & 49 \\ 2 & 0 & 1 & 1 & 1 \\ 3 & 1 & 1 & 1 & 1\end{array}$

Listing of Strongly Implicit Procedure Output Program

10000 PROGRAM SECTION ONE

10001 REM

10002 REM *This program is run either from OUTALL or OUTSEL

10003 REM *to output necessary data for the MacDonald-Harbaugh

10004 REM *modular model.

10005 REM

10006 SEL SIP.CNTL

10007 SAVE SIP COMPRESS INIT

Listing of S1ice-Successive Overrelaxation Output Program

10000 PROGRAM SECTION ONE

10001 REM

10002 REM *This program is run either from OUTALL or OUTSEL

10003 REM *to output necessary data for the MacDonald-Harbaugh

10004 REM *modular model.

10005 REM

10006 SEL SOR.CNTL

10007 SAVE SOR COMPRESS INIT 
Listing of Output Control Program

10000 PROGRAM SECTION ONE

10001 REM

10002 REM *This program is run either from OUTALL or OUTSEL

10003 REM *to output necessary data for the MacDonald-Harbaugh

10004 REM *modular model.

10005 REM

10006 SEL OC.CNTL

10007 SAVE OC COMPRESS INIT

\section{Control of the Package Output Programs}

TWo INF0 programs-OUTALL and OUTSEL-and the MAIN.CPL program control the output programs. The INF0 programs are similar to main programs in Fortran and contain the package output programs as subroutines. Running either OUTALL or OUTSEL depends on the options chosen when running MAIN.CPL.

Usage and argument format used within the interface CPLs are similar to commands used in ARC/INF0. If the user wishes to see the usage, type ' $R$ MAIN' and the usage, which includes arguments will be displayed. That usage and a description of options follows.

Usage: R MAIN <INFO|PRIMOS $\mid$ BOTH $>\langle$ LIST $|$ WIDE $>\langle$ ARC $|$ ASCII $>$

1. <INFO|PRIMOS|BOTH>--The argument controls output from INFO to the model and is a required argument as are all arguments bracketed by the greater than $(>)$ and less than (<) symbols. The flow of MAIN.CPL is affected by the choice of option. The effect of the choice of each option is as follows:

a. INF0--Generates a complete new set of PRIMOS level package data files for the model by entering INFO and running OUTALL.

b. PRIMOS--Runs the model with the existing PRIMOS data files. In this case, neither OUTALL nor OUTSEL are run, and none of the package output programs are run.

c. BOTH--Runs the model with some of the existing PRIMOS data files and with some new files created from INF0. MAIN.CPL will enter INFO and run INFO program OUTSEL.IF, which allows for full-screen updating of OUTSEL.DF. OUTSEL.DF contains one record for each package with a "Yes" or "No" flag. "Yes" means that the package output program will be run and will overwrite the existing PRIMOS data file with data currently in INFO. "No" means that the package output program will not be run. 
2. <LIST|WIDE>--Controls the format with which two-dimensional arrays are written to the PRIMOS package data files from INF0.

a. LIST--Outputs all two-dimensional arrays as 1ists with one value per line.

b. WIDE--Outputs all two-dimensional arrays across the page by rows of the model grid. This format is used for the sample files shown by McDonald and Harbaugh (1988).

3. $\angle A R C \mid A S C I I>$ This option specifies whether model output will be returned to ARC/INFO.

a. ARC--Generates PRIMOS data files of selected model outputs for entry to ARC/INFO. Following the model run, MAIN.CPL will run a Fortran program called WLSIN.F77 to generate those files.

b. ASCII--Terminates processing following the model run. ASCII means only standard model outputs are desired and no ARC coverages will be generated. Note that if the PRIMOS option and the ASCII option are selected, the result will be simply to run the model with no interaction with $A R C / I N F O$.

Program MAIN.CPL will write a PRIMOS como file that will save everything that appears on screen from the time that the como file is opened until it is closed. The como file is a means of tracking program execution and can be used to locate errors in programming if they occur.

\section{Listing of MAIN.CPL Program}

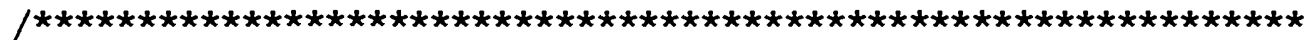

* PROGRAM NAME: MAIN.CPL

$/ *$

/* DESCRIPTION: This CPL will run the GW model using

${ }^{*}$ inputs from ARC/INFO (INFO option), the existing

$/ *$ Primos files (PRIMOS option), or a combination of

/* both (BOTH option, specific files picked from a

$/^{*}$ menu). Arrays can be output to Primos as lists or in

$/^{*}$ wide format (written across page). List vs. wide format

$/ *$ CPU and IO are about equal, if less than 132 characters

$/^{*}$ needed per row (ie. format times ncols $<132$ ). If $>132$

${ }^{*}$ characters, wide takes at least 2 to 3 times more

/* computer time.

$/ * \quad$ To move model output into ARC, select

* ARC output option. Either WLSIN.CPL or CBCIN.CPL

$/^{*}$ can then be run to generate coverages of specified

/* output parameters.

$/ *$ AUTHOR: Peter Van Metre

DATE: $4 / 27 / 87$ 
COMO COMO.MAIN

TIME

\&ARGS INPUT ; FMTIN ; OUTPUT

${ }^{*}$ Test if first two inputs have been entered.

\&IF [NULL \%OUTPUT\%] \&THEN \&DO

TYPE Usage: R MAIN <INFO|PRIMOS|BOTH> <LIST|WIDE> <ARC $\mid$ ASCII >

\&END \&RETURN 1

\&IF \%INPUT\% $=$ INFO $\mid \%$ INPUT\% = PRIMOS $\mid \%$ INPUT\% = BOTH \&THEN \&GOTO \%INPUT\%

\&LABEL INFO

\&IF \%FMTIN\% = WIDE | \%FMTIN\% = LIST \&THEN \&GOTO \%FMTIN\%

\&LABEL WIDE

\&DATA ARC INFO

RUN OUTALL

Q STOP

\&END

\&GOTO PRIMOS

\&LABEL LIST

\&DATA ARC INFO

FORMAT \$CHR39, 4, C

MOVE 'LIST' TO \$CHR39

RUN OUTALL

Q STOP

\&END

\&GOTO PRIMOS

\&LABEL BOTH

\&DATA ARC INFO

SEL OUTSEL.DF

PURG

$Y$

IPF OUTSEL.IF LN

\&TTY

\&END

\&IF \%FMTIN\% = WIDE | \%FMTIN\% = LIST \&THEN \&GOTO \%FMTIN\%2

\&LABEL WIDE2

\&DATA ARC INFO

RUN OUTSEL

Q STOP

\&END

\&GOTO PRIMOS

\&LABEL LIST2

\&DATA ARC INFO

FORMAT \$CHR39, 4, C

MOVE 'LIST' TO \$CHR39

RUN OUTSEL

Q STOP 
\&END

\&GOTO PRIMOS

\&LABEL PRIMOS

/* SEG MODEL 2 (Run CPL Program SEGMODEL.CPL)

\&DATA R SEGMODEL

\&END

\&IF \%OUTPUT\% = ARC | \%OUTPUT\% = ASCII \&THEN \&GOTO \%OUTPUT\% \&LABEL ARC

$A *>$ INFO

R WLSIN

UP

\&LABEL ASCII

TIME

COMO -E

2Listing of CPL Program SEGMODEL.CPL

(called from MAIN.CPL)

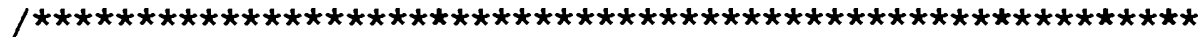

* PROGRAM NAME: SEGMODEL.CPL

${ }^{*}$ Unit numbers correspond to FORTRAN unit numbers in

$/ *$ INF0 data file BAS.CNTL (IUNITs). Units not in use

${ }^{*}$ should be commented out with ' $/ *$ ' in first two spaces.

${ }^{*}$ Files ending in 'UNF' are unformatted files

/* for model outputs 'saved on disk'; unit numbers must

$/^{*}$ match IxxxCB value for each package when output is

/* saved.

* DESCRIPTION: Called from MAIN.CPL to run the GW model.

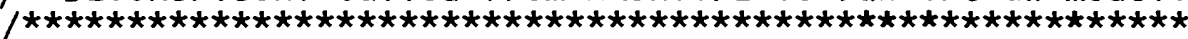

TIME

FOPEN * $>$ INF0 $>$ BAS 51

FOPEN * $>$ INFO $>$ INOUT 62

FOPEN $*>$ INFO $>$ BCF 291

FOPEN * $>$ INFO $>$ WEL 301

FOPEN *>INFO $>$ DRN 311

FOPEN *>INFO $>$ RIV 321

FOPEN *>INFO $>$ EVT 331

FOPEN * $>$ INFO $>$ GHB 351

FOPEN * $>$ INFO $>$ RCH 361

FOPEN *>INFO>SIP 371

FOPEN * $>$ INF0 $>0$ C 381

FOPEN *>INFO>BCFUNF 412

FOPEN * $>$ INFO $>$ WELUNF 422

FOPEN *>INFO>DRNUNF 432

FOPEN * $>$ INFO $>$ RIVUNF 442

FOPEN *>INFO $>$ EVTUNF 452

FOPEN *>INFO $>$ GHBUNF 462

FOPEN *>INFO $>$ RCHUNF 472

FOPEN *>INFO>WLSUNF 482

FOPEN *>INFO>DDSUNF 492 


\begin{abstract}
/* Pathname must point to SEG directory for GW model on users system. /* If using BIND, change SEG to R. \&DATA SEG MODELS>GW>MODFLOW \&END
\end{abstract}

\title{
Description of Programs OUTALL and OUTSEL
}

INF0 program OUTALL will run all of the package output programs for which IUNIT in BAS.CNTL is greater than zero. This includes all packages being used in the particular model and creates a complete new set of PRIMOS data files for the model. OUTALL probably would be run only to create the files for a first model run or after some major update such as changing the model grid.

INFO program OUTSEL will run only those package output programs for which a "Yes" response is entered in the INFO data file OUTSEL.DF and for which IUNIT in BAS.CNTL is greater than zero. OUTSEL.DF is automatically brought on screen for menu-driven updating by MAIN.CPL if the "BOTH" option is specified. OUTSEL would be run after one or more model data files were updated in INFO to create one or more PRIMOS data files for the model.

Narrative of INFO Program OUTALL

1. Select INF0 data file BAS.CNTL, reselect for record number four that contains the IUNIT values for all other packages, and read those values into dimensioned INF0 variables. Reselect for record number three and move number of layers, rows, and columns into INF0 variables for later use in controlling output.

2. Test each IUNIT value and run each package output program for which the corresponding IUNIT value is greater than zero.

\section{Listing of INFO Program OUTALL}

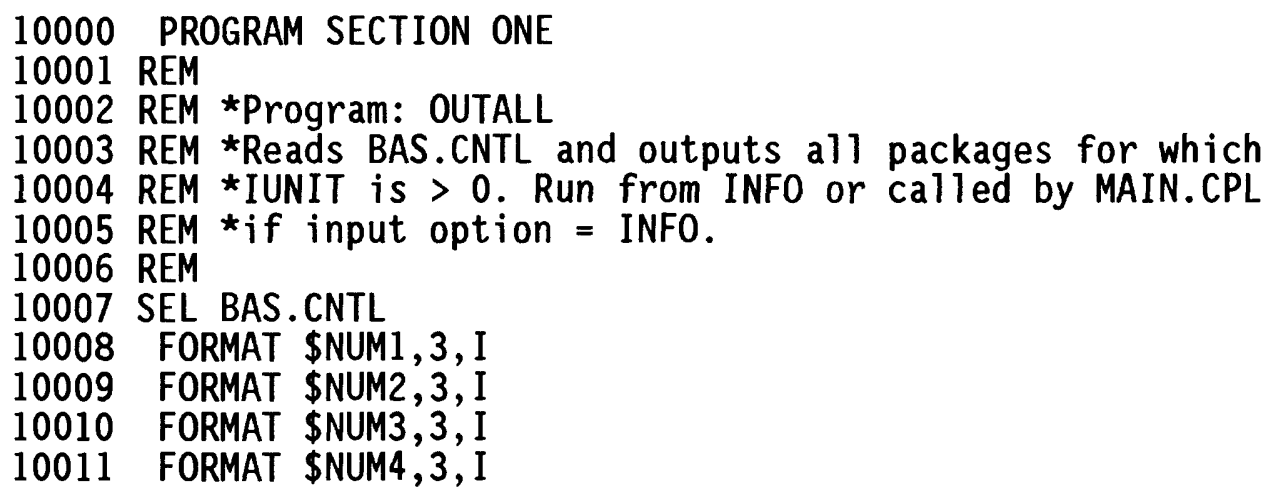




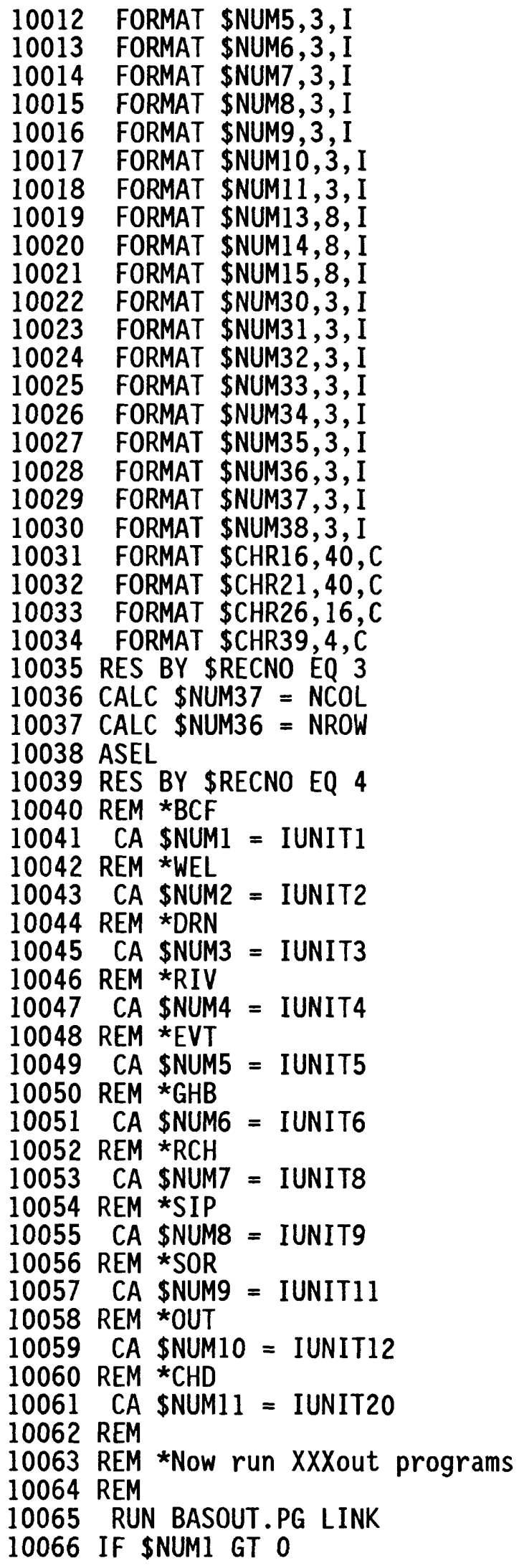




\author{
10067 RUN BCFOUT.PG LINK \\ 10068 ENDIF \\ 10069 IF \$NUM2 GT 0 \\ 10070 RUN WELOUT.PG LINK \\ 10071 ENDIF \\ 10072 IF \$NUM3 GT 0 \\ 10073 RUN DRNOUT.PG LINK \\ 10074 ENDIF \\ 10075 IF \$NUM4 GT 0 \\ 10076 RUN RIVOUT.PG LINK \\ 10077 ENDIF \\ 10078 IF \$NUM5 GT 0 \\ 10079 RUN EVTOUT.PG LINK \\ 10080 ENDIF \\ 10081 IF \$NUM6 GT 0 \\ 10082 RUN GHBOUT.PG LINK \\ 10083 ENDIF \\ 10084 IF \$NUM7 GT 0 \\ 10085 RUN RCHOUT.PG LINK \\ 10086 ENDIF \\ 10087 IF \$NUM8 GT 0 \\ 10088 RUN SIPOUT.PG LINK \\ 10089 ENDIF \\ 10090 IF \$NUM9 GT 0 \\ 10091 RUN SOROUT.PG LINK \\ 10092 ENDIF \\ 10093 IF \$NUM10 GT 0 \\ 10094 RUN OCOUT.PG LINK \\ 10095 ENDIF \\ 10096 IF \$NUM11 GT 0 \\ 10097 RUN CHDOUT.PG LINK \\ 10098 ENDIF \\ 10099 END
}

1. Select INF0 data file BAS.CNTL, reselect for record number four which contains the IUNIT values for all other packages, and read those values into dimensioned INF0 variables. Reselect for record number three and move number of layers, rows, and columns into INFO variables for later use in controlling output.

2. Select INFO data file OUTSEL.DF and read the "Yes" or "No" response into dimensioned INFO variables.

3. Test each variable for value equal $Y$ or $y$ and IUNIT value greater than zero and run each package output program passing those two tests. 
Listing of INFO Program OUTSEL

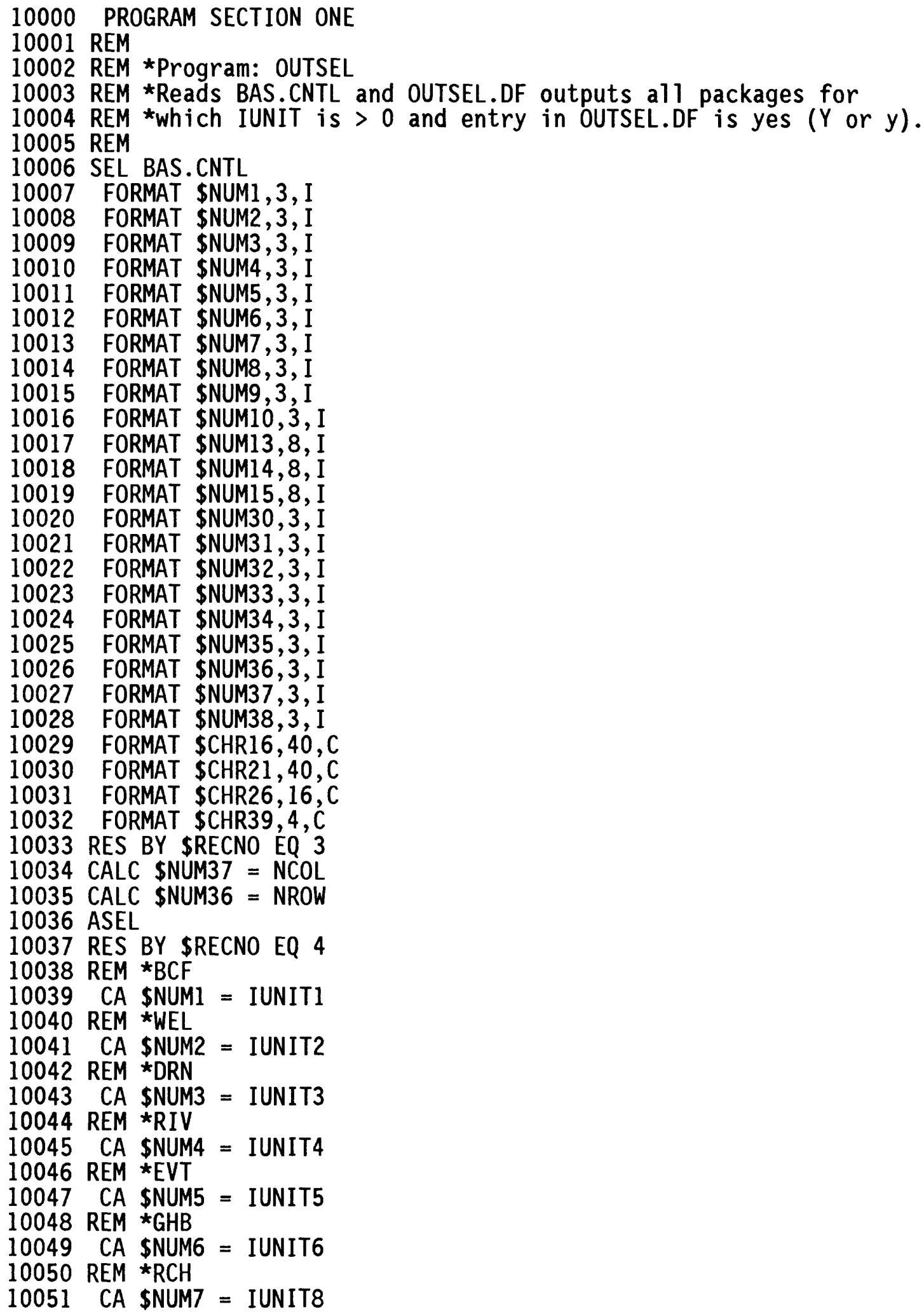




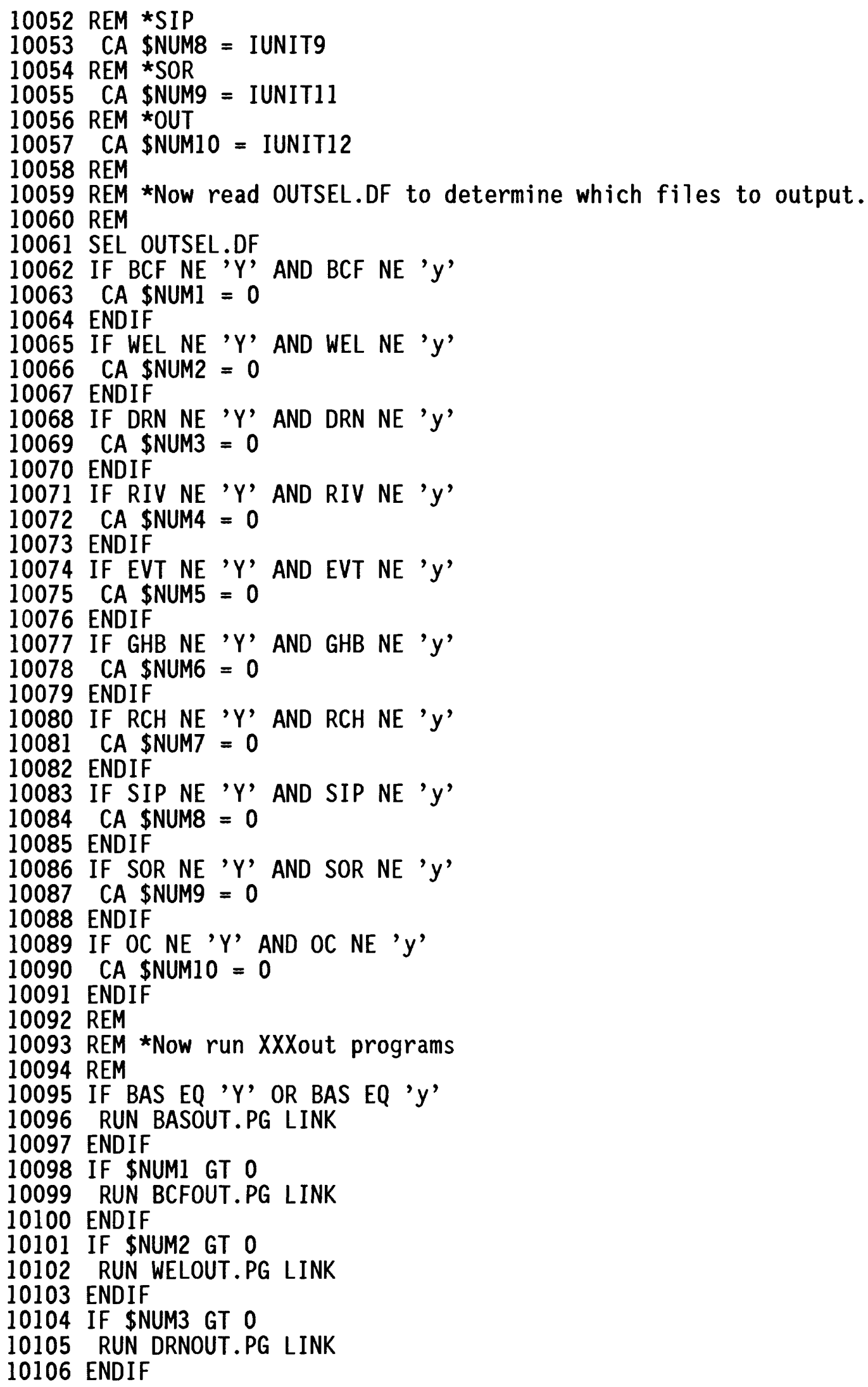




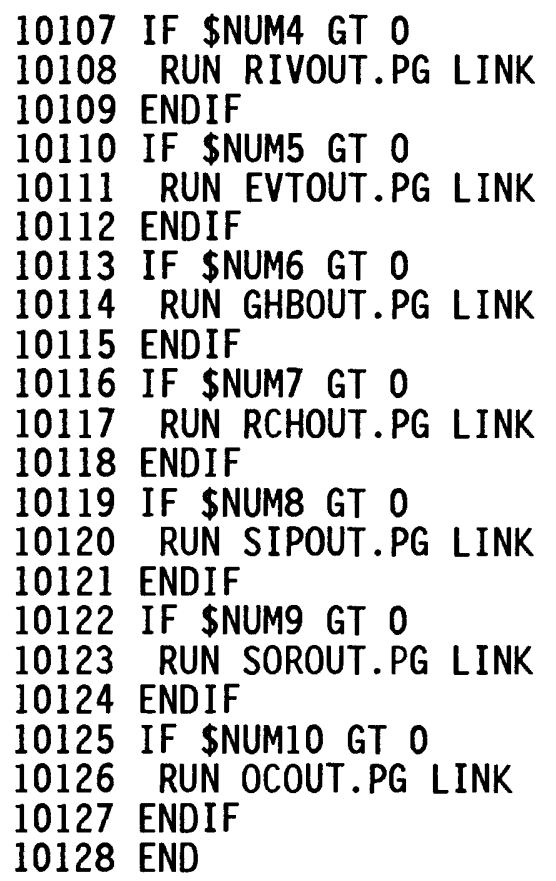

Listing of INFO Input form OUTSEL.DF

ENTER COMMAND >TYPE OUTSEL. IF

FORM NAME : OUTSEL. IF

2,25, 'SELECTED OUTPUT FROM ARC/INFO'

3,30, 'FOR GW MODEL RUN'

5,28 , 'PACKAGE OUTPUT? $(\mathrm{Y} / \mathrm{N})$ '

6,30 , 'BAS'

$6,40, ':$

7,30 , 'BCF'

$7,40, '$ ',

8,30 , 'WEL'

$8,40, '$ :

9, 30, 'DRN'

9,40,' :'

10,30 , 'RIV'

$10,40, '$ :

11,30 ,' $\mathrm{EVT}$ '

$11,40, ':$

12,30 , ' $G H B$ '

$12,40, '$ ''

13,30 , ' $\mathrm{RCH}$ '

13,40, ':

14,30 ,' SIP'

$14,40, ':$ '

15,30 ,' SOR'

$15,40, '$ ' '

16,30, ' $O C$ '

$16,40, '$ :'

18,2,' IF EXECUTED FROM MAIN.CPL, ENTER "Q STOP" AT "ENTER COMMAND>" 
PROMPT'

$6,41, \mathrm{BAS}$

$7,41, \mathrm{BCF}$

8,41 ,WEL

9,41, DRN

10,41, RIV

$11,41, \mathrm{EVT}$

$12,41, \mathrm{GHB}$

$13,41, \mathrm{RCH}$

14,41, SIP

15,41, SOR

16,41, OC

INFO File Structure and Example Data Files for OUTSEL.DF

DATAFILE NAME: OUTSEL.DF

$12 / 9 / 1988$

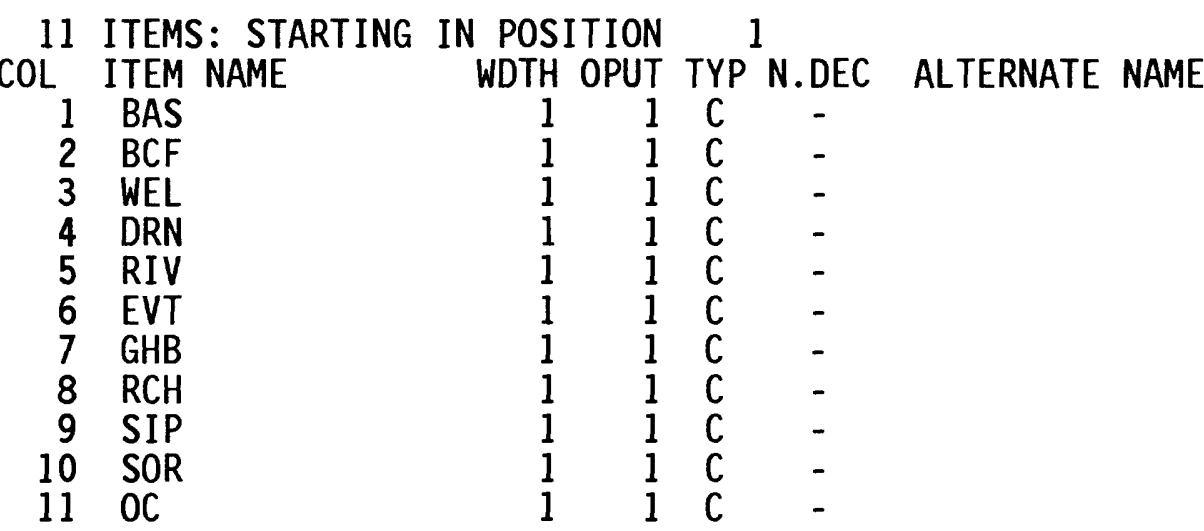

ENTER COMMAND >LI

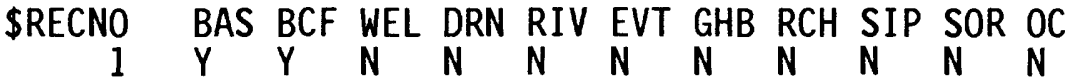

\section{Returning Model Output to ARC/INFO}

Three CPL programs-MAIN.CPL, CBCIN.CPL and WLSIN.CPL-affect the return of model-output heads, drawdowns, and flow terms to ARC/INFO by using one Fortran program and two INF0 programs. WLSIN.CPL and CBCIN.CPL can be run at any time after a model run has been completed if MAIN.CPL was run with the ARC option. WLSIN.CPL and CBCIN.CPL will create a coverage of only one model output data set each time they are run-for example, head values for all layers for a particular stress period and time step.

The process of returning model outputs to ARC/INFO is accomplished by the following steps.

1. If the ARC option is specified when MAIN.CPL is run, MAIN.CPL will run Fortran program WLSIN.F77. This program 
will open the output control (OC) PRIMOS file and the appropriate PRIMOS package data files as necessary, determine what was saved on disk, then read and reformat those records for entry to INFO. Each reformatted data set will carry a unique PRIMOS filename assigned by the program; for example, heads for stress period 2 after time step 1 will be called (by default) HED.02.01.

2. At any time after a model run is completed, the user can run either CBCIN.CPL or WLSIN.CPL. Either requires one argument, which is the PRIMOS filename of the reformatted (step 1) data set awaiting entry to INF0. Each CPL follows the same general steps which are:

a. Determine if a coverage already exists by the data set name given.

b. If that coverage does exist, enter INFO and run INFO program LOADWLS.PG. LOADWLS.PG will bring the data set into INFO using "GET filename COPY," relate that data set to the .PAT file of the same name and move that data into that file.

c. If that coverage does not exist, use ARC commands to make a copy of the NODES coverage, and add the necessary INFO items. Then enter INFO and run LOADWLS.PG to bring the specified data set into INFO and load those values to the new coverage.

\section{Listing of CPL Program WLSIN.CPL}

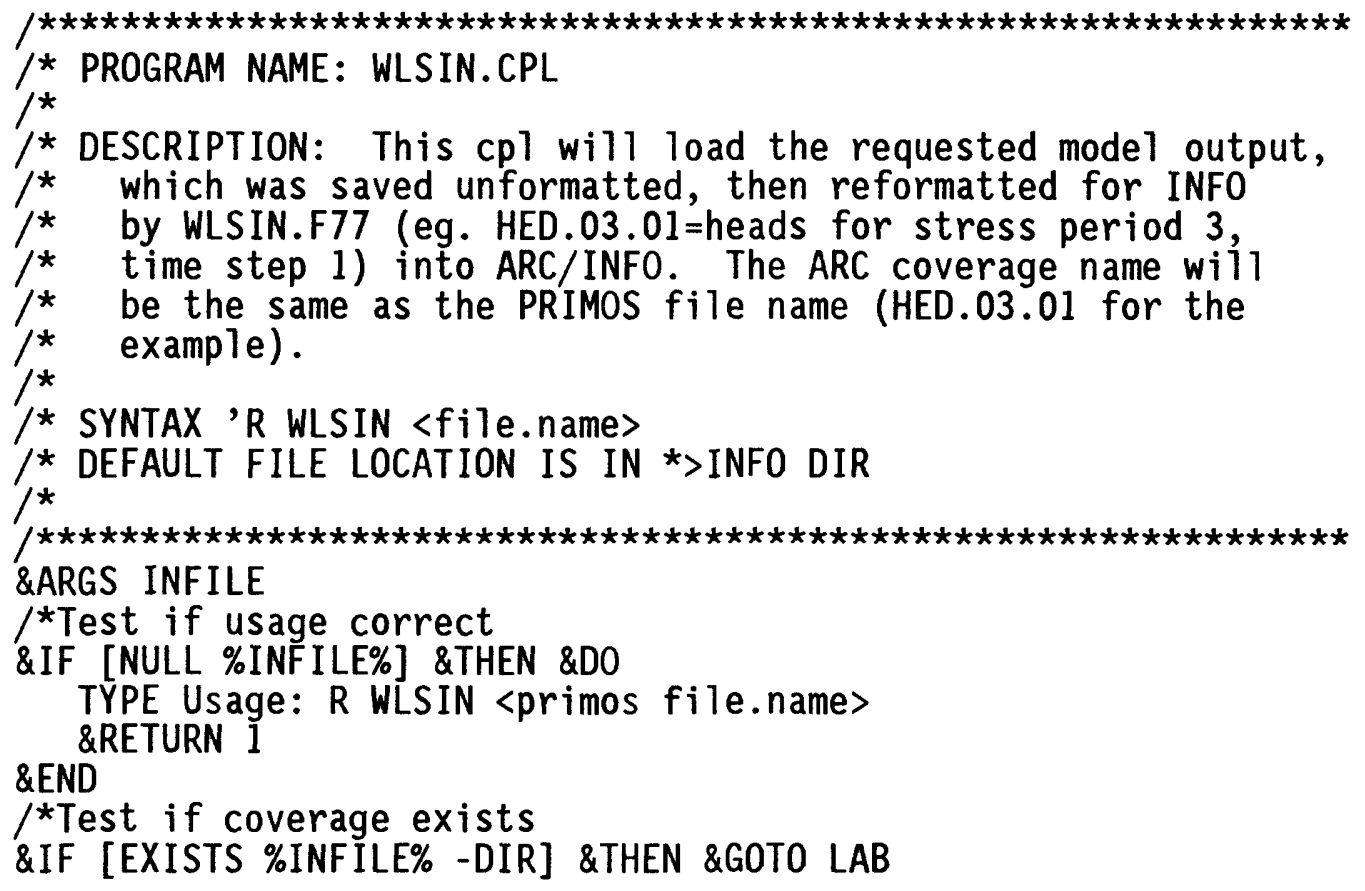


\&DATA ARC COPY NODES \%INFILE\%

\&END

\&DATA ARC INFO

SEL WLS.DAT

PURGE

$Y$

$/ *$ Model output pathname, if not in INFO directory

$/ *$ used by ARC, should be entered here in the 'GET-COPY'

$/{ }^{*}$ command.

GET \%INFILE\% COPY

Q STOP

\&END

\&DATA ARC JOINITEM \%INFILE\%.PAT WLS.DAT \%INFILE\%.PAT KEY KEY LINK

\&END

\&RETURN

${ }^{*}$ If coverage did exist, enter here

\&LABEL LAB

\&DATA ARC INFO

SEL WLS.DAT

PURGE

Y

GET \%INFILE\% COPY

SEL \%INFILE\%.PAT

REL WLS.DAT BY KEY LINK

RUN LOADWLS.PG

/* LOADWLS.PG is an INFO program containing one calculate statement

/* for each layer in model. It will need to be modified for each

$/ *$ application, depending on number of layers simulated.

Q STOP

\&END

\&RETURN

Listing of CPL Program CBCIN.CPL

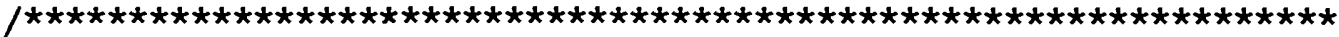

$/ *$ PROGRAM NAME: CBCIN.CPL

$/ *$

/* DESCRIPTION: This cpl will load the requested model output,

${ }^{*}$ which was saved unformatted, then reformatted for INFO

/* by CBCIN.F77 (eg. RIV.03.01=river node flows for stress

${ }^{*}$ time step 1) into ARC/INFO. The ARC coverage name will

${ }^{*}$ be the same as the PRIMOS file name (RIV03.01 for the

/* example).

/*

/* SYNTAX 'R CBCIN <file.name>

* DEFAULT FILE LOCATION IS IN * $>$ INFO DIR

/*

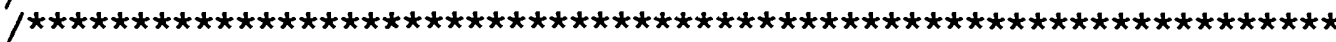

\&ARGS INFILE

$/^{*}$ Test if usage correct

\&IF [NULL \%INFILE\%] \&THEN \&DO
} 
TYPE Usage: R CBCIN <primos file.name> \&END \&RETURN 1

$/ *$ Test if coverage exists

\&IF [EXISTS \%INFILE\% -DIR] \&THEN \&GOTO LAB

\&DATA ARC COPY NODES \%INFILE\%

\&END

$/ *$ Default model output pathname, if not in INFO directory

$/{ }^{*}$ used by ARC should be entered here in the 'GET-COPY'

$/{ }^{*}$ command

\&DATA ARC INFO

SEL CBC.DAT

PURGE

$Y$

GET \%INF ILE\% COPY

Q STOP

\&END

\&DATA ARC JOINITEM \%INFILE\%.PAT CBC.DAT \%INFILE\%.PAT KEY KEY LINK

\&END

\&RETURN

${ }^{*}$ If coverage did exist, enter here

\&LABEL LAB

\&DATA ARC INFO

SEL CBC.DAT

PURGE

Y

GET \%INFILE\% COPY

SEL \%INFILE\%.PAT

REL CBC.DAT BY KEY LINK

RUN LOADWLS.PG

$/^{*}$ LOADWLS.PG is an INFO program containing one calculate statement

/* for each layer in model. It will need to be modified for each

/* application, depending on number of layers.

Q STOP

\&END

\&RETURN

INFO File Structure of Files CBC.DAT and WLS.DAT

DATAFILE NAME: CBC.DAT

4 ITEMS: STARTING IN POSITION 1

COL ITEM NAME

1 LAY 1

13 LAY2

25 LAY3

37 LAY4

WDTH OPUT TYP N.DEC ALTERNATE NAME

$\begin{array}{llll}12 & 12 & \mathrm{~N} & 5 \\ 12 & 12 & \mathrm{~N} & 5 \\ 12 & 12 & \mathrm{~N} & 5 \\ 12 & 12 & \mathrm{~N} & 5\end{array}$


ENTER COMMAND >LI

$\begin{array}{rrrrr}\text { \$RECNO } & \text { LAY1 } & \text { LAY2 } & \text { LAY3 } & \text { LAY4 } \\ 1 & -0.31440 & -0.10342 & -0.07110 & -0.05892 \\ 2 & -0.03636 & -0.08400 & -0.09931 & -0.09921 \\ 3 & 0.00000 & -0.13171 & -0.11544 & -0.11637 \\ 4 & 0.00000 & -0.03337 & -0.08699 & -0.01782 \\ 5 & 0.00000 & 0.00000 & 0.11766 & 0.03803 \\ 6 & 0.00000 & 0.00000 & -0.00540 & -0.00214 \\ 7 & 0.00000 & 0.00000 & 0.00000 & -0.04041 \\ 8 & 0.00000 & 0.00000 & 0.00000 & -0.05003 \\ 9 & 0.00000 & 0.00000 & 0.00000 & 0.00000 \\ 10 & -0.21430 & -0.09512 & -0.07336 & -0.06501 \\ 11 & -0.10019 & -0.11520 & -0.11911 & -0.12887 \\ 12 & 0.00000 & -0.24951 & -0.15375 & -0.24306 \\ 13 & 0.00000 & 0.11479 & 0.02516 & 0.12596 \\ 14 & 0.00000 & 0.00000 & 0.05881 & 0.05081 \\ 15 & 0.00000 & 0.00000 & -0.01357 & -0.00159 \\ 16 & 0.00000 & 0.00000 & 0.00000 & -0.04082 \\ 17 & 0.00000 & 0.00000 & 0.00000 & -0.05010 \\ 18 & 0.00000 & 0.00000 & 0.00000 & 0.00000\end{array}$

DATAFILE NAME: WLS.DAT

4 ITEMS: STARTING IN POSITION 1 COL ITEM NAME

$\begin{array}{rlrrrr}1 & \text { LAY1 } & 12 & 12 & \mathrm{~N} & 3 \\ 13 & \text { LAY2 } & 12 & 12 & \mathrm{~N} & 3 \\ 25 & \text { LAY3 } & 12 & 12 & \mathrm{~N} & 3 \\ 37 & \text { LAY4 } & 12 & 12 & \mathrm{~N} & 3\end{array}$

\begin{tabular}{rrrrr}
\multicolumn{1}{l}{$\begin{array}{l}\text { ENTER COMMAND } \\
\text { \$RECN0 }\end{array}$} & LI & & \\
LRE1 & LAY2 & LAY3 & LAY4 \\
1 & 252.708 & 261.011 & 266.257 & 268.977 \\
2 & 265.738 & 267.447 & 270.568 & 272.719 \\
3 & 267.484 & 273.175 & 276.816 & 279.227 \\
4 & 999.000 & 280.730 & 284.364 & 287.119 \\
5 & 999.000 & 282.369 & 290.284 & 288.370 \\
6 & 999.000 & 999.000 & 283.795 & 285.603 \\
7 & 999.000 & 999.000 & 284.066 & 285.764 \\
8 & 999.000 & 999.000 & 999.000 & 288.232 \\
9 & 999.000 & 999.000 & 999.000 & 290.884 \\
10 & 252.353 & 260.799 & 266.249 & 269.086 \\
11 & 262.013 & 266.718 & 270.697 & 273.215 \\
12 & 267.201 & 274.573 & 278.190 & 281.668 \\
13 & 999.000 & 288.885 & 288.243 & 298.152 \\
14 & 999.000 & 283.246 & 286.530 & 289.310 \\
15 & 999.000 & 999.000 & 283.271 & 285.614 \\
16 & 999.000 & 999.000 & 283.957 & 285.734 \\
17 & 999.000 & 999.000 & 999.000 & 288.227 \\
18 & 999.000 & 999.000 & 999.000 & 290.883
\end{tabular}




\section{Listing of INFO Program LOADWLS.PG}

10000 PROGRAM SECTION ONE

10001 REM

10002 REM *Program: LOADWLS.PG

10003 REM *Run from WLSIN.CPL to calculate wls in .PAT file

10004 REM *equal to wls in newly get/copied data file WLS.DAT.

10005 REM *Also run from CBCIN.CPL to calculate flow terms

10006 REM * in .PAT file equal to newly get/copied data file

10007 REM $*$ CBC.DAT. Number of CA commands below must equal

10008 REM * number of model layers.

20000 PROG 2

20001 CA LAY $1=\$ 1$ LAY 1

20002 CA LAY2 $=\$ 1$ LAY2

20003 CA LAY3 $=\$ 1$ LAY3

20004 CA LAY4 $=$ \$1LAY4

30000 PROG 3

30001 END

\section{Description of Fortran Program WLSIN.F77}

A flag was necessary to tell the programs within the interface what model output was to be saved for return to ARC/INF0. One option available within the output-control package is to specify that output be saved (unformatted) on disk. The interface, using program WLSIN.F77, recognizes this as a flag. Any model output data set that has been saved on disk will be read from there, reformatted, and written to a file in a format acceptable for entry to INF0.

A default-naming convention was established for those files. The first three letters of the file name tell what parameter is saved. These are followed by a period '.' and a two-digit integer representing the stress period, followed by another period '.' and a two-digit integer representing the time step for which that parameter was saved. The three-character parameter codes are:

$\begin{array}{ll}\text { CODE } & \text { PARAMETER } \\ \text { HED } & \text { Head } \\ \text { DRD } & \text { Drawdowns } \\ \text { DRN } & \text { Flows to drain nodes } \\ \text { RIV } & \text { Flows to river nodes } \\ \text { WEL } & \text { Flows to well nodes } \\ \text { GHB } & \text { Flows to general head boundary nodes } \\ \text { EVT } & \text { Flows to evaporation nodes } \\ \text { RCH } & \text { Flows to recharge nodes } \\ \text { KHD } & \text { Flows to constant head nodes } \\ \text { STO } & \text { Storage changes for al1 nodes } \\ \text { CBR } & \text { Flow through the right face of all nodes } \\ \text { CBF } & \text { Flow through the front face of all nodes } \\ \text { CBL } & \text { Flow through the lower face of all nodes }\end{array}$




\section{Listing of Fortran Program WLSIN.F77}

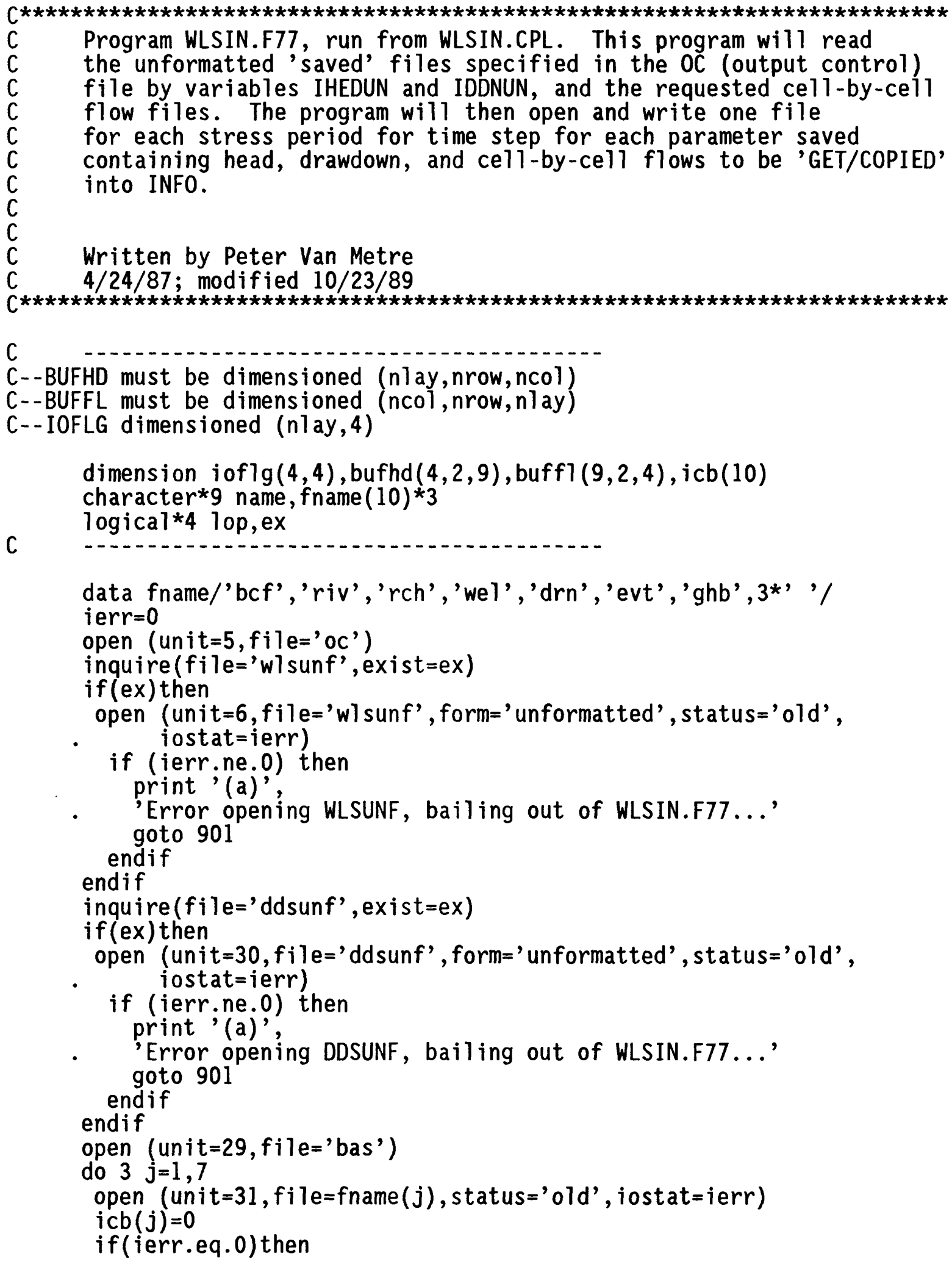


58

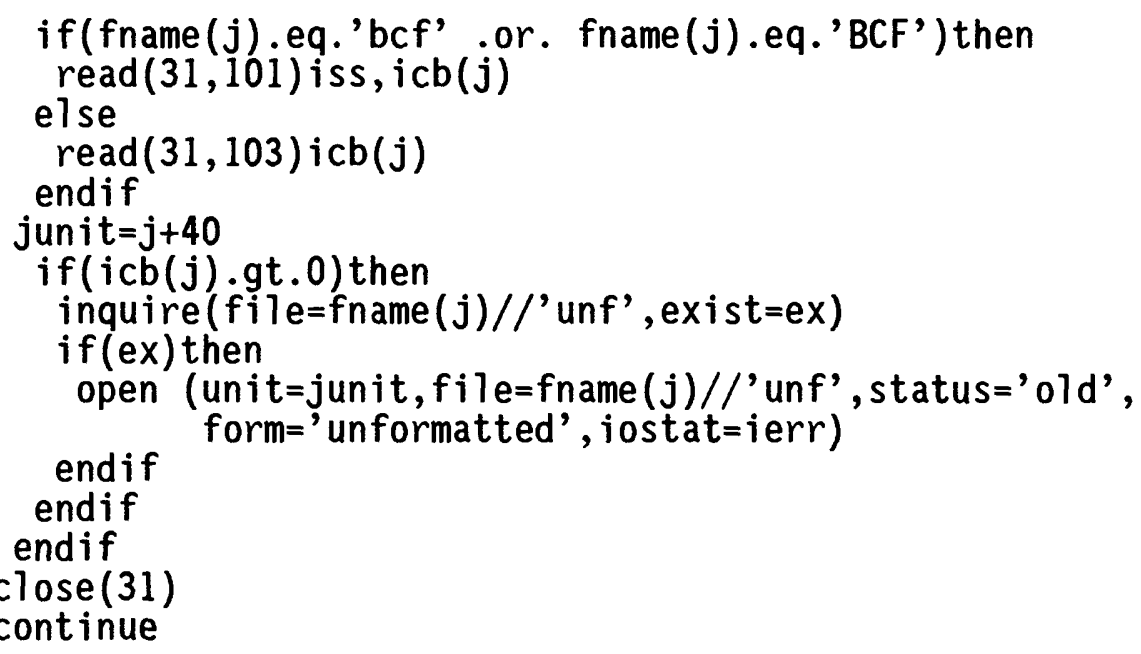

$i b c f c b=i c b(1)$

irivcb=icb (2)

irch $c b=i c b(3)$

iwel $c b=i c b(4)$

idrncb $=\mathrm{icb}(5)$

ievt $c b=i c b(6)$

ighbcb=icb(7)

data name /'hed.00.00'\%

C--Read control information

$\operatorname{read}(29,102)$ nlay, nrow, ncol, nper

read $(5,100)$ ihedun, iddnun

C--Check to see if head or drawdown saved for this simulation if (ihedun.1t.1 . and. iddnun.1t.1) then

go to 901

endif

4 continue

C--Read oc specifications for this time step

$\operatorname{read}(5,101$, end $=901)$ incode, ihddf 1 , ibudf 1 , icbcf 1

C--Decode incode to determine how to set flags

if (incode) $10,20,30$

C--use ioflg from last step

10 continue go to 500

C--read ioflg for 1 ayerl and assign to all layers

$20 \operatorname{read}(5,101)(\operatorname{ioflg}(1, \mathrm{~m}), \mathrm{m}=1,4)$

do $5 \mathrm{k}=1, \mathrm{n} 1$ ay

ioflg $(k, 1)=$ i of $\lg (1,1)$

ioflg $(k, 2)=$ ioflg $(1,2)$

ioflg $(k, 3)=$ i oflg $(1,3)$

5 continue

ioflg $(k, 4)=$ ioflg $(1,4)$

go to 500

C--read ioflg in entirety 
$\operatorname{read}(5,101)((\mathrm{ioflg}(k, i), i=1,4), k=1, n 1$ ay $)$

C--Ioflg is set; read appropriate data sets and write

500 continue

if (inddfl. ne.0) then

C--heads and/or dd printed or saved

iwrite $=0$

iunit $=0$

do $6 \mathrm{k}=1, \mathrm{n} 7 \mathrm{ay}$

do $6 \mathrm{j}=1$, nrow

do $6 \mathrm{j}=1, \mathrm{ncol}$

$\operatorname{bufhd}(k, i, j)=0.0$

6 continue

do $15 k=1, n l$ ay

if (ioflg $(k, 3)$.ne.0)then

read(6)

read (6)kstp, kper, pertim, totim, text, nc, nr, ilay

111 format $(2 i 5,4 \mathrm{a} 4)$

iwrite $=1$

tst $p=k s t p$

sper $=$ kper

sper $=$ sper $/ 100$.

tst $p=\operatorname{tst} / 100$.

endif

15 continue

if ( iwrite.gt.0)then

write (name (1:3),'(a)') 'hed'

write(name (4:6),' (f3.2)') sper

write(name $(7: 9)$, ' (f3.2)') tstp

do 7 i $0=50,139$

inquire (un it $=$ io, opened $=10 p$ )

if (.not. lop) then

open (unit=io, file=name)

iun $=i 0$

go to 8

endif

7 continue

8 continue

do 16 ir $=1$, nrow

do 16 ic $=1$, ncol

16

write (iun, 105) (bufhd ( $k$, ir, ic), k=1, nlay)

continue

endif

C--Now read and write drawdowns

iwrite $=0$

do $25 \mathrm{k}=1, \mathrm{n}$ lay

do $25 j=1$, nrow

do $25 \mathrm{j}=1$, ncol

bufhd $(k, i, j)=0.0$

25 continue

do $35 k=1, n 1$ ay

if ( iof lg $(k, 4)$, ne.0) then

read (30)kstp, kper, pertim, totim, text, nc, nr, i l ay

$\operatorname{read}(30)$ ( (bufhd $(k$, ir,$i c), i c=1$, ncol ) , i $r=1$, nrow)

iwrite $=1$ 


$$
\begin{aligned}
& \text { sper }=k p e r \\
& \text { tst }=k s t p \\
& \text { sper }=\text { sper } / 100 \\
& \text { tst } p=\operatorname{tst} p / 100 \\
& \text { endif }
\end{aligned}
$$

C--Check to see if cell-by-cell flow terms saved for this time C--step. If so call subroutine CBCIN to read those unformatted C--files and write files for INFO to GET/COPY.

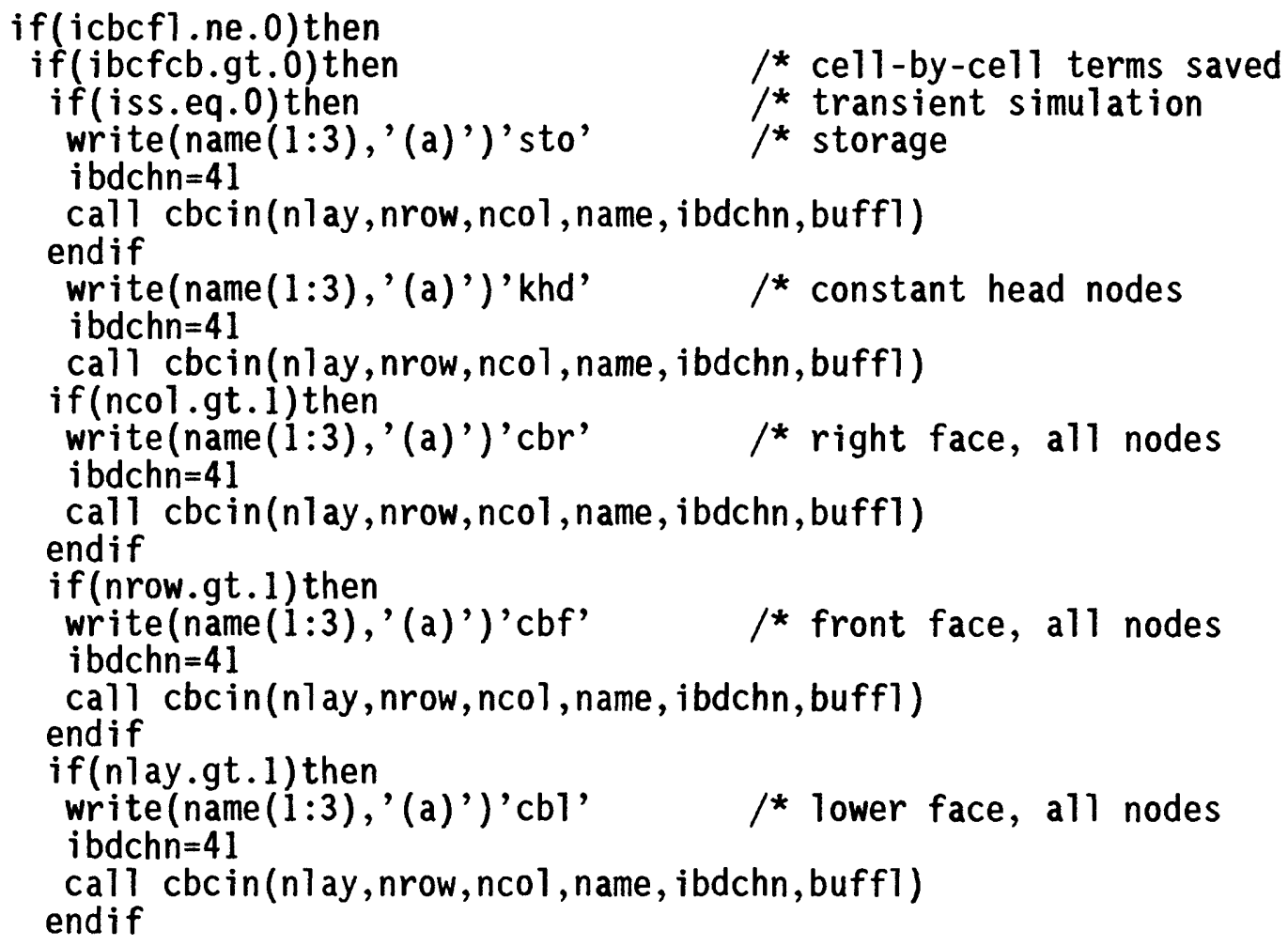




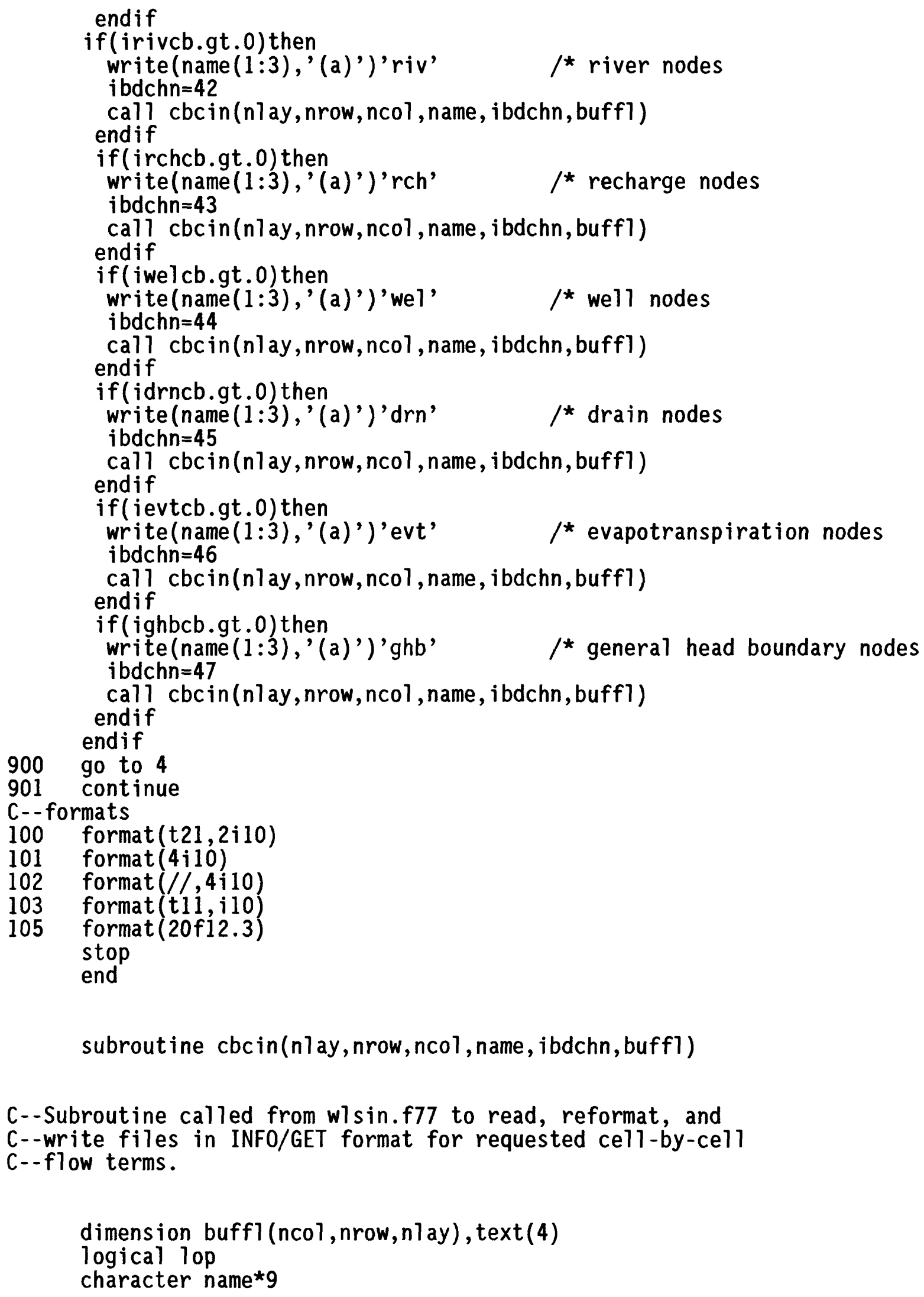

subroutine cbcin(nlay, nrow, ncol, name, ibdchn, buffl)

C--Subroutine called from w7sin.f77 to read, reformat, and C--write files in INF0/GET format for requested cell-by-cell C--flow terms.

dimension buffl (ncol, nrow, nlay), text (4)

logical lop

character name* 9 
62

C--Open output file, read unformatted records and write to output file.

101

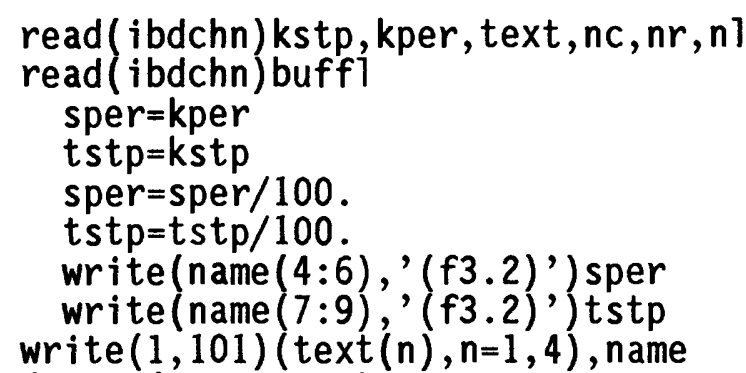

format $(4 a 4,2 x, a 9)$

do 7 i $0=50,139$

inquire (un $i t=i 0$, opened $=1$ op)

if (.not. 1 op) then open (unit $=i 0$, fi]e=name)

iun $=i 0$

go to 8

endif

7 continue

8 continue

do $9 i=1$, nrow

do $9 j=1, n$ col

9

write(iun, 100) (buffl $(j, i, k), k=1, n]$ ay)

C--This format may need to be varied depending on units used and flows

C--generated. If it is changed, item definitions in CBC.DAT INFO data

C--file must be changed to correspond. For f12.5, info definition is:

C--item. name, $12,12, \mathrm{n}, 5$.

100 format (20f12.5)

return

end

\section{APPLICATION OF THE INTERFACE PROGRAM}

Developing a mode 1 in ARC/INFO using the interface can be accomplished by following a general series of steps. First the programs and INFO file definitions must be loaded to the users system. Copies of the interface have the two-column by nine-row by four-layer test model to illustrate the interface loaded to the INFO data files. In some cases, the steps listed below can be accomplished in several ways and in different order.

1. Generate a point coverage of the centers of model blocks with items row and column. In the test model, this coverage is called NODES.

2. Add item KEY to the NODES.PAT file using the ARC command ADDITEM.

3. Sort the NODES.PAT file on ROW, COLUMN and calculate item KEY $=$ \$RECNO. Sort back on NODES\# before exiting. 
4. Copy coverage NODES to create coverages BAS and BCF using ARC COPY. Add items for each nonconstant two-dimensional array to each coverages .PAT file. For example, if the model is three layers and starting heads are not constant, add items SHEAD1, SHEAD2, and SHEAD3 to BAS.PAT.

5. Load the appropriate data sets to each item. This can be accomplished in many ways and depends on how the original data are stored.

6. Enter controlling information to each package control file with the INFO ADD command, the INFO UPDATE command, or a PRIMOS level editor. The control file can be created at the PRIMOS level and brought into INFO using the "GET COPY" command. The .FMTS INFO data files associated with each package also may be created in the same manner.

7. Enter the array-control card information to each package .FMTS INFO data file using the INFO ADD command or the INFO UPDATE command if modifying an existing record.

8. Following the example files set up for each list formatted package load data for the packages.

9. Run program OUTALL or program OUTSEL from INFO and check the PRIMOS level ASCII files created. Either program can be run from INFO by typing the following sequence:

Format \$CHR39, 4, C

Move 'LIST' to \$CHR39

Run OUTALL

Note: 'List' can be replaced by 'WIDE' and OUTALL can be replaced by OUTSEL.

10. Edit program WLSIN.F77 in the INFO directory to set the dimensions of BUFHD and BUFFL equal to the dimensions of your model. Recompile the program (F77 WLSIN) and reload the program (BIND - LO WLSIN - LI).

Three suggestions that may help avoid problems are:

1. Make sure the formats in the array-control cards correspond to the formats in the data files to which they relate. By default, INF0 will insert one space between items output with the DISPLAY or LIST commands. This means that an item that has an INFO definition of $5, N, 2$ ( 5 spaces wide, numeric, 2 places to the right of the decimal point) will use six spaces when it is output to PRIMOS. If the item definition for SHEADI, in BAS.PAT, therefore, is $5, N, 2$, the format for the SHEADI array-control card in BAS.FMTS should be F6.0.

2. INFO does not support ' $E$ ' format (scientific notation in Fortran). The only place ' $E$ ' format shows up in the example model is in item CONST in the. FMTS data files 
(array-control cards). This item is defined as a character item, and values are entered as character strings. When the values are output to PRIMOS, these values are read as numbers in ' $E$ ' format by the model. There is a tradeoff by allowing for ' $E$ ' format in this way. An INF0 calculate command cannot be used on these items. If this is a problem, redefine CONST as a numeric item and do not use ' $E$ ' format.

3. INF0 program LOADWLS.PG must have one calculate statement for each model layer to properly load water levels or cell-by-cell flow terms to ARC/INFO coverages. For the example problem, LOADWLS.PG has four calculate statements. Also, when water levels or flow terms are loaded to INFO, they are temporarily loaded to either the WLS.DAT or the CBC.DAT INFO data files. Each of those data files must have one item for each model layer. Use ADDITEM or DROPITEM from ARC to give each of those files the correct number of items following the naming convention and formats specified (LAY\#, 12, N, 3 for WLS.DAT and LAY\#, 12, N, 5 for CBC.DAT.

\section{SUMMARY}

A computer-program interface between a geographic-information system and a ground-water flow model links two unrelated software systems for use in developing the flow models. The interface program allows the modeler to compile and manage geographic components of a ground-water model with in the geographic-information system. A significant savings of time and effort is realized in developing, calibrating, and displaying the ground-water flow model.

Four major guidelines were followed in developing the interface program: (1) no changes to the ground-water flow model code were to be made, (2) a structure was to be designed within the GIS that follows the same basic structure as the ground-water flow model, (3) the interface program was to be flexible enough to support all options available within the model, and (4) the interface program was to be as efficient as possible in terms of computer time used and online-storage space needed.

The program was written in Fortran, control-program language and INFO program language. INF0 data files and ARC/INFO coverages are defined to hold all model-related data. Output of data from INFO for ground-water model runs and return of model results to INFO are automated using control-program language programs. Because some programs are written in control-program language, the interface will work only on a PRIME computer using the PRIMOS operating system.

The interface program performs no data transformations or manipulations and is used only to conveniently store and move data between $A R C / I N F 0$ and the ground-water flow model. The report documents an interface program that can be used to move data between a GIS and a ground-water flow model. 


\section{REFERENCES CITED}

McDonald, M.G., and Harbaugh, A.W., 1984, A modular three-dimensional finite-difference ground-water flow model: U.S. Geological Survey Open-File Report 83-875, 528 p.

1988, A modular three-dimensional finite-difference ground-water flow model: U.S. Geological Survey Techniques of Water-Resources Investigations, book 6, chap. A1, $586 \mathrm{p}$. (Supersedes U.S. Geological Survey Open-File Report 83-875)

Seybold, John, 1985, PRIME user's guide, 4th ed.: Natick, Massachusetts, PRIME Computer, Inc., DOC4130-4LA, Revision 19.4, v.p.

Environmental Systems Research Institute, 1987, ARC/INF0, Command references-The Geographic Information System Software: Redlands, California, Environmental Systems Research Institute, v. 2, variably paged.

\section{GLOSSARY OF TERMS}

Selected terms used in the text of this report are defined below. Additional definitions in the computer program listings of ground-water model variables can be found in McDonald and Harbaugh (1988), Seybold (1985), and Environmental Systems Research Institute (1987).

ADDITEM An ARC/INFO command that will add an additional item to an INFO data file.

ARC/INFO A commercially available GIS software system.

ARCPLOT A plotting software package that is a subset of the ARC/INFO system.

ARRAY An INFO item containing the name of the array that the array-control card corresponds to and must match the item name of that array in the corresponding. PAT file. The value stored in ARRAY is used to output its corresponding data values from the .PAT file.

ARRAY A line in a model-input data file that contains information CONTROL about the array of data to follow.

CARD

BAS

Basic package: Handles those tasks that are part of the model as a whole. Among those tasks are specification of boundaries, determination of time-step length, establishment of initial conditions, and printing of results. 
66

BCF

Block-Centered Flow Package: Calculates terms of finitedifference equations that represent flow within porous medium; specifically, flow from cell to cell and flow into storage.

CPL Command procedure language is a high-level programming language that operates at the PRIMOS command level (Seybold, 1985).

.CNTL A control file that is an INFO data file containing information such as number of time steps, layers, rows, and columns used for output to the ground-water flow model.

Coverage A digital map with associated information in ARC/INFO.

DELR

Cell width along the rows of the model.

DELC

Cell width along the columns of the model.

DRN

Drain Package: Adds terms representing flow to drains to the finite-difference equations.

EVT Evapotranspiration Package: Adds terms representing evapotranspiration to the finite-difference equations.

.FMTS INFO data files containing the array control cards for a particular ground-water flow model package.

FORTRAN A language in which computer programs are written.

FMTIN FORTRAN format statement in an array-control card describing the format of the array.

GHB General-Head Boundary Package: Adds terms representing general-head boundaries to the finite-difference equations.

GIS A geographic-information system that is a combination of digital mapping and display software system with a data-base management system used to manage, analyze, and display tabular and geographic data.

GRID A polygon coverage of the model grid, used primarily for plotting purposes.

HNOFLO Value assigned to head in inactive (no-flow) cells. It makes those cells stand out in listing of heads.

IBOUND Array defining boundary conditions for a model layer.

IKEY An integer item that equals 9 in all files and is used as part of the file-relating sequence in INFO that is used for all packages that produce two-dimensional arrays.

INEVTR Maximum evapotranspiration rate read flag.

INEXDP Evapotranspiration extinction depth read flag. 
INFO A computer software system designed for data-base and file management.

INIEVT Evapotranspiration layer read flag.

INIT An argument to an INFO command that opens PRIMOS files and initializes those files as they are opened. This procedure deletes existing values in those files.

INRECH Recharge read flag.

INSURF Evapotranspiration surface read flag.

ITEM A variable defined in an INFO data file.

INIRCH Recharge read flag.

IUNIT A 24-element array that indicates which major options are to be used and the unit numbers from which input is to be read for the ground-water flow model.

.KEY A.KEY file is an INFO data file containing record numbers for two other INF0 data files and is used as an intermediary file when relating the two other files to each other. This results in much faster output of data and controls the order in which data are output.

KPER

An INFO item in a package. CNTL data file that contains the name of a different INFO data file that holds information to be output. For example, an array of values for the Evapotranspiration package to be output following an array-control card in EVT.CNTL file will be stored in an INF0 data file whose name is specified in item KPER of the array-control card.

LOCAT PRIMOS file unit location of the data that will be put in the array.

NODES A point coverage of the center points of each model block and is the basic building block for each coverage that contains model data for all model blocks. For example, coverage, BAS, containing starting head values for each model block is a copy of coverage NODES.

NSTP Number of time steps in a stress period.

NEVTOP Evapotranspiration package option code.

PERLEN Length of a model stress period. 
.PAT Point or polygon attribute file is the INFO data file created by ARC/INFO to hold information associated with a coverage. For example, if the coverage is a digital map of well locations called wells, each well will have a record in the INFO data file WELLS.PAT associated with that well location and will contain information about that well. Each piece of information, for example well depth, is an attribute.

PRIMOS A mainframe computer and operating system.

RCH Recharge Package: Adds terms representing areally distributed recharge to the finite-difference equations.

RIV River Package: Adds terms representing flow to rivers to the finite-difference equations.

ROW INFO item containing model row number that is necessary for arrays that are written across the page and are wider than 132 characters.

\$RECNO Record number for an INFO data file.

SEG

címmand

PRIMOS command that will execute a FORTRAN program.

SIP

Strongly Implicit Procedure: Iteratively solves the system of finite-difference equations.

SOR

Slice-Successive Overrelaxation: Iteratively solves the system of finite-difference equations.

SORT An INF0 item containing an integer that is used to sort that INF0 data file in a particular order.

SHEAD1 Starting head value or values for model 1 ayer 1.

TIN A software package that is a subset of ARC/INF0 that allows the storage and use of surface data (such as land surfaces) in a GIS.

TRPY

Ratio of transmissivity in the column direction to transmissivity in the row direction.

TSMULT The multiplier for the length of successive time steps.

WEL Well Package: Adds terms representing flow to wells to the finite-difference equations. 